Crescimento relativo e idade de embriões do Tubarão-Azul, Prionace glauca (Linnaeus, 1758) no Sudeste-Sul do Brasil.

Dissertação apresentada ao Instituto Oceanográfico da Universidade de São Paulo, como parte dos requisitos para obtenção do título de Mestre em Ciências, área de Oceanografia Biológica.

Orientadora: Profa. Dra. Carmen Lúcia Del Bianco Rossi-Wongtschowski 
Universidade de São Paulo

Instituto Oceanográfico

\title{
Crescimento relativo e idade de embriões do Tubarão-Azul, Prionace glauca (Linnaeus, 1758) no Sudeste-Sul do Brasil.
}

\author{
Fabio Prior Caltabellotta
}

Dissertação apresentada ao Instituto Oceanográfico da Universidade de São Paulo, como parte dos requisitos para obtenção do título de Mestre em Ciências, área de Oceanografia Biológica.

Julgada em

$\operatorname{Prof}(\mathrm{a}) . \operatorname{Dr}(\mathrm{a})$

Conceito

$\operatorname{Prof}(\mathrm{a}) \cdot \operatorname{Dr}(\mathrm{a})$

Conceito

Prof(a). Dr(a)

Conceito 
Dedico este trabalho à memória de meu querido avô Herculano Caltabellotta. 


\section{Sumário}

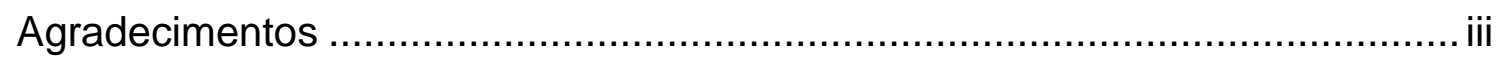

Lista de Tabelas ...............................................................................

Lista de Figuras .................................................................................. viii

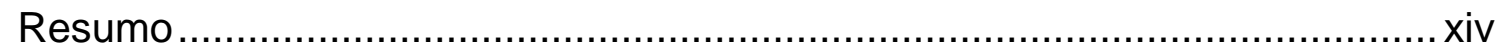

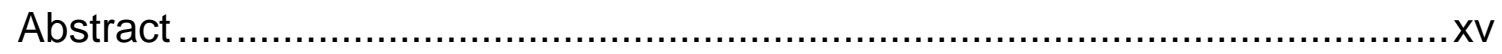

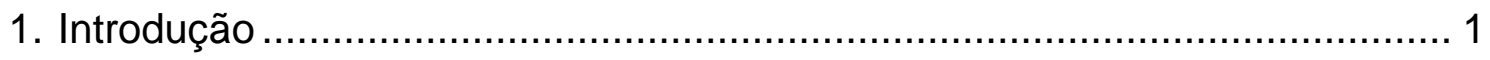

1.1 A espécie Prionace glauca (Linnaeus, 1758) ..................................... 1

$1.2 \mathrm{O}$ estudo da morfometria ............................................................ 5

$1.3 \mathrm{O}$ estudo do crescimento de elasmobrânquios .................................. 7

1.4 Ontogenia e composição das vértebras............................................ 11

1.5 Situação da pesca e a exploração de P.glauca ................................ 13

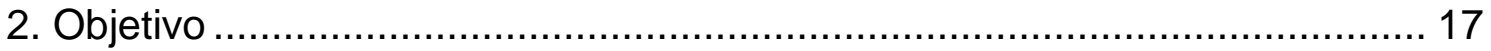

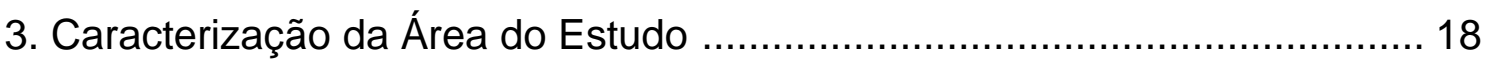

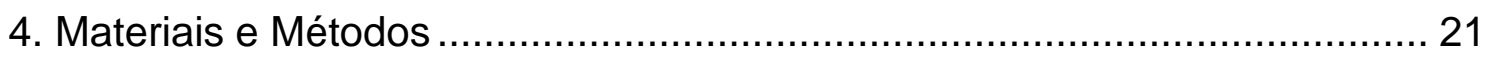

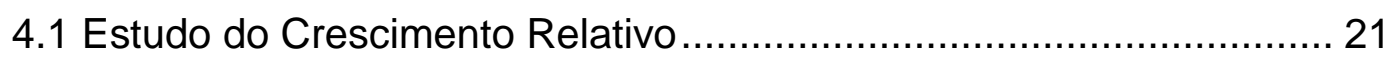

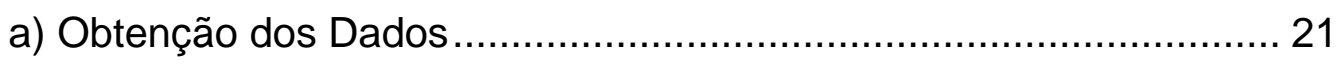

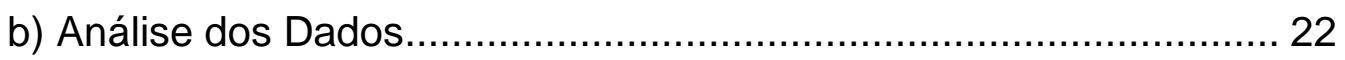

4.2 Estudo da Idade e do Crescimento ..................................................... 24

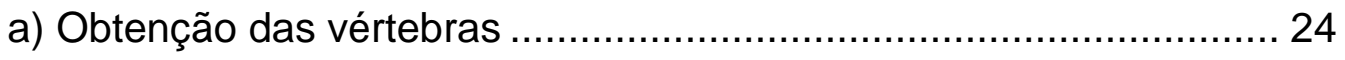

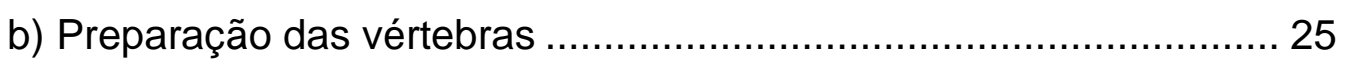

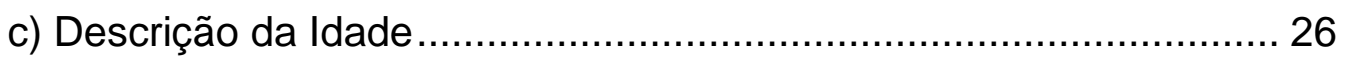

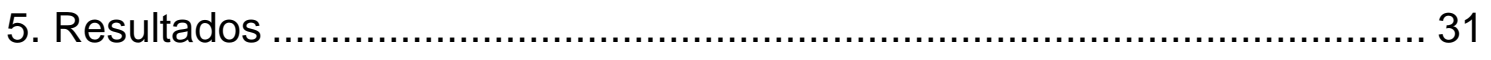

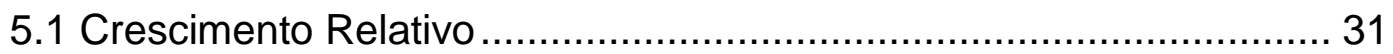

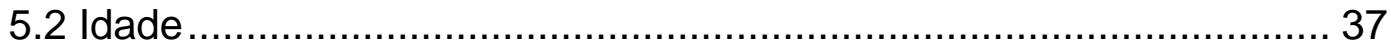

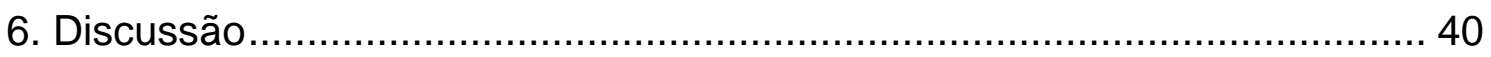

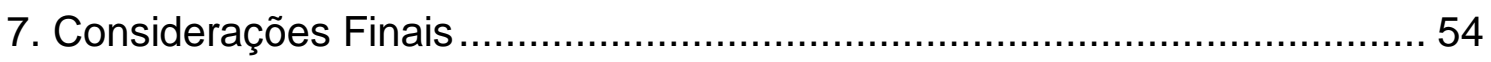

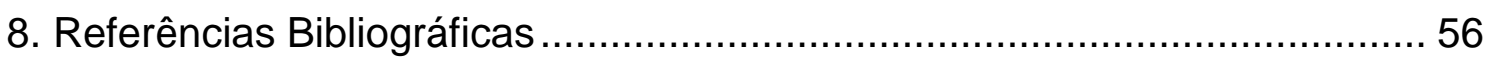

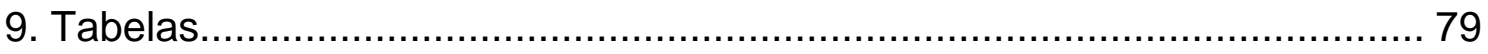

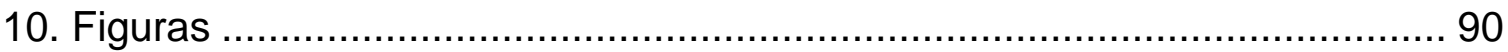




\section{Agradecimentos}

Inicialmente gostaria de agradecer aos meus pais, Odair Caltabellotta e Eloisa P. Caltabellotta por todo amor, apoio, esforço, carinho e educação que sempre dedicaram a mim e meus irmãos. Espero que meu filho sinta o mesmo orgulho que tenho pelos meus pais. Agradeço também, à minha esposa Ariana que nos deu o maior presente de nossas vidas, nosso amado filho Pedro, e que me acompanha na busca do meu aperfeiçoamento profissional desde a conclusão da graduação.

Gostaria de agradecer aos meus irmãos Fabíola e Fabrizio, à minha tia Márcia por toda atenção, ouvidos e opiniões sobre muitas das frases deste trabalho e a minha amada avó Dona Anna.

Agradeço à Profa. Dra. Carmen Lúcia Del Bianco RossiWongtschowski, por todo seu ensinamento e dedicação para minha formação acadêmica, profissional e pessoal, e espero ter correspondido no desenvolvimento deste estudo conforme suas expectativas.

Ao Dr. Guilherme Carvalhal Ribas e toda sua equipe, agradeço por me possibilitarem estar aqui hoje, com muita saúde, fazendo o que realmente eu gosto e aproveitando tudo que a vida oferece.

Agradeço à Profa. Dra. Rosângela Lessa, e a toda sua equipe em especial ao Dr. Francisco Santana e Msc. Rodrigo Barreto, por toda colaboração, atenção, receptividade, apoio e amizade durante 0 desenvolvimento deste estudo e por toda cordialidade enquanto estive 
brevemente presente no Laboratório de Dinâmica de Populações Marinha DIMAR/UFRPE.

Ao Prof. Dr. Otto Bismark Fazzano Gadig, agradeço por toda contribuição e atenção, enquanto parecerista dos relatórios exigidos durante o andamento da dissertação.

Aos pesquisadores Dr. Greg Cailliet, Dr. Greg Skomal, Dr. Steven Campana, Dr. Alexandre Aires-da-Silva e a Dra. Susan Smith, agradeço por toda atenção, sugestões quanto a metodologia e o fornecimento de muitas das referências bibliográficas utilizadas no estudo.

Do Instituto Oceanográfico - IOUSP, agradeço os professores Dr. Mario Katsuragawa, Dr. Josef Harari, Dr. Alexander Turra e Dr. Valdenir Veronese Furtado, às professoras Dra. June Ferraz Dias, Dra. Lucy Satiko Hashimoto Soares e Dra. Maria de los Angeles Gasalla, por todo ensinamento durante as disciplinas ministradas por esses grandes professores e pesquisadores, assim como, pelos bons momentos durante as saídas de campo para Base Clarimundo de Jesus (Ubatuba). Também agradeço aos funcionários da Base, Jonathan e os demais, pela excelente hospitalidade.

Do Museu de Zoologia - MZUSP, agradeço ao professor Dr. José Lima de Figueiredo, por toda atenção e ensinamento durante sua disciplina ministrada no Museu, assim como, aos funcionários da Biblioteca que sempre foram muito prestativos e atenciosos.

Aos funcionários da Biblioteca do IOUSP, Dona Rai, ao grande Wagner, à querida Cidinha e Pureza, por toda ajuda e apoio durante todo o desenvolvimento deste estudo. As funcionárias da Secretaria de Pós- 
Graduação, Ana Paula e Silvana, por toda atenção, ajuda e apoio durante todo o andamento do trabalho.

Agradeço também a toda tripulação do "N/Oc. Atlântico Sul" ao Dr. Lauro Madureira e ao futuro Dr. Stefan C. Weigert, pelo breve momento que passei embarcado durante o ECOSAR $\mathrm{V}$, onde aprendi muito com algumas lições de vida e valores, os quais permaneceram para vida toda.

Aos companheiros de laboratório, Dr. André Martins Vaz-dos-Santos, Msc. André Bellucco, Msc. Carolina Siliprandi, Biól. Carolina Contato, Biól. Denis Bannwart, Biól. Nayra Nicolau dos Santos Cruz, Biól. Daniel, Caio de Moto, César, Thiago e em especial a uma grande pessoa Dona Aparecida Martins, a todos agradeço pelo companheirismo, apoio e ajuda durante todos anos juntos.

Agradeço aos meus amigos Fausto Silvestri, Bruno Mourato, Duda, André Ribas, Marcelo Floriani e Luiz Barros com os quais partilhei muitos dos melhores momentos da minha vida, surfando! A todos meus colegas da Biologia na UFSC, especialmente a minha ex-orientadora na graduação Msc. Gisela Costa Ribeiro e aos meus amigos de Floripa, Rais, Barra, Thiago e Nei pela parceria.

Aos amigos e colegas da pós-graduação, Gabi, Kika, Márcio, Luis (técnico), Cássia, Cau, Bica, Betina, Aruanã, Priscilla, Maira, Felipe, Fabio Matsue, Juliano Bicalho, Cíntia, Piseta, Wellington, Maria Luiza Rocha, Michel, Carol Bertozzi, Ana Carolina, Leandro, Maria Clara, Thais, Lilian e os demais que por ventura tenha deixado de agradecer.

Por fim, agradeço ao CNPq - Conselho Nacional de Desenvolvimento Científico e Tecnológico pelo apoio financeiro concedido. 


\section{Lista de Tabelas}

Tabela 1. Medidas morfométricas usadas no estudo, com suas abreviações correspondentes (Compagno, 1984). Todas as medidas foram tomadas com precisão de 0,01 mm com exceção das medidas marcadas com asterístico (*), que foram tomadas com precisão de $1 \mathrm{~mm}$

Tabela 2. Descrição estatística das variáveis morfométricas, para a amostra total. Descrição das medidas na Tabela 1

Tabela 3. Descrição estatística das variáveis morfométricas, para fêmeas. Descrição das medidas na Tabela 1

Tabela 4. Descrição estatística das variáveis morfométricas, para machos. Descrição das medidas na Tabela 1

Tabela 5. Estatística descritiva das proporções, para a amostra total. Todos os valores referem-se à percentagem do comprimento total (LT). Descrição das medidas na Tabela 1

Tabela 6. Comparação entre as proporções das variáveis morfométricas de fêmeas e machos, aplicando o Teste 't de Student - para duas amostras independentes". Descrição das medidas na Tabela 1. $\left(\mathrm{s}^{*}\right)=$ Variáveis significativas 84

Tabela 7. Comparação entre as proporções das variáveis morfométricas de fêmeas e machos, aplicando o Teste de "Wilcoxon Rank". Descrição das medidas na Tabela 1 85

Tabela 8. Resultados das regressões lineares para os valores das variáveis morfométricas logaritmizadas; valores do teste $t$ e seu p-valor, aplicado para 
testar a significância do coeficiente alométrico (b) em relação à isometria $(b=1)$. Descrição das medidas na Tabela $1 .\left(\mathrm{s}^{*}\right)=$ Variáveis significativas ... 86

Tabela 9. Análise de covariância (ANCOVA), valores do teste $t$ e seu p-valor aplicado para verificar diferenças significativas no coeficiente alométrico (b) e no intercepto (a) entre machos e fêmeas. gl: graus de liberdade. Descrição das medidas na Tabela 1

Tabela 10. Média e o desvio padrão das idades entre os métodos aplicados da proporção direta e da modificada de Dahl-Lea, por classes de comprimento total $(\mathrm{mm}) . \mathrm{N}=$ número de indivíduos

Tabela 11. Análise da regressão não linear. Ajuste do modelo Logístico, com o cálculo dos Intervalos de Confiança de $95 \%$ para os parâmetros do modelo. LT - Comprimento Total; idades esperadas dos embriões em meses, a partir do método modificado da proporção direta de Dahl-Lea 88

Tabela 12. Análise da regressão não linear. Ajuste do modelo de von Bertalanffy, com o cálculo dos Intervalos de Confiança de $95 \%$ para os parâmetros do modelo. LT - Comprimento Total; idades esperadas em meses dos embriões, a partir do método modificado da proporção direta de Dahl-Lea . 89

Tabela 13. Análise da regressão não linear. Ajuste do modelo de Gompertz, com o cálculo dos Intervalos de Confiança de $95 \%$ para os parâmetros do modelo. LT - Comprimento Total; idade esperada em meses dos embriões, a partir do método modificado da proporção direta de Dahl-Lea 89

Tabela 14. Média dos parâmetros de crescimento obtidos pelos modelos de crescimento Logístico, von Bertalanffy e Gompertz, e comparação entre os modelos através dos critérios de informação de Akaike (AIC, $\Delta_{i}$ e $\left.w_{i}\right)$ e da soma dos quadrados dos erros (SQE) 89 


\section{Lista de Figuras}

Figura 1. Exemplar de embrião de Prionace glauca (LT - 299,00 mm) 90

Figura 2. Localização dos pontos de captura das fêmeas com embriões durante a prospecção

Figura 3a. Plot da temperatura média na superfície (TSM) para a Região Sudeste-Sul do Brasil para junho de 1998 (Nasa, 2009)

Figura 3b. Plot da temperatura média na superfície (TSM) para a Região Sudeste-Sul do Brasil para outubro de 1998 (Nasa, 2009)

Figura 4a. Medidas analisadas. Descrição das medidas no texto 92

Figura 4b. (continuação) Medidas analisadas. Descrição das medidas no texto 93

Figura 5a. Representação esquemática das etapas (A, B e C) na preparação dos "centrum" vertebrais de Prionace glauca. Fonte: Aires-da-Silva, (1996) .. 94

Figura 5b. Centrum vertebral pré-processado com aumento de 1,5X 94

Figura 6. Frequência dos indivíduos adultos por classe de comprimento $(\mathrm{cm})$, para a amostra total 95

Figura 7. Frequência de machos e fêmeas adultos por classe de comprimento (cm) 
Figura 8. Frequência dos embriões por classe de comprimento $(\mathrm{mm})$, para a amostra total

Figura 9. Frequência dos embriões machos e fêmeas por classe de comprimento $(\mathrm{mm})$ 96

Figura 10. Box Plot da distribuição da variável Comprimento Total $(\mathrm{cm})$ para os indivíduos adultos, por sexo. ( $F$ - Fêmeas ; $M$ - Machos)

Figura 11. Box Plot da distribuição da variável Comprimento Total $(\mathrm{mm})$ para os embriões, por sexo. ( $F$ - Fêmeas ; $M$ - Machos)

Figura 12. Regressões entre o Comprimento Total (LT) e as variáveis Comprimento Furcal (LF), Espaço Pélvico-Caudal (PCA) e Espaço PeitoralPélvico (PPS) - crescimento isométrico. Valores logaritmizados 98

Figura 13. Regressões entre o Comprimento Total (LT) e as variáveis Comprimento Pré-Caudal (PRC), Comprimento Inicial da Primeira Nadadeira Dorsal (PD1), Comprimento Inicial da Segunda Nadadeira Dorsal (PD2), Comprimento Pré-Anal (PAL), Comprimento Pré-Peitoral (PP1) e Comprimento Pré-Pélvico (PP2) - crescimento alométrico negativo. Valores logaritmizados

Figura 14. Regressões entre o Comprimento Total (LT) e as variáveis Comprimento do Tronco (TRL), Espaço Entre Dorsais (IDS) e Espaço DorsalCaudal (DCS) - crescimento alométrico positivo. Valores logaritmizados ... 100

Figura 15. Regressão entre o Comprimento Total (LT) e a variável Comprimento da Boca (MOL) - crescimento alométrico positivo. Valores logaritmizados 101

Figura 16. Regressões entre o Comprimento Total $(L T)$ e as variáveis Comprimento da Cabeça (HDL), Comprimento Pré-Orbital (POB) e Comprimento Pré-Oral (POR) - crescimento alométrico negativo. Valores logaritmizados 
Figura 17. Regressões entre o Comprimento Total (LT) e as variáveis Largura da Boca (MOW), Comprimento do Olho (EYL), Altura do Olho (EYH) e Espaço Internasal (INW) - crescimento alométrico negativo. Valores logaritmizados

Figura 18. Regressões entre o Comprimento Total (LT) e as variáveis Comprimento Entre as Fendas Branquiais (ING), Altura da Primeira Fenda Branquial (GS1) e Altura da Quinta Fenda Branquial (GS5) - crescimento alométrico negativo. Valores logaritmizados 103

Figura 19. Regressões entre o Comprimento Total (LT) e as variáveis Comprimento da Margem Anterior da Primeira Nadadeira Dorsal (D1A), Altura da Primeira Nadadeira Dorsal (D1H), Comprimento da Margem Interna da Primeira Nadadeira Dorsal (D1I), Comprimento da Primeira Nadadeira Dorsal (D1L), Comprimento do Lobo Inferior (CPV) e Comprimento da Margem Interna do Lobo Superior (CPU) - crescimento alométrico positivo. Valores logaritmizados 104

Figura 20. Regressões entre o Comprimento Total (LT) e as variáveis Comprimento Terminal do Lobo Superior (CTR), Comprimento da Margem Anterior da Nadadeira Peitoral (P1A), Comprimento da Margem Posterior da Nadadeira Peitoral (P1P) e Comprimento da Margem Interna da Nadadeira Peitoral (P1I) - crescimento alométrico negativo. Valores logaritmizados ... 105

Figura 21. Regressões entre o Comprimento Total $(L T)$ e as variáveis Comprimento da Base da Primeira Nadadeira Dorsal (D1B) e Comprimento do Lobo Superior (CDM) - crescimento isométrico. Valores logaritmizados 106

Figura 22. Regressões entre o Comprimento Total (LT) das variáveis Comprimento da Margem Posterior da Primeira Nadadeira Dorsal (D1P) e Comprimento da Base da Nadadeira Peitoral (P1B) - crescimento alométrico positivo. Valores logaritmizados 107

Figura 23. Regressão entre o Comprimento Total (LT) e a variável Altura da Cabeça (HDH) - crescimento alométrico positivo. Valores logaritmizados... 108 
Figura 24. Regressões entre o Comprimento Total (LT) e as variáveis Altura do Tronco (TRH), Altura do Abdomen (ABH), Altura da Cauda (TAH) e Altura do Pedúnculo da Nadadeira Caudal $(\mathrm{CPH})$ - crescimento alométrico negativo. Valores logaritmizados 108

Figura 25. Regressão entre o Comprimento Total (LT) e a variável Largura da Cabeça (HDW) - crescimento alométrico positivo. Valores logaritmizados . 109

Figura 26. Regressões entre o Comprimento Total (LT) e as variáveis Largura do Abdomen (ABW), Largura da Cauda (TAW) e Largura do Pedúnculo da Nadadeira Caudal (CPW) - crescimento alométrico negativo. Valores logaritmizados 109

Figura 27. Gráficos de envelope para os resíduos padronizados das variáveis Comprimento Pré-Caudal (PRC), Comprimento do Tronco (TRL), Comprimento Furcal (LF), Comprimento Pré-Orbital (POB), Espaço Internasal (INW) e Espaço Interorbital (INO) 110

Figura 28. Gráficos de envelope para os resíduos padronizados das variáveis Comprimento do Olho (EYL), Altura do Olho (EYH), Comprimento da Cabeça (HDL), Comprimento da Boca (MOL), Largura da Boca (MOW) e Comprimento Pré-Oral (POR) 111

Figura 29. Gráficos de envelope para os resíduos padronizados das variáveis Largura da Cabeça (HDW), Altura da Cabeça (HDH), Comprimento Entre as Fendas Branquiais (ING), Altura da Primeira Fenda Branquial (GS1), Altura da Quinta Fenda Branquial (GS5) e Altura do Tronco (TRH) 112

Figura 30. Gráficos de envelope para os resíduos padronizados das variáveis Comprimento Inicial da Primeira Nadadeira Dorsal (PD1), Comprimento Inicial da Segunda Nadadeira Dorsal (PD2), Espaço Entre Dorsais (IDS), Espaço Dorsal-Caudal (DCS), Comprimento da Margem Anterior da Primeira Nadadeira Dorsal (D1A) e Altura da Primeira Nadadeira Dorsal (D1H) 113

Figura 31. Gráficos de envelope para os resíduos padronizados das variáveis Comprimento da Margem Posterior da Primeira Nadadeira Dorsal (D1P), Comprimento da Base da Primeira Nadadeira Dorsal (D1B), Comprimento da Margem Interna da Primeira Nadadeira Dorsal (D1I), Comprimento da Primeira 
Nadadeira Dorsal (D1L), Altura do Abdomen (ABH) e Largura do Abdomen (ABW)

Figura 32. Gráficos de envelope para os resíduos padronizados das variáveis Comprimento Pré-Anal (PAL), Comprimento Pré-Peitoral (PP1), Comprimento Pré-Pélvico (PP2), Espaço Peitoral-Pélvico (PPS), Espaço Pélvico-Caudal (PCA) e Altura da Cauda (TAH) 115

Figura 33. Gráficos de envelope para os resíduos padronizados das variáveis Largura da Cauda (TAW), Altura do Pedúnculo da Nadadeira Caudal (CPH), Largura do Pedúnculo da Nadadeira Caudal (CPW), Comprimento do Lobo Superior (CDM), Comprimento do Lobo Inferior (CPV) e Comprimento da Margem Interna do Lobo Superior (CPU) 116

Figura 34. Gráficos de envelope para os resíduos padronizados das variáveis Comprimento do Terminal do Lobo Superior (CTR), Comprimento da Margem Anterior da Nadadeira Peitoral (P1A), Comprimento da Base da Nadadeira Peitoral (P1B), Comprimento da Margem Posterior da Nadadeira Peitoral (P1P) e Comprimento da Margem Interna da Nadadeira Peitoral (P1I)

Figura 35. Regressão linear entre a variável Comprimento Total (LT) e o Raio do Centro Vertebral $\left(R V_{\mathrm{e}}\right)$. Coeficientes estimados do ajuste, $a=69,50$ e $b=$ 188,18, utilizados como fatores de correção no modelo modificado da proporção direta de Dahl-Lea 118

Figura 36. Regressão não linear entre o Comprimento Total (LT) e a Idade, em meses, dos embriões de tubarão-azul, com ajuste do modelo Logístico e seu pseudo-coeficiente de explicação $\left(r^{2}\right)$. $N$ = número de indivíduos 118

Figura 37. Regressão não linear entre o Comprimento Total (LT) e a Idade, em meses, dos embriões de tubarão-azul, com ajuste do modelo de von Bertalanffy e seu pseudo-coeficiente de explicação $\left(r^{2}\right) \cdot \mathrm{N}=$ número de indivíduos 119

Figura 38. Regressão não linear entre o Comprimento Total (LT) e a Idade, em meses, dos embriões de tubarão-azul, com ajuste do modelo de Gompertz e seu pseudo-coeficiente de explicação $\left(r^{2}\right) . N$ número de indivíduos 119 
Figura 39. Comparação entre as curvas de crescimento ajustadas por regressões não lineares entre o Comprimento Total (LT) e a Idade, em meses, dos embriões de tubarão-azul, para os três modelos estudados. $\mathrm{N}$ = número de indivíduos 120 


\section{Resumo}

O tubarão-azul, Prionace glauca, é uma das espécies de elasmobrânquios pelágicos, mais capturadas pela frota de espinhel-de-superfície. No presente estudo analisou-se o crescimento relativo e a idade de 83 embriões, provenientes de fêmeas grávidas capturadas em 1998, durante o Programa "Avaliação do Potencial Sustentável de Recursos Vivos da Zona Econômica Exclusiva" - REVIZEE, na região Sudeste-Sul do Brasil. Foram analisados 48 caracteres morfométricos, verificando-se que entre as variáveis morfométricas mais expressivas, o comprimento furcal, o comprimento pré-caudal, o comprimento inicial da segunda nadadeira dorsal, o comprimento pré-anal e o comprimento pré-pélvico contribuíram com valores acima de $50 \%$ na composição do corpo do embrião. Por meio de regressões lineares de variáveis logaritmizadas, constatou-se alometria negativa em (53,2\%), positiva em $(36,1 \%)$ e isometria em $(10,7 \%)$ dos caracteres morfométricos analisados. A idade de cada embrião foi estimada por meio da utilização do método da proporção direta modificada de Dahl-Lea, e os parâmetros de crescimento foram ajustados através das curvas de crescimento logística, de von Bertalanffy e de Gompertz. De acordo com os critérios de seleção de Akaike (AIC $C_{\min }, \Delta_{i}$ e $w_{i}$ ) e da soma dos quadrados dos erros (SQE), o modelo de Gompertz foi escolhido como o melhor representante do crescimento embrionário de P.glauca.

Palavras-chave: tubarão-azul, Prionace glauca, crescimento relativo, idade e crescimento, embrionário. 


\section{Abstract}

The blue shark, Prionace glauca, is a pelagic elasmobranchs, mainly captured by the Brazilian pelagic longline fleet. In this study we analyzed both the relative growth and the age of 83 of pregnant females captured in 1998 during the Program "Evaluation of the Sustainable Potential of Living Resources of the Exclusive Economic Zone" - REVIZEE in the Brazilian Southeast-South region. We analyzed 48 morphometric characters, showing that among the most expressive, fork length, the length pre-flow, the initial length of the second dorsal fin, the length pre-anal and the length pre-pelvic represented above $50 \%$ of the composition of the embryos bodies. By means of linear regressions of logarithmic morphometric variables values, we found negative allometry (53.2\%), positive allometry (36.1\%) and isometry in (10.7\%). The age of each embryo was estimated applying the direct proportion of Dahl-Lea method modified, and the parameters of growth were adjusted to logistic growth curves of von Bertalanffy and Gompertz. According to the selection criteria of Akaike $\left(\mathrm{AlC}_{\min }, \Delta_{\mathrm{i}}\right.$ and $\left.w_{\mathrm{i}}\right)$ and the sum of the squares of errors (SSE), the Gompertz model was chosen as the most representative of the growth of P.glauca embryos.

Key-words: blue shark, Prionace glauca, relative growth, age and growth, embryonic. 


\section{Introdução}

\section{1 - A espécie Prionace glauca (Linnaeus, 1758)}

Os elasmobrânquios pertencem a um grupo monofilético dividido em dois grandes grupos: Galeomorphii e Squalea. Os Galeomorphii representam mais de $73 \%$ das espécies conhecidas de tubarões e dentro desse grupo somente a família Carcharhinidae totaliza 58\% das espécies (Compagno, 1977; Carvalho, 1996).

O tubarão-azul Prionace glauca (Linnaeus, 1758), (Figura 1) faz parte dessa família, sendo o mais abundante dentre os grandes tubarões pelágicos presentes no Oceano Atlântico. Entre seus principais caracteres, estão um longo focinho, longas nadadeiras peitorais, a primeira nadadeira dorsal encontra-se mais próxima a base da nadadeira pélvica, os olhos são grandes, e suas partes dorsais possuem uma cor azul índigo (Bigelow \& Scroeder, 1948).

É uma espécie oceânica, altamente migratória, apresenta distribuição circumglobal, entre as latitudes de $60^{\circ} \mathrm{N}$ e $50^{\circ} \mathrm{S}$, ocorrendo em águas tropicais e temperadas, predominantemente naquelas com temperaturas entre $12-20^{\circ} \mathrm{C}$, mas toleram temperaturas superiores. Embora possua hábito oceânico, pode ocorrer ocasionalmente próximo a costa, onde a plataforma continental é mais estreita, na superfície, principalmente durante a noite, até 600 metros de

profundidade. (Carey \& Scharold, 1990; Compagno et al., 2005; Nakano \& Stevens, 2008). 
Um padrão especial de distribuição e abundância do tubarão-azul é encontrado no Oceano Pacífico, principalmente entre as latitudes de $20^{\circ} \mathrm{N}$ a $50^{\circ} \mathrm{N}$, atribuído a variações sazonais, sendo a espécie mais comum durante o inverno entre $20^{\circ} \mathrm{N}$ e $30^{\circ} \mathrm{N}$, na primavera entre as latitudes de $30^{\circ} \mathrm{N}$ a $40^{\circ} \mathrm{N}$ e no verão entre 40N a 50N (Strasburg, 1958; Compagno, 1984; Nakano, 1994).

No Oceano Atlântico, observa-se um padrão de variação espacial semelhante ao encontrado no Oceano Pacífico. Através do primeiro programa de marcação e recaptura do tubarão-azul no Atlântico Norte, foi observada uma migração sazonal entre as latitudes $30^{\circ} \mathrm{N}$ e $50^{\circ} \mathrm{N}$, utilizando a espécie dos principais sistemas de correntes da região. Através da recaptura e das freqüências de comprimento, foi possível diferenciar padrões de movimento dos segmentos da população, inferindo-se uma segregação por tamanho (Stevens, 1976).

Mais recentemente no Atlântico Norte, Queiroz et al. (2005) verificaram que os tubarões-azuis são encontrados durante as estações de inverno e primavera entre as latitudes de $30^{\circ}-43^{\circ} \mathrm{N}$, estando a temperatura de superfície entre $14-22^{\circ} \mathrm{C}$, entretanto, durante os meses de verão e outono, são encontrados em latitudes acima de $48^{\circ} \mathrm{N}$, com a temperatura de superfície variando entre $16-28^{\circ} \mathrm{C}$.

No Atlântico Sul, especificamente no Brasil, Prionace glauca ocorre do nordeste ao sul do país, sendo que a distribuição e a abundância das fêmeas estão relacionadas a um padrão migratório resultante de seu ciclo reprodutivo (Amorim, 1992; Hazin et al., 1994a), embora não exista confirmação precisa sobre este evento. Alguns trabalhos como o de Amorim et al. (1998) corroboram essas informações, apontando a existência de uma área de cópula 
restrita a região sudeste em latitudes superiores a $25^{\circ} \mathrm{S}$, durante 0 verão, enquanto os demais eventos do ciclo reprodutivo, até a fase final do desenvolvimento embrionário, ocorrem em latitudes um pouco menores.

Hazin et al. (2000) consideram que a área de cópula ocorre na região sudeste-sul do Brasil, enquanto que a ovulação e o início da gestação ocorrem na região nordeste. A partir daí, as fêmeas grávidas realizariam uma migração em direção ao Golfo de Guiné, onde estaria localizada uma área de parto.

Dados mais recentes, obtidos por Montealegre-Quijano (2007), demonstraram que o ciclo reprodutivo e a distribuição espacial do tubarão-azul seguem um padrão anual e apresentam limites latitudinais. Assim, este autor considera como região de cópula as latitudes entre $20^{\circ}$ e $35^{\circ} \mathrm{S}$, a qual ocorreria durante os meses de setembro a dezembro; a ovulação e o início do desenvolvimento dos embriões estariam na área entre $0^{\circ}-35^{\circ} \mathrm{S}$, ocorrendo durante os meses de janeiro a julho. As fêmeas grávidas migrariam em direção a região sul do Brasil entre as latitudes de $30^{\circ}-35^{\circ} \mathrm{S}$, onde completariam sua gestação, deslocando-se finalmente para o sul dos $35^{\circ} \mathrm{S}$, a qual poderia ser denominada área de parto.

Contudo, a distribuição e o movimento desta espécie são extremamente influenciados por variações sazonais da temperatura da água, pelas condições reprodutivas e pela disponibilidade de alimento (Kohler et al., 2002).

Os hábitos alimentares do tubarão-azul incluem presas relativamente pequenas, especialmente peixes ósseos e lulas, pequenos tubarões, como Squalus acanthias, mamíferos e aves marinhas, que ocasionalmente são 
capturadas na superfície (Compagno, 1984; Harvey, 1989; Henderson et al., 2001).

Vaske \& Rincón (1998) identificaram para o Sul do Brasil, entre as principais presas, especialmente lulas como Chiroteuthis verany, Moroteuthis robsoni, Ancistrocheirus lesueuri e diversos peixes ósseos como, Lepidocybium flavobrunneum. Kubodera et al. (2007), recentemente, identificaram para a região de transição do Pacífico Norte $\left(30^{\circ}-45^{\circ} \mathrm{N}\right) 24$ presas entre espécies de cefalópodes e 16 espécies de peixes, sendo que, entre os cefalópodes, o item de maior freqüência de ocorrência foi Chiroteuthis calyx e, entre os peixes, Maurolicus imperatorius.

Os elasmobrânquios são caracterizados pelos seguintes padrões reprodutivos: fertilização interna, oviparidade ou viviparidade e mecanismos placentários, responsáveis pela manutenção fetal através de diferentes padrões nutricionais: placentotrófico e lecitotrófico (Wourms, 1977).

O tubarão-azul (Prionace glauca) é uma espécie vivípara placentária, sendo que somente o ovário direito está presente e funcional. O período de gestação varia entre 9 e 12 meses, estando relatada na literatura a quantidade de até 135 embriões em uma fêmea (Gubanov \& Grigor'yev, 1975).

Entre alguns dos trabalhos já realizados enfocando aspectos da reprodução de $P$. glauca, destacam-se: Pratt (1979), no Atlântico Norte, sobre a morfologia do sistema reprodutivo de machos e fêmeas, Hazin et al. (1994b), na costa nordeste do Brasil sobre a biologia reprodutiva e estádios de maturidade, Castro \& Mejuto (1995), nas águas do Atlântico Equatorial no Golfo de Guiné sobre parâmetros reprodutivos da espécie, como tamanho e 
proporção sexual de embriões e Legat \& Vooren (2008), caracterizando a morfologia uterina e as fases de desenvolvimento dos embriões.

\section{2 - 0 estudo da morfometria}

O uso da morfometria para o estudo dos elasmobrânquios tem sido utilizado em trabalhos que envolvem sua morfologia, o crescimento e a estrutura populacional. No entanto, a aplicação de técnicas adequadas, que

permitem a comparação dos resultados entre os estudos, depende da metodologia utilizada na obtenção das medidas corpóreas (Francis, 2006).

A morfometria pode ser considerada apenas como uma análise quantitativa da forma do corpo e de suas mudanças em relação ao tamanho, por meio da aplicação de métodos numéricos que possibilitam a comparação dos padrões de variação entre as distâncias corpóreas (Marcus, 1990).

Ela também pode ser entendida como uma área de estudo dentro da biometria que combina aspectos de geometria, biologia e estatística. Deste modo, analisa a forma geométrica entre dois ou mais organismos, através de pontos biológicos homólogos entre suas partes ou estruturas (Bookstein et al., 1985; Bookstein, 1986).

A análise da forma representa um importante papel em diversos estudos, em função das diferenças atribuídas a determinados processos biológicos, tais como o desenvolvimento ontogenético, adaptações a fatores ambientais, doenças e o próprio processo evolutivo (Zelditch et al., 2004).

O estudo da morfometria teve início com o trabalho "On Growth and Form" de D'Arcy Thompson em 1917, que correlacionou algumas leis da física 
e da matemática com o fenômeno do crescimento diferencial. O método utilizado pelo autor foi o das coordenadas e se baseava na deformação de uma figura em duas dimensões para outra em um plano cartesiano (Thompson, 1966).

Desde então, o estudo do crescimento diferencial fez com que diversos pesquisadores passassem a desenvolver e aplicar modelos quantitativos para analisar a forma e o tamanho dos organismos (Strauss, 1993).

A partir do trabalho de Huxley (1932), observou-se que as estruturas morfológicas evidenciam uma mudança progressiva e significativa do seu tamanho relativo com o aumento do tamanho absoluto do indivíduo. Através da utilização do conceito de alometria, o autor demonstrou a existência de algumas "leis" que pareciam reger a maioria dos processos envolvendo 0 crescimento diferencial (Strauss, op cit). Sendo assim, o modelo alométrico de Huxley ficou conhecido por utilizar uma simples expressão quantitativa, resultado da proporção constante entre a intensidade (ou taxa relativa) de crescimento de um órgão e do corpo ao longo de grandes períodos na vida dos indivíduos (Huxley, 1932).

O termo alometria também foi empregado por Gould (1966) como o estudo do tamanho e suas conseqüências, representado pelas diferenças nas proporções corpóreas diante das mudanças do indivíduo como um todo ou de suas partes específicas. Segundo Lele \& Richtsmeier (2001), em seu conceito mais amplo, a alometria se refere à relação entre o tamanho e a forma e não disponibiliza informações sobre a geometria dos organismos em duas ou três dimensões. 
Atualmente, os conceitos da forma e tamanho bem como sua análise têm sido abordada em diversos estudos sob o contexto geométrico (Monteiro et al., 2005; Zelditch et al., 2004; Bookstein, 1999), embora esse tipo de metodologia ainda não tenha sido utilizado para o estudo de elasmobrânquios.

Entre alguns dos trabalhos enfocando a morfometria de elasmobrânquios, podemos citar Jones \& Geen (1977), que analisaram as mudanças morfométricas, que ocorrem em Squalus acanthias após sua preservação; Hughes et al. (1986), que efetuaram um estudo sobre a morfometria das fendas branquiais de Scyliorhinus stellaris em relação ao tamanho do corpo; Lessa (1988), que realizou a biometria de tubarões costeiros obtidos no controle de desembarques no norte do Brasil; Hazin et al. (1991), descreveram a morfometria do tubarão-azul no Atlântico Equatorial; Lessa et al. (1999a), estudaram a biologia e morfometria do tubarão galhabranca oceânico Carcharhinus longimanus, encontrando diferenças significativas entre os sexos para algumas características morfométricas; Lessa et al. (1999b), utilizaram a morfometria para estabelecer relações entre o comprimento total e a carcaça do tubarão galha-branca oceânico; Schluessel et al. (2008), compararam a morfometria e a ultraestrutura do sistema olfativo em elasmobrânquios, relacionando-as com sua filogenia e ecologia; e Marshall et al. (2008), compararam as medidas morfométricas entre uma raia manta, Manta birostris, capturada no sul da África com um feto de Manta birostris capturado na região de Moçambique. 


\section{3 - O estudo do crescimento de elasmobrânquios}

Dentro dos estudos sobre o crescimento de elasmobrânquios, o uso da vértebra, como estrutura para a determinação da idade, teve início com os trabalhos de Ridewood (1921 in Cailliet et al., 1983a), o primeiro a descrever as bandas calcificadas dessa estrutura, mas sem associá-las à idade. Posteriormente, Haskell (1949 in Cailliet op cit.) sugeriu a existência de relação entre tais bandas e a idade desses organismos. A partir de então, diversos autores vem desenvolvendo e utilizando diferentes técnicas para realçar as bandas nas vértebras e em outras estruturas, em diversas espécies de peixes, inclusive nos elasmobrânquios (Holden \& Meadows, 1962; La Marca, 1966; Holden \& Vince, 1973; Stevens, 1975; Cailliet et al., 1983a; Casey et al., 1985; Branstetter, 1987; Hoenig \& Browmn, 1988; Tanaka, 1990; Officer et al., 1996 e Torres et al., 2005).

Nem sempre a vértebra, como estrutura rígida, pode ser aplicada para a determinação da idade, pois algumas espécies de tubarões de profundidade mais primitivos podem ter estas estruturas pouco calcificadas (Cailliet, 1990).

O estudo do crescimento em elasmobrânquios compreende também o emprego de outras estruturas para a determinação da idade, como os arcos neurais nos Hexanchiformes, os espinhos das nadadeiras dorsais nos Squaliformes e Heterodontiformes e o espinho anterior a nadadeira dorsal nos Chimaeriformes, assim como o espinho caudal em algumas espécies da família Rajidae. Entre os trabalhos utilizando estas estruturas, podemos citar McFarlane et al. (2002) aplicando a técnica do nitrato de prata para realçar as bandas de crescimento nos arcos neurais na determinação da idade em 
Hexanchus griseus; Gallagher \& Nolan (1999) desenvolvendo um novo método para estimar a idade em quatro espécies de Rajidae; Gallagher et al. (2006) utilizando o espinho caudal da raia Amblyraja radiata; e Clarke \& Irvine (2006) para abordar a terminologia utilizada nos espinhos das nadadeiras dorsais em peixes cartilaginosos.

Diversas metodologias são empregadas para verificação e validação da idade. A aplicação das técnicas do nitrato de prata, lizarina e do cristal de violeta na preparação das vértebras e arcos neurais possibilitam uma melhor visualização das bandas de crescimento para leitura e verificação da idade. Entre algumas das metodologias empregadas na validação da idade, consta a utilização do incremento marginal (MI), o uso de radiocarbono e da oxitetraciclina (Cailliet \& Goldman, 2004).

Atualmente, a capacidade de verificar a idade com base na utilização de bandas existentes nas partes anatômicas duras permite a obtenção de informações etárias precisas, possibilitando estimativas qualitativas do crescimento e outras taxas vitais, como mortalidade e longevidade, e que são essenciais para o sucesso do manejo pesqueiro desses recursos (Goldman, 2005).

Dentre os estudos de crescimento já realizados para adultos do tubarão-azul $P$. glauca utilizando vértebras, destacam-se os de Aasen (1966), Stevens (1975); Cailliet et al. (1983b); Tanaka et al. (1990); Skomal \& Natanson (2003). No Brasil, Lessa et al. $(2004,2006)$ estimaram os parâmetros de crescimento para a espécie na região nordeste, através da curva de von Bertallanfy e realizaram análise de incrementos marginais. Recentemente, 
Montealegre-Quijano (2007) estudou o crescimento, idade e estrutura etária do tubarão-azul na região sudoeste do Oceano Atlântico.

Nestes estudos, em que foram utilizadas vértebras de exemplares adultos, foi verificada a presença de uma marca de nascimento "birthmark" e a subseqüente formação do primeiro anel etário. Esta marca de nascimento é representada por uma mudança no ângulo junto à face do centro vertebral ou junto da interface do corpo-intermediário calcáreo e associada a um anel (Stevens, 1975; Goldman, 2005).

Há também a formação de uma marca de pré-nascimento ("pre-birth ring"), que pode ser facilmente distinguida das demais e cuja formação tem sido relacionada à mudança nutricional embrionária (Casey et al., 1985; RibotCarballal et al., 2005).

No Brasil, estudos enfocando a descrição do crescimento embrionário de Prionace glauca já foram realizados por Rincon et al. (2000) e Lessa \& Santana (2004), mas em nenhum destes foi utilizada a vértebra dos embriões como estrutura para a estimação da idade e do crescimento. Em Portugal, Aires-Da-Silva (1996) realça a necessidade de informação sobre o crescimento intrauterino para o estabelecimento de uma relação entre o comprimento do tubarão e sua estrutura (vértebra) quanto à hipótese de linearidade levantada por Stevens (1975). Dessa maneira, este último autor, destaca que, sem o conhecimento dos processos biológicos vitais intrauterinos, não é possível estabelecer quando e porque ocorre a formação da marca de nascimento.

Neste contexto, o estudo ora realizado sobre a idade e o crescimento de Prionace glauca nas etapas iniciais do ciclo de vida constitui uma importante 
informação para complementar a lacuna existente sobre esta fase do desenvolvimento da espécie.

Em teleósteos, a análise do crescimento nas fases larvais e juvenis tem sido realizada através da análise da microestrutura dos otólitos (anéis diários) e associados às influências das variáveis oceanográficas e disponibilidade de alimento (Brothers et al., 1983; Radtkle, 1983; De Vries, 1990; Jenkins \& Davis, 1990; Berkeley et al., 2004; Sponaugle et al., 2005; Takasuka \& Aoki, 2006).

\section{4 - Ontogenia e composição das vértebras}

O endoesqueleto dos elasmobrânquios é formado por cartilagem hialina composta por condrócitos e matriz extracelular, revestida por uma fina camada de fosfato de cálcio mineralizada de hidroxiapatita, conhecida como "tesserae". A mineralização da cartilagem pode ocorrer em diferentes níveis, conforme a deposição dos cristais de fosfato de cálcio (Dean et al., 2005).

A "tesserae" forma uma parte importante do tecido mineralizado dos tubarões, é composta por calcificações prismáticas e está envolvida na formação do condocrânio, das mandíbulas, dos arcos viscerais, no suporte das nadadeiras, e no revestimento dos arcos hemal e neural (Applegate, 1967).

O endoesqueleto, ou esqueleto interno dos tubarões, é formado pelo esqueleto axial, ou crânio, pela coluna vertebral e pelo esqueleto apendicular, que fornece sustentação as nadadeiras. A coluna vertebral é composta por um conjunto de estruturas calcificadas, as vértebras, que são formadas por um centrum vertebral e pelos arcos hemal e neural (Compagno, 1999). 
$\mathrm{Na}$ ontogenia da vértebra, ocorre a diferenciação inicial dos tecidos precedida pela deposição de cristais de apatita (mineral) nos espaços intercelulares (Applegate, 1967).

A vértebra de um Carcharhinidae apresenta uma bainha na notocorda que pode variar muito em tamanho, quatro cristas nas áreas basais estão sempre presentes, sendo completamente calcificadas entre a intermedialia e as áreas basais (Applegate, 1967).

Por sua macroestrutura, o esqueleto dos elasmobrânquios pode ser diferenciado em dois tipos: cartilagem vertebral, composta pela vértebra que pode apresentar três tipos de calcificação (areolar, prismática e globular) e a cartilagem "tesserae", formando o restante do esqueleto axial e apendicular, por calcificação prismática e globular (Moss, 1977; Dean \& Summers, 2006).

Em nível de microestrutura, a calcificação areolar é constituída por um tecido densamente calcificado que ocorre no centrum na maioria dos peixes cartilaginosos, sendo que este tipo de mineralização forma anéis que são utilizados para estimar a idade e o crescimento. A calcificação prismática é quase sempre associada ao pericôndrio celular, sendo também muito densa. $O$ terceiro tipo de calcificação, a globular, é formada por um tecido moderadamente mineralizado, composto em nível de nanoescala (40 - $55 \mathrm{~mm}$ ) de esferas de hidroxiapatita fusionadas (Dean \& Summers, 2006).

Entre os trabalhos já realizados sobre a morfologia, a ultraestrutura e a composição da cartilagem envolvendo as vértebras destacam-se os clássicos como de Ørvig (1951) e Kemp (1977) e outros mais recentes como os de Clement (1992) re-examinando a estrutura da mineralização do endoesqueleto; Dean et al. (2005) visualizando a morfologia e a ultraestrutura da cartilagem 
prismática calcificada; Dean \& Summers (2006) abordando os tipos de cartilagens assim como sua micro, meso e macroestrutura; Poter et al. (2006) analisando as propriedades materiais e composição bioquímica da cartilagem mineralizada vertebral em sete espécies de elasmobrânquios e Porter et al. (2007) analisando a contribuição dos minerais para a cartilagem da coluna vertebral em Mustelus californicus.

\section{5 - Situação da pesca e a exploração de P.glauca}

Em termos de pesca, P.glauca é apontada desde a década de 50 como a principal espécie, em todos os oceanos, capturada acidentalmente através das pescarias realizadas com espinhel-de-superfície (Strasburg, 1958). Atualmente, este quadro permanece o mesmo, já que o tubarão-azul raramente é um alvo da pesca comercial, prevalecendo entre as espécies capturadas acidentalmente por embarcações que operam com espinhel-de-superfície e redes de deriva em mar aberto (Nakano \& Stevens, 2008). O tubarão-azul também é considerado o tubarão pelágico mais comum entre os capturados pela pesca esportiva, principalmente nos Estados Unidos, Europa e Austrália (Babcock, 2008).

Bonfil (1994) estimou que, no final dos anos 1980 e início de 1990, as capturas acidentais de tubarões-azuis pela pesca da frota de alto mar ao redor do mundo, encontravam-se entre 6,2 - 6,5 milhões de indivíduos por ano, embora essa quantia seja somente uma estimativa grosseira, mas que demonstra a pressão exercida sobre a espécie. 
Devido ao baixo valor comercial da sua carne, considerada de má qualidade para consumo humano, os indivíduos são descartados no mar logo após a retirada de suas nadadeiras, constituindo a prática conhecida como "finning" (Castro et al., 1999). Com a expansão global do mercado desse produto, sendo as suas nadadeiras comercializadas principalmente com 0 mercado asiático, o crescimento das pescarias em alto mar intensificaram a pressão sobre os tubarões oceânicos, como P.glauca, tornando-o alvo da pesca em vários oceanos do mundo (Vannuccini, 1999; Camhi et al., 2008).

Com base nos dados de Baum et al. (2003) sobre a frota de espinhel que atua no Atlântico Norte, a captura do tubarão-azul sofreu um decréscimo de $60 \%$ no período de 1986 a 2000 e informações apresentadas pela ICCAT (2006a) indicam que o tubarão-azul representaria $73 \%$ do total capturado de tubarões pelágicos por peso entre 1980 a 2005.

No Brasil, os principais portos que abrigam a frota de espinhel responsável pela captura do tubarão-azul estão localizados em Natal (RN), Cabedelo (PB), Santos (SP), Itajaí (SC) e Rio Grande (RS) (Azevedo, 2003). A frota brasileira atuneira de espinhel-de-superfíce, em 2004, sofreu decréscimo em relação a 2003, estando constituída por 89 embarcações, sendo 55 nacionais e 34 de bandeira estrangeira (ICCAT, 2006b).

No Nordeste, estudos sobre a distribuição e a abundância de tubarões pelágicos capturados pela frota espinheleira, entre 1983 e 1987, indicaram Prionace glauca como uma das espécies mais abundantes (Hazin et al., 1998). No Sudeste, Amorim (1992) mostrou que o tubarão-azul tornou-se o principal alvo da pesca com espinhel-de-superfície no período entre 1984 e 1994, devido ao declínio da captura de atuns, representando $30 \%$ da captura total. 
A Comissão Internacional para Conservação de Atuns e Afins do Atlântico (ICCAT) avaliou o estoque de tubarão-azul no Atlântico em 2004, gerando um documento detalhado sobre as incertezas relacionadas à estrutura do estoque, movimentos, e características de algumas pescarias que os afetam. Considerando que, embora as informações disponíveis ao Comitê sejam limitadas quali e quantitativamente, os resultados devem ser considerados preliminares, sendo que tanto para o Atlântico Norte como o Atlântico Sul, a biomassa atual do tubarão-azul encontra-se acima dos valores suporte da captura máxima sustentável (ICCAT, 2007).

$\mathrm{Na}$ última reunião para preparação do relatório da avaliação dos estoques de tubarões pelágicos, realizada em 2008, constatou-se que os dados obtidos anteriormente permanecem os mesmos, para a maioria dos modelos de produção utilizada, presumindo-se que a espécie não está sobreexplorada e que não esteja ocorrendo sobrepesca (ICCAT, 2008).

Atualmente, dados da estatística pesqueira da frota espinheleira na região Sudeste-Sul do Brasil, entre 2000 e 2008, informam que a captura do tubarão-azul representa, em média, $3.932 .797 \mathrm{Kg}$ da captura total realizada com espinhel-de-superfíce (UNIVALI, 2008).

Informações específicas sobre a biologia das espécies, associadas a variações temporais e espaciais de sua distribuição, são necessárias para implantações futuras de uma política de manejo adequada para os tubarões pelágicos associados ao Oceano Atlântico Sul, como P.glauca (Hazin et al., 2008).

Devido à captura acidental dos tubarões pelágicos, ou em razão da comercialização de suas nadadeiras, medidas que têm por objetivo evitar tais 
atividades, promovendo a liberação do indivíduo vivo, e melhorando sua sobrevivência após liberação são extremamente importantes (Camhi et al., 2008).

Muitos gestores pesqueiros acreditam que o tubarão-azul é resistente a sobrepesca devido a sua abundância, entretanto, registros em diversas áreas do oceano no mundo apontam para um declínio. A dimensão dessa queda ainda não pode ser determinada; sendo assim, a incerteza atribuída à tendência populacional da espécie sob intensa pressão pesqueira, levou a IUCN a colocá-la na lista vermelha como "quase ameaçada" e pela FAO como categoria "3" (Castro et al., 1999; IUCN, 2006; Camhi, 2008). 


\section{Objetivo}

O presente estudo teve como objetivo a análise do crescimento relativo e da idade de embriões do tubarão-azul (Prionace glauca), capturados na região Sudeste-Sul do Brasil. Para tanto, foram analisadas:

- As mudanças nos caracteres morfométricos ao longo do crescimento embrionário, verificando se elas são alométricas ou isométricas;

- As relações métricas entre as vértebras e o tamanho dos embriões;

- O crescimento por meio das vértebras dos embriões. 


\section{Caracterização da Área do Estudo}

A área do estudo compreendeu a região externa da plataforma continental e a região oceânica do talude sudeste-sul do Brasil (Figura 2), ambas influenciadas pelo modelo de circulação do Giro Subtropical do Atlântico Sul (GS).

Este Giro é resultante da convergência do transporte de Ekman na camada de superfície impulsionada pelos ventos alísios de sudeste e pelo cinturão de ventos oeste do Atlântico Sul. Esses elementos forçam uma elevação do nível do mar nas regiões subtropicais do Atlântico Sul, induzindo a aceleração da circulação de superfície no sentido anticiclônico, que fica retida pela chegada das ondas longas de Rossby provindas da costa africana (Lass \& Mohrholz, 2008).

Quanto ao modelo de circulação decorrente do GS, alguns padrões gerais podem ser identificados para suas massas d'água, provenientes de diferentes origens e com suas respectivas misturas. As principais correntes constituídas pelo GS são a Corrente do Atlântico Sul, no sul; a Corrente da Benguela, no leste; a Corrente Sul Equatoriana, no norte; e a Corrente do Brasil, como fronteira limite fechando o giro a oeste (Lass \& Mohrholz op cit.).

A Plataforma Continental Sul (PCS) está localizada entre o Cabo de Santa Marta Grande e o Arroio Chuí, delimitada pela isóbata de 180 m, é mais estreita ao norte $(110 \mathrm{~km})$ e alarga-se ao sul $(170 \mathrm{~km})$. As águas costeiras e oceânicas desta região estão sob a ação dinâmica da convergência bilateral das correntes do Brasil (CB) e das Malvinas (CM). A CB flui no talude 
continental em direção ao sul, sustentada por um mecanismo termohalino, contornando o continente sul-americano até a região da Convergência Subtropical $\left(33-38^{\circ} S\right)$, onde se encontra com a Corrente das Malvinas, separando-se da costa (Castro et al., 2006).

Um dos principais processos oceanográficos que influenciam a dinâmica da plataforma nas regiões costeiras e oceânica sudeste-sul do Brasil, durante o período de inverno, é a penetração das águas de origem sub antártica transportadas para norte por uma ramificação costeira da Corrente das Malvinas (CM) (Da Silva Jr et al., 1996).

Diversas massas de água podem ser identificadas para a área externa da plataforma continental sul. Entre elas, destacam-se: a Água Tropical (AT) da corrente do Brasil com temperatura acima dos $20^{\circ} \mathrm{C}$ e salinidade maior que 36,0 ppm e a Água Central do Atlântico Sul (ACAS) com temperaturas menores entre 10 e $20^{\circ} \mathrm{C}$ e salinidade entre 34,4 e $35,9 \mathrm{ppm}$. Esta massa de água desloca-se logo abaixo da corrente do Brasil, sendo formada pela mistura da Água Tropical e da Água Subantártica na Zona de Convergência Subtropical. A Água Antártica originária da Convergência da Antártica, também presente nessa região, sendo reconhecida pela baixa salinidade em profundidades entre 700 e $1100 \mathrm{~m}$. Esta massa pode alcançar a quebra da plataforma até os $400 \mathrm{~m}$ com salinidades entre 34,26 e $34,41 \mathrm{ppm}$ e temperatura abaixo dos $10^{\circ} \mathrm{C}$ durante o inverno em latitudes próximas a Rio Grande-RS (Haimovici et al., 1994).

Uma representação mais detalhada da condição oceanográfica para a média da temperatura de superfície (TSM), no período que compreendeu a amostragem das fêmeas grávidas deste estudo, pode ser visualizada (Figuras 
3a e $3 b)$, para os meses de junho e outubro, respectivamente. As informações que compõe a representação das imagens foram geradas pela ferramenta de análise de dados (Hurricane), utilizando a base de dados TMI-SST disponível no endereço eletrônico da NASA (2009).

Quanto à disponibilidade de alimento na região sudeste-sul do Brasil, o principal item alimentar de P.glauca, os cefalópodes, distribuem-se mais ao sul, muitas vezes em associação com a Corrente do Brasil. Algumas outras espécies desse grupo têm sua distribuição mais concentrada ao sul, particularmente na região externa da PCS e do talude, freqüentemente na estação do verão, época associada à desova (Haimovici \& Perez, 1991; Santos \& Haimovici, 2001).

A compreensão dos padrões de circulação, sistemas de correntes e massas d'água atuantes na região é de extrema importância, já que permite uma maior percepção do ecossistema utilizado por P.glauca em vista dos padrões de distribuição e dos movimentos que a espécie realiza no Atlântico Sul, assim como, das demais comunidades que fazem parte da ecologia da espécie. 


\section{Materiais e Métodos}

Em 1998, no contexto do Programa "Avaliação do Potencial Sustentável de Recursos Vivos da Zona Econômica Exclusiva" - REVIZEE, no decorrer dos meses de março, abril, junho, julho, setembro e outubro, foram capturados 255 exemplares de tubarão-azul, através da utilização de espinhelde-superfície (monofilamento), em cruzeiros realizados pelas embarcações: BASCO e YAMAHA III pertencentes da frota pesqueira de Itajaí e Navegantes (SC), entre as latitudes $27^{\circ} 30^{\prime} \mathrm{S}$ e $34^{\circ} 30^{\prime} \mathrm{S}$ e longitudes de $52^{\circ} 00^{\prime} \mathrm{W}$ e $36^{\circ} 00^{\prime} \mathrm{W}$.

Dentre estes exemplares, constatou-se a presença de fêmeas grávidas, capturadas durante os meses de junho e outubro, entre as latitudes $27^{\circ} 37^{\prime} \mathrm{S}$ e $32^{\circ} 33^{\prime} \mathrm{S}$ e longitudes de $46^{\circ} 31^{\prime} \mathrm{W}$ e $50^{\circ} 11^{\prime} \mathrm{W}$ (Figura 2). Destas fêmeas, foram extraídos 83 embriões, sendo 42 fêmeas e 41 machos que apresentaram comprimentos totais (LT) entre 120 e $432 \mathrm{~mm}$.

\section{1 - Estudo do Crescimento Relativo}

\section{a) Obtenção dos Dados}

Para cada um dos embriões, foi verificado o sexo através da presença ou ausência do clásper e mensurados 48 caracteres morfométricos distintos. As medições abrangeram todas as áreas corpóreas dos embriões (cabeça, tronco e cauda), incluindo medidas gerais de comprimento, largura e altura corporal e nadadeiras (Tabela I). Foi obtido o comprimento total (LT), da ponta 
do nariz até a ponta posterior da nadadeira caudal flexionada para baixo e seu lobo superior alinhado ao longo da linha mediana do corpo, de acordo com a recomendação proposta em Francis (2006). Para a maioria das medições, utilizou-se um paquímetro digital (precisão de 0,01 mm), com exceção dos maiores comprimentos quando foi utilizado um ictiômetro com precisão milimétrica. Todas as medidas foram armazenadas em um banco de dados morfométricos no software ACCESS (Microsoft, Inc 2007).

A realização destas 48 medidas (Figuras $4 a$ e $4 b$ ), destinadas a descrever o desenvolvimento corporal dos embriões, assim como os nomes e abreviações utilizadas seguiram os moldes do estudo de Compagno (1984) e se adéquam perfeitamente a $P$. glauca.

\section{b) Análise dos Dados}

Foi feita a distribuição do comprimento total para os indivíduos adultos e os embriões, da amostra total e por sexo. Para os embriões, foi realizada também a descrição estatística para a amostra total e por sexo de todas as variáveis, verificando-se a normalidade através do teste de D’Agostino \& Pearson com nível de significância de 5\%, utilizando o pacote estatístico NCSS (Hintze, 2007). Todas as 48 variáveis, com exceção do comprimento total, foram expressas em percentagem (\%) do comprimento total (LT) e utilizadas para averiguar se havia diferença significativa nas médias das proporções corporais entre machos e fêmeas. A priori testou-se a normalidade das proporções aplicando o teste de D’Agostino \& Pearson com nível de significância de $5 \%$ e, a partir da verificação desse pressuposto, foi utilizado o 
teste "t de Student - para duas amostras independentes" em 35 variáveis e o teste equivalente não-paramétrico de "Wilcoxon Rank" em 12 variáveis.

Para explicitar e avaliar as relações dos caracteres morfométricos durante o desenvolvimento dos embriões, os valores das 48 variáveis foram transformados em logaritmos, sendo em seguida ajustadas regressões lineares aos dados entre o logaritmo do comprimento total e o logaritmo de cada uma das variáveis. Estimou-se o coeficiente de alometria para cada variável através de regressão linear, segundo o modelo exponencial $Y=a+b x$, transformado na equação logarítmica $\log Y=\log a+b^{*} \log X$, como proposto por (Huxley, 1932) sendo: $Y$ a característica ou variável cujo crescimento relativo é avaliado; $X o$ comprimento total (característica de referência); a o valor da origem no eixo das ordenadas; e $b$ o coeficiente de alometria. $O$ valor de $b=1$ representa crescimento isométrico para a variável estudada, $\mathrm{b}<1$ demonstra crescimento alométrico negativo e $\mathrm{b}>1$ crescimento alométrico positivo. Para testar a significância do coeficiente alométrico das regressões, ou seja, verificar se $b$ era significativamente diferente de 1 (isometria), foi empregado o teste " $t$ " com graus de liberdade (n-2) e significância de 5\%, através da seguinte equação:

$$
t=\left(b_{1}-b\right) / \mathrm{s}_{\mathrm{b} 1}
$$

sendo, $b_{1}$ o coeficiente alométrico calculado, $b$ o coeficiente esperado para isometria $(b=1)$ e $s_{b 1} 0$ erro padrão do coeficiente alométrico calculado. Foi empregada também a técnica denominada gráfico de envelope para 0 diagnóstico dos resíduos padronizados das regressões lineares, permitindo 
uma melhor comparação entre os resíduos e os percentis da distribuição normal padrão (Paula, 2004).

Foi realizada uma análise de covariância para verificar se havia diferença significativa no coeficiente alométrico (b) e no intercepto (a) entre machos e fêmeas (Zar, 1999).

O pacote estatístico utilizado para as análises de comparação entre as amostras (Teste " $t$ " e "Wilcoxon Rank"), as regressões e os gráficos de envelope dos resíduos padronizados foi o software S-PLUS 8 (Insightful Corp, 2007).

\section{2- Estudo da Idade e do Crescimento}

\section{a) Obtenção das Vértebras}

Foram utilizadas, para o estudo da idade, as vértebras localizadas na região sob a primeira nadadeira dorsal de cada embrião, que foram extraídas a partir de uma incisão no tegumento da porção anterior à base da primeira nadadeira dorsal, retirando-se um bloco único contendo 10 vértebras (Figura 5a). Desses blocos, foi inicialmente removido todo o excesso de tecido, manualmente com o auxílio de uma pinça, sendo então os "centrum" individuais separados. Somente um "centrum" vertebral pré-processado de cada indivíduo foi utilizado (Figura 5b), sendo armazenado em frasco individual (eppendorff) com álcool isopropílico 70\%. Os demais "centrum", de cada indivíduo, foram conservados em potes de vidro com álcool etílico $70 \%$. 


\section{b) Preparação das Vértebras}

Tendo em vista a análise das vértebras no estudo da idade e crescimento dos embriões, várias técnicas foram aplicadas com a finalidade de realçar as bandas de crescimento, dentre elas, as técnicas do nitrato de prata e do cristal de violeta, que não foram satisfatórias nos testes realizados.

Como conseqüência foi adotada uma nova metodologia, que permitiu a utilização do "centrum" da vértebra como estrutura rígida na descrição "esperada" do crescimento embrionário. O tratamento das vértebras ocorreu em três etapas, seguindo o protocolo descrito em Goldman (2004). Na primeira etapa, todos os "centrum" vertebrais pré-processados passaram novamente por um processo de limpeza, removendo-se qualquer tipo de tecido aderido a ele.

A segunda etapa envolveu o processo de emblocamento dos "centrum" vertebrais (Figura 5a). Para isso, foram utilizadas formas de gelo previamente preenchidas com resina e monômero de estireno na proporção de $100 \mathrm{~g} / 10 \mathrm{ml}$ respectivamente, adicionando-se catalisador para acelerar a reação de endurecimento da resina. Depois de 24 horas, as formas já se encontravam prontas para dar continuidade ao processo de emblocamento. Cada "centrum" vertebral foi colocado individualmente em seu compartimento da forma de gelo e coberto com a mesma proporção de resina e monômero usados anteriormente. Após um novo período de 24 horas, obteve-se o endurecimento da resina por completo, encerrando a etapa de emblocamento.

A terceira etapa empregada na preparação dos "centrum" vertebrais foi o corte. Nessa etapa, o bloco de resina formado foi colocado em uma Isomet Buehler $^{\circledR}$ com lâmina adiamantada de $0,3 \mathrm{~mm}$ de espessura, sendo realizados 
dois cortes no plano sagital, para cada centro vertebral: um anterior ao "foco" e outro logo em seguida, com espessura de 0,6 mm (Figura 5a).

\section{c) Descrição da Idade}

Foram utilizados 83 cortes, resultantes das etapas anteriores, para se obter o raio das vértebras. Usando um microscópio estereoscópico marca WILD com aumento máximo de 50X e com escala micrométrica na ocular, foram feitas as medidas dos raios nos "centrum" vertebrais. Tais medidas foram tomadas ao longo do eixo transversal, sendo obtidas as distâncias do "foco" do "centrum" da vértebra até seu bordo superior, com magnificação de 18X (18,0 unidades micrométricas $=1,0 \mathrm{~mm}$ ), usando luz refletida. As medidas obtidas foram convertidas em milímetros e armazenadas no banco de dados, através do software ACCESS (Microsoft, Inc 2007).

A relação entre a estrutura - vértebra - e o corpo dos embriões foi verificada através de regressão linear, ajustada entre o raio da vértebra do embrião $\left(R V_{e}\right)$ e o comprimento total $(L T)$, para todos os embriões da amostra. Os parâmetros das regressões, inclinação e intercepto, foram comparados entre os sexos por análise de covariância - ANCOVA (Zar, 1999).

Assumindo a existência de relação linear entre a estrutura e o comprimento total, foi utilizado para o cálculo da idade "esperada" em meses de cada embrião, o método da proporção direta de Dahl-Lea, constante em Carlander (1969) e da proporção modificada de Dahl-Lea, constante em Francis (1990), por meio de uma parametrização. Através do método da

proporção direta, pode-se dizer que a idade esperada para cada embrião 
considerou a proporcionalidade direta entre o raio da vértebra e o tempo de gestação, conforme a equação:

$$
T_{\text {esp }}=\left(R V_{e} / R V_{m n}\right) \times T_{g}
$$

onde, $T_{\text {esp }}$ é o tempo esperado, em meses, para cada embrião, $T_{g}$ o tempo de gestação de P.glauca considerado na literatura correlata (12 meses), $R V_{e} 0$ raio do centro vertebral do embrião e $\mathrm{RV}_{\mathrm{mn}}$ o raio do "centrum" vertebral, do "foco" até a marca de nascimento considerado por Skomal (com.pess ${ }^{1}$ ) e Montealegre-Quijano (2007) em 2,22 mm.

Pelo método da proporção modificada, considerou-se que o ajuste da reta para a relação entre o raio do centro vertebral do embrião $\left(R V_{e}\right)$ e 0 comprimento total (LT) não passa através da origem, sendo incorporado na equação o intercepto e a inclinação, como fatores de correção, onde:

$$
T_{e s p}=T_{g}\left[\left(a+b \times R V_{e}\right) /\left(a+b \times R V_{m n}\right)\right]
$$

sendo, $\mathrm{T}_{\text {esp }}$ o tempo esperado, em meses, para cada embrião; a e b os coeficientes estimados do ajuste linear, utilizados como fatores de correção, obtidos na regressão linear entre, $R V_{e}$ : variável independente e $L T$ : variável dependente; $\mathrm{T}_{\mathrm{g}}$ o tempo de gestação de P.glauca considerado na literatura correlata (12 meses); $\mathrm{RV}_{\mathrm{e}} \mathrm{o}$ raio do centro vertebral do embrião e $\mathrm{RV}$ mn 0 raio

\footnotetext{
${ }^{1}$ PhD. Gregory Skomal. Pesquisador Científico. Departamento de Pesca e Desporto - Divisão de Pesca Marinha. Massachusetts, MA - Estados Unidos. gregory.skomal@state.ma.us
} 
do "centrum" vertebral, do "foco" até a marca de nascimento considerado por Skomal (com.pess ${ }^{1}$ ) e Montealegre-Quijano (2007) em 2,22 mm.

Apesar da existência de uma ampla variedade de modelos utilizados para estimar os parâmetros da curva de crescimento, a escolha dos modelos Logístico, de von Bertalanffy e de Gompertz, levou em conta seu embasamento biológico, facilidade na aplicação e sua freqüente utilização entre os estudos de idade e crescimento (Ricker, 1979; Goldman, 2005).

Os valores iniciais, utilizados para estimar os parâmetros da curva de crescimento, foram calculados através do algoritmo não-linear dos mínimos quadrados de Levenberg-Marquardt, rotina empregada no ajuste das curvas para modelos de crescimento, do pacote estatístico NCSS (Hintze, 2007).

Os modelos de crescimento foram ajustados, comparados e selecionados por meio do critério de informação de Akaike (AIC), utilizando a rotina do modelo não-linear generalizado, do software S-PLUS 8 (Insightful Corp, 2007). O modelo que apresentou o menor valor de $\mathrm{AIC}\left(\mathrm{AIC}_{\min }\right)$ foi indicado como o mais adequado para representar a curva de crescimento dos embriões do tubarão-azul. As diferenças dos valores de AIC $\left(\Delta_{\mathrm{i}}\right)$ foram computadas para todos os modelos, através da equação (Katsanevakis, 2006):

$$
\Delta_{\mathrm{i}}=A I C_{\mathrm{i}}-\mathrm{AIC}_{\min }
$$

onde, $\Delta_{\mathrm{i}}$ é a diferença entre o valores de AIC para os modelos de crescimento, $\mathrm{AIC}_{\mathrm{i}}$ é o valor de AIC para o modelo e $\mathrm{AIC}_{\min }$ é o menor valor de $\mathrm{AIC}$. Os valores encontrados de $\Delta_{\mathrm{i}}$ foram classificados de acordo com o critério utilizado por Burnham \& Anderson (2002 in Katsanevakis, 2006) sendo que os modelos $\operatorname{com} \Delta_{\mathrm{i}}>10$ não fornecem valores adequados para os parâmetros da curva de 
crescimento e devem ser desconsiderados, com $4<\Delta_{i}<7$ fornecem valores consideráveis e com $\Delta_{\mathrm{i}}<2$ fornecem os valores mais adequados aos parâmetros da curva. A quantificação da plausibilidade de cada modelo foi verificada através do "Peso de Akaike $\left(w_{\mathrm{i}}\right)$ ", sendo considerado o melhor dos modelos entre os disponíveis, aquele com o maior $w_{\mathrm{i}}$, calculado pela equação constante em Katsanevakis (2006).

Os modelos de crescimento também foram comparados conforme a sugestão proposta em Cailliet et al. (2006), que recomendam o uso do valor da soma dos quadrados dos erros (SQE) na avaliação do desempenho dos modelos de crescimento, permitindo sua escolha conforme o menor valor encontrado, que possibilita mais confiança ao ajuste realizado para os parâmetros da curva de crescimento.

O modelo da curva de crescimento Logística foi proposto por Verhulst (1838 in Ricker, 1979) para descrever o crescimento do tamanho de uma população ou um órgão, embora também represente a "lei autocatalítica" da fisiologia e química (Seber \& Wild, 1989), onde:

$$
\mathrm{LT}=\mathrm{L}_{\infty} \times\left(1+\exp \times\left(-\mathrm{k} \times\left(\text { Idade }-\mathrm{t}_{0}\right)\right)\right)^{\wedge}(-1)
$$

sendo, $\mathrm{LT}=$ comprimento total; $\mathrm{L} \infty=$ comprimento total assintótico; $\mathrm{k}=$ taxa instantânea de crescimento quando LT tende a 0; Idade = idade (calculada pelo método modificado de Dahl-Lea) e $t_{0}=$ tempo na qual a taxa de crescimento absoluta começa a diminuir (ponto de inflexão). 
A função do crescimento de von Bertalanffy (1938) é a mais utilizada nas estimativas dos parâmetros da curva, nos estudos de idade e crescimento em cartilaginosos (Cailliet \& Goldman, 2004; Cailliet et al., 2006), onde:

$$
L T=L_{\infty} \times\left(1-\exp \times\left(-k \times\left(\text { Idade }-t_{0}\right)\right)\right)
$$

sendo, $\mathrm{LT}=$ comprimento total predito na "Idade"; $\mathrm{L} \infty=$ comprimento total assintótico; $\mathrm{k}$ = coeficiente de crescimento; Idade = idade (calculada pelo método modificado de Dahl-Lea) e $t_{0}=$ tempo ou idade quando o comprimento é teoricamente igual a 0 .

A aplicação do modelo de Gompertz (1825 in Ricker 1979) tem sua maior utilização na estimativa dos parâmetros da curva de crescimento, nos estágios iniciais da vida (Ricker, 1979; Goldman, 2005), onde:

$$
L T=L_{\infty} x\left(\operatorname{Exp}\left(-\operatorname{Exp}\left(-k x\left(\text { Idade }-t_{0}\right)\right)\right)\right)
$$

sendo, $\mathrm{LT}=$ Comprimento Total; $\mathrm{L} \infty=$ comprimento total assintótico; $\mathrm{k}=$ taxa instantânea de crescimento quando $t=t_{0}$; Idade $=$ idade (calculada pelo método modificado de Dahl-Lea) e $t_{0}=$ tempo na qual a taxa de crescimento absoluto começa a diminuir (ponto de inflexão). 


\section{Resultados}

\section{1- Crescimento Relativo}

A distribuição por classe de comprimento total dos tubarões adultos, para a amostra total e por sexo, é exibida nas figuras 6 e 7. A composição da amostra total esteve representada por indivíduos entre as classes de comprimento de 165 - $285 \mathrm{~cm}$ (Figura 6). A figura 7 mostra a distribuição da amostra por sexo, composta predominantemente por machos e por poucas fêmeas, com comprimentos totais entre as classes 210 a $255 \mathrm{~cm}$. Não foram capturadas fêmeas entre as classes de comprimento total de 165 a $195 \mathrm{~cm}$.

A distribuição por classe de comprimento dos embriões, para a amostra total e por sexo, é apresentada nas figuras 8 e 9, verificando-se que na amostra total estiveram presentes indivíduos entre as classes de comprimento total de 120 a $450 \mathrm{~mm}$. Verifica-se a presença de duas modas para a amostra total, representadas por indivíduos entre as classes de comprimento total de 180 a $210 \mathrm{~mm}$ e 270 a $360 \mathrm{~mm}$ (Figura 8). A baixa freqüência de embriões, entre as classes de comprimento total de 120 a $150 \mathrm{~mm}$ e 210 a $270 \mathrm{~mm}$, é resultado da amostragem que não contemplou fêmeas grávidas nessas classes de comprimento.

Analisando a distribuição das classes de comprimento total dos embriões por sexo, podemos observar que o maior número de fêmeas encontra-se nas classes de comprimento total entre 180 a $210 \mathrm{~mm}$ e de machos entre 300 a 360 mm (Figura 9). 
A distribuição da variável comprimento total para os indivíduos adultos e embriões da amostra por sexo foi avaliada com base nos parâmetros descritivos de posição, dispersão e simetria, representados pelos gráficos de boxplot nas figuras 10 e 11. Pela figura 10, podemos verificar que a distribuição do comprimento total dos indivíduos adultos mostra uma maior assimetria dos dados para as fêmeas, com maior concentração das observações abaixo da mediana, compreendendo comprimentos inferiores a $240 \mathrm{~cm}$. Entretanto, a distribuição do comprimento total é mais dispersa para os machos, com a linha central da mediana dividindo os quartis em partes iguais, atribuindo simetria aos dados. Nos embriões, a distribuição do comprimento total é assimétrica para fêmeas e machos, exibindo dispersão similar, com maior concentração das observações abaixo da mediana, abrangendo comprimentos inferiores a 270 mm (Figura 11). Não foram observados elementos discrepantes, "outliers", na distribuição da variável comprimento total, nos adultos e embriões.

A descrição estatística de todas as variáveis morfométricas, para a amostra total e por sexo, encontra-se nas tabelas 2, 3 e 4. São apresentadas, para cada caractere morfométrico, os valores mínimo e máximo, média e desvio padrão, assim como, o p-valor da normalidade para simetria $\left(s_{z}\right)$, curtose $\left(s_{k}\right)$ e omnibus $\left(K^{2}\right)$ do teste D’Agostino \& Pearson, com nível de significância em $5 \%$.

Para a amostra total (Tabela 2), foram significantes os p-valores da normalidade (acima de \%5) das variáveis morfométricas, altura do olho (EYH), altura do tronco $(\mathrm{TRH})$, espaço dorsal-caudal (DCS), comprimento da margem posterior da primeira nadadeira dorsal (D1P), largura do abdômen (ABW), espaço pélvico-caudal (PCA), altura da cauda (TAH), largura da cauda (TAW), 
altura do pedúnculo da nadadeira caudal $(\mathrm{CPH})$ e largura do pedúnculo da nadadeira caudal (CPW).

Para as fêmeas (Tabela 3), foram significantes pelo p-valor da normalidade (acima de 5\%) as variáveis morfométricas, espaço interorbital (INO), altura do olho $(E Y H)$, altura da primeira fenda branquial (GS1), altura da quinta fenda branquial (GS5), altura do tronco (TRH), comprimento da margem posterior da primeira nadadeira dorsal (D1P), largura da cauda (TAW), altura do pedúnculo da nadadeira caudal $(\mathrm{CPH})$ e largura do pedúnculo da nadadeira caudal (CPW).

Pela tabela 4 , verifica-se que das 48 variáveis morfométricas analisadas para machos, somente o comprimento da boca (MOL), altura da primeira fenda branquial (GS1), altura da quinta fenda branquial (GS5), altura do abdômen $(\mathrm{ABH})$, comprimento da margem interna da primeira nadadeira dorsal (D1I) e comprimento do terminal do lobo superior (CTR) não foram significantes, com p-valor da normalidade abaixo de $5 \%$.

A variação de cada caractere morfométrico transformado em percentagem do comprimento total consta da tabela 5 para a amostra total. Entre as variáveis morfométricas mais expressivas, contribuindo com valores acima de $50 \%$ na composição do corpo do embrião, temos o comprimento furcal (LF) que variou de $77,68 \%$ a $84,12 \%$ com média em $81,37 \%$, o comprimento pré-caudal (PRC) que variou de $68,47 \%$ a $75,94 \%$ com média em $72,72 \%$, o comprimento inicial da segunda nadadeira dorsal (PD2) que variou de $58,73 \%$ a $67,57 \%$ com média em $62,78 \%$, o comprimento pré-anal (PAL) que variou de $57,14 \%$ a $67,04 \%$ com valor médio de $62,21 \%$ e o comprimento pré-pélvico (PP2) que variou de $46,36 \%$ a $55,87 \%$ com valor médio de $51,14 \%$. 
Na região da cabeça, o caractere morfométrico mais significativo foi o comprimento da cabeça (HDL) que variou de $23,41 \%$ a $30,43 \%$ com uma média em $26,23 \%$ e aquele que se demonstrou menos significativo foi a altura da primeira fenda branquial (GS1) que variou de $1,41 \%$ a $2,70 \%$ com valor médio de $2,00 \%$.

Entre as nadadeiras, a caudal foi a mais significativa na composição do embrião, com o comprimento do lobo superior (CDM) variando entre $24,20 \%$ e 29,76\% (média em 26,96\%) e o comprimento da margem interna do lobo superior (CPU) cujos valores variaram entre 10,42\% e 14,31\% (média em $12,37 \%)$, seguida pela nadadeira peitoral cujo comprimento da margem anterior (P1A) variou de $11,76 \%$ a $15,88 \%$ com média em $13,96 \%$.

De acordo com os p-valores da normalidade obtidos para as variáveis morfométricas transformadas em percentagem (Tabela 5), não foram significantes ao nível de 5\%, o espaço interorbital (INO), o comprimento do olho (EYL), a altura do olho $(E Y H)$, altura da cabeça $(\mathrm{HDH})$, comprimento entre as fendas branquiais (ING), a altura da quinta fenda branquial (GS5), a altura do tronco (TRH), o comprimento inicial da primeira nadadeira dorsal (PD1), a altura do abdômen $(\mathrm{ABH})$, a largura do abdômen (ABW), o comprimento do lobo inferior (CPV) e o comprimento da base da nadadeira peitoral (P1B).

Depois de verificada a normalidade das percentagens, estes valores forma comparados entre machos e fêmeas procurando analisar a existência de diferenças corpóreas. Os resultados da aplicação do teste 't de Student - para duas amostras independentes" consta da tabela VI. Pode-se ver que somente as variáveis, espaço entre dorsais (IDS), comprimento pré-pélvico (PP2) e espaço peitoral-pélvico (PPS) apontaram diferenças significativas (> 5\%) entre 
os sexos. Para as demais variáveis que tiveram a normalidade rejeitada, foi aplicado o teste de "Wilcoxon Rank" (resultados na tabela 7), não tendo sido apontadas diferenças significativas corpóreas entre os sexos para esses caracteres.

As regressões lineares das medidas logaritimizadas, mostraram a presença de alometria negativa em $(53,2 \%)$, positiva em $(36,1 \%)$ e isometria em $(10,7 \%)$ dos caracteres morfométricos analisados em relação ao comprimento total dos embriões, como apresentado na tabela 8. Entre as variáveis que apresentaram alometria negativa, a maior parte $(44,0 \%)$ situa-se na região da cabeça e entre as variáveis que compõe as nadadeiras 58,9\% delas apresentaram alometria positiva. Dentre os caracteres que apresentaram crescimento isométrico, $(6,4 \%)$ foram variáveis relacionadas ao comprimento do corpo.

O comprimento furcal, o espaço pélvico-caudal e o espaço peitoralpélvico, foram as três variáveis que apresentaram crescimento isométrico quando relacionadas ao comprimento total $(b=0,9924 ; b=1,0078 ; b=1,0212$, respectivamente) ao longo do crescimento (Figura 12 e Tabela 8).

Por outro lado, ao longo do crescimento dos embriões, apresentaram alometria negativa o comprimento pré-caudal $(b=0,9613)$, o comprimento inicial da primeira nadadeira dorsal $(b=0,8326)$, o comprimento inicial da segunda nadadeira dorsal $(b=0,9409)$, o comprimento pré-anal $(b=0,9403)$, o comprimento pré-peitoral $(b=0,9054)$ e o comprimento pré-pélvico $(b=0,9081)$ ao longo do crescimento (Figura 13 e Tabela 8). 
Verificou-se alometria positiva para o comprimento do tronco $(\mathrm{b}=$ $1,0309)$, o espaço entre dorsais $(b=1,0775)$ e o espaço dorsal-caudal $(b=$ 1,0841) ao longo do crescimento (Figura 14 e Tabela 8).

Dentre os caracteres presentes na região da cabeça, apenas o comprimento da boca $(b=1,1460)$ apresentou alometria positiva (Figura 15), enquanto que o comprimento da cabeça ( $b=0,8388)$, o comprimento préorbital $(b=0,8924)$, o comprimento pré-oral $(b=0,9102)$, a largura da boca $(b=$ $0,8038)$, o espaço interorbital $(b=0,5913)$, o comprimento do olho $(b=0,4216)$, a altura do olho $(b=0,2041)$, o espaço internasal $(b=0,8571)$, o comprimento entre as fendas branquiais $(b=0,8527)$, a altura da primeira fenda branquial $(b=0,6765)$ e a altura da quinta fenda branquial $(b=0,5862)$ desenvolveramse com alometria negativa (Figuras 16 a 18 e Tabela 8).

No estudo do crescimento nas nadadeiras, verificou-se alometria positiva para quase todos os caracteres morfométricos estudados (Figuras $19 \mathrm{e}$ 20), com exceção do comprimento da base da primeira nadadeira dorsal $(b=1,0187)$ e o comprimento do lobo superior $(b=1,0114)$ que apresentaram crescimento isométrico em relação ao comprimento total (Figura 21 e Tabela 8). Verificou-se também crescimento alométrico negativo do comprimento da margem posterior da primeira nadadeira dorsal $(b=0,7896)$ e do comprimento da base da nadadeira peitoral $(b=0,8507)$ ao longo do desenvolvimento (Figura 22).

Para as variáveis relacionadas a altura do corpo, somente a altura da cabeça apresentou alometria positiva $(b=1,2573)$ ao longo do crescimento (Figura 23). As demais variáveis situadas nessa região, altura do tronco $(b=0,8734)$, altura do abdômen $(b=0,8669)$, altura da cauda $(b=0,8171)$ e 
altura do pedúnculo da nadadeira caudal $(b=0,6578)$, apresentaram alometria negativa (Figura 24).

Em relação a largura do corpo, as variáveis morfométricas, largura do abdômen ( $b=0,8722)$, largura da cauda $(b=0,8462)$ e a largura do pedúnculo da nadadeira caudal $(b=0,6483)$, apresentaram alometria negativa ao longo do crescimento (Figura 25), enquanto o caractere largura da cabeça ( $b=1,1096)$ foi o único a apresentar alometria positiva (Figura 26).

Os gráficos de envelope utilizados na análise dos resíduos padronizados mostraram que os resíduos e os percentis seguiram uma distribuição normal, com uma boa acomodação dos pontos dentro do envelope, confirmando a adequação dos dados ao modelo linear (Figuras 27 a 34).

As análises de covariância não revelaram diferenças significativas entre os sexos para todas as variáveis morfométricas analisadas em relação ao comprimento total, conforme apresentado na tabela 9 não havendo, portanto, necessidade de aplicação das regressões lineares, para fêmeas e machos, separadamente.

\section{2- Idade}

A relação entre o raio da vértebra do embrião $\left(R V_{e}\right)$ e o comprimento total (LT) não apresentou diferença significativa entre os sexos (ANCOVA: inclinação (b) $t=-0,40, g l=79, p$-valor $=0,6880$; intercepto $(a) t=-0,6056$, $g l=80, p$-valor $=0,5465)$. Desse modo a relação descrita para os sexos combinados, foi ajustada através de modelo linear (Figura 35). Os valores do 
intercepto $(a=69,50)$ e da inclinação $(b=188,18)$ foram utilizados como fatores de parametrização na aplicação do método modificado da proporção direta de Dahl-Lea.

As estimativas das idades esperadas constam da tabela 10, que fornece os valores das médias e o desvio padrão, dos dois métodos de DahlLea aplicados, conforme as classes de comprimento total dos embriões de P.glauca. De acordo com a tabela, podemos verificar que não ocorreram grandes diferenças nas médias das idades esperadas entre os dois métodos.

A figura 36 traz o ajuste do modelo Logístico entre a idade e o comprimento total dos embriões. As médias e os Intervalos de Confiança dos parâmetros estimados para curva são apresentados na tabela 11. O modelo convergiu com 14 iterações e seu pseudo-coeficiente de explicação $\left(r^{2}=0,94\right)$ mostrou um bom ajuste aos dados, embora o valor médio encontrado para 0 comprimento assintótico, referente ao comprimento de nascimento dos embriões, esteja abaixo do valor encontrado na literatura correlata. O valor médio observado para a idade na qual a taxa de crescimento absoluto começa a diminuir $\left(\mathrm{t}_{0}\right)$, ponto de inflexão, contempla os menores embriões da amostra.

O ajuste da curva de crescimento para o modelo de von Bertalanffy, entre a idade e o comprimento total dos embriões, é apresentado na figura 37. As médias e os Intervalos de Confiança dos parâmetros estimados para curva estão na tabela 12. O modelo convergiu com apenas 6 iterações e seu pseudocoeficiente de explicação $\left(r^{2}=0,94\right)$ mostrou um bom ajuste aos dados. $O$ valor médio encontrado para o comprimento assintótico, referente ao comprimento de nascimento dos embriões, esta próximo do valor citado na literatura correlata. $\mathrm{O}$ valor obtido para o parâmetro da curva $\left(\mathrm{t}_{0}\right)$, referente ao tempo ou 
idade quando o comprimento é teoricamente igual a 0 , está próximo do valor da idade estimada para o menor embrião da amostra.

A figura 38 apresenta o ajuste da curva de crescimento para do modelo de Gompertz, entre a idade e o comprimento total dos embriões. As médias e os Intervalos de Confiança dos parâmetros estimados constam da tabela 13. O modelo convergiu com apenas 5 iterações e seu pseudo-coeficiente de explicação $\left(r^{2}=0,94\right)$ mostrou um bom ajuste aos dados. $O$ valor médio encontrado para o comprimento assintótico, referente ao comprimento de nascimento dos embriões, está de acordo com o referido na literatura correlata. Os menores embriões da amostra se encontram próximos ao ponto de inflexão da curva, $t_{0}=4,40$, onde a taxa de crescimento absoluta começa a diminuir.

A comparação entre as curvas de crescimento ajustadas pelos três modelos estudados pode ser observada na figura 39. Todos os modelos apresentaram ajuste de curvas muito similares, entretanto, o modelo de von Bertalanffy mostrou comportamento diferenciado para o inicio da curva, referente ao parâmetro de crescimento $t_{0}$.

A escolha do melhor modelo de crescimento ficou condicionada aos valores calculados para os critérios de Akaike $\left(\mathrm{AlC}_{\min }, \Delta_{\mathrm{i}}\right.$ e $\left.w_{\mathrm{i}}\right)$ e da soma dos quadrados dos erros (SQE), presentes na tabela 14. Todos os modelos são compatíveis com os parâmetros da curva, pois apresentaram $\Delta_{i}<2$. Entretanto, o modelo selecionado para representação da curva de crescimento dos embriões de P.glauca foi o de Gompertz que apresentou o menor valor de AIC $\left(\mathrm{AlC}_{\min }\right), \Delta \mathrm{i}<2(0,00)$, maior peso de Akaike $(43,73 \%)$ e o menor valor para a soma dos quadrados dos erros (SQE) em relação aos demais modelos aplicados. 


\section{Discussão}

A análise da distribuição e da segregação espacial do tubarão-azul, por tamanho e por sexo, tem sido avaliada desde o trabalho de Strasburg (1958). Segundo Montealegre-Quijano (2007), a proporção sexual em uma área ou época é o resultado de variações na abundância dos machos, das fêmeas ou de ambos os sexos, sendo que a variação temporal e espacial desta proporção deve ser interpretada em conjunto com as informações sobre a abundância (CPUE - captura por unidade de esforço) dos sexos, das classes de tamanho, e das expectativas de vida por sexo.

Variações na abundância dos machos já haviam sido encontradas por Hazin (1993), que analisou a média mensal das CPUEs (captura por unidade de esforço) de machos e fêmeas de P.glauca capturados na região sudoeste equatorial do Oceano Atlântico. Este autor encontrou uma grande abundância relativa de machos do tubarão-azul durante o terceiro e quarto trimestre de 1990, além de diferenças na flutuação sazonal da CPUE para os diferentes grupos etários de machos, indicando a existência de uma segregação temporal tanto por sexo quanto por tamanho.

Amorim (1992) constatou para a região sudeste do Oceano Atlântico, que a captura do tubarão-azul era composta principalmente por machos, e compreendia o período do segundo ao quarto trimestre. Azevedo (2003) utilizando a mesma amostra de indivíduos adultos do presente estudo, encontrou também oscilação na captura dos machos e que foi semelhante à apresentada no trabalho de Amorim op cit. Entretanto, ele sugere que a 
segregação sexual tenha como fator importante a área de atuação da frota pesqueira.

A distribuição da amostra (Figura 7) sugere a existência de segregação por sexo, conforme citado pelos autores acima mencionados corroborando com suas preposições. Por outro lado, Hazin et al. (1994a) e Nakano \& Seki (2003), verificaram que diferenças na distribuição vertical de machos e fêmeas, indicam a existência de uma segregação vertical, o que também poderia estar ocorrendo com os indivíduos adultos da amostra analisada por nós, em função da seletividade da captura e em conseqüência da profundidade de atuação do aparelho de pesca.

No entanto, Montealegre-Quijano (2007) levanta dúvidas a esse respeito, pois considera que a diferença na abundância de machos e fêmeas na fase adulta, possa estar relacionada a diferenças na longevidade, à segregação vertical ou outros eventos, sendo necessários dados de CPUE por sexo nos aparelhos de pesca e prospecções a maiores profundidades.

A distribuição do comprimento total dos embriões de tubarão-azul (Figura 8) foi comparada com as observações feitas por Pratt (1979), Amorim (1992), Hazin et al. (1994b), Castro \& Mejuto (1995), Montealegre-Quijano (2007) e Legat \& Vooren (2008). Desse modo, observamos que a nossa amostra contempla tamanhos similares às observações aferidas pelos autores, embora, não tenham sido observados embriões que estivessem nas fases iniciais de desenvolvimento como encontrado por Hazin et al. (1994b) e Montealegre-Quijano (2007).

De acordo com Pratt (1979), Castro \& Mejuto (1995) e MontealegreQuijano (2007), a proporção sexual dos embriões de P.glauca apresenta razão 
1:1. Confrontando essa informação com o número de embriões de cada sexo observados na distribuição das classes de comprimento total (Figura 9), verificamos que a proporção sexual esperada não variou significativamente corroborando com a preposição dos autores mencionados.

A variação da proporção de cada caractere morfométrico na composição do corpo do embrião foi comparada com as observadas por Strasburg (1958), Hazin et al. (1991) e Legat \& Vooren (2004), em indivíduos adultos de P.glauca. Em relação às variáveis que contribuíram com valores acima de $50 \%$ na composição do corpo dos embriões, verificamos que o comprimento pré-caudal (PRC), o comprimento inicial da segunda nadadeira dorsal (PD2), o comprimento pré-anal (PAL) e o comprimento pré-pélvico (PP2), continuam como as mais expressivas nos indivíduos adultos de P.glauca.

Quando comparamos os caracteres morfométricos da região da cabeça e da nadadeira caudal e peitoral com os observados por Hazin et al. (1991) e Legat \& Vooren (2004), constatamos que os resultados obtidos por estes autores foram os mesmos encontrados no presente estudo, demonstrando que as variáveis mais significativas na composição dos embriões para essas regiões permanecem as mesmas nos indivíduos adultos do tubarão-azul.

As diferenças encontradas nas proporções corpóreas, espaço entre dorsais (IDS), comprimento pré-pélvico (PP2) e espaço peitoral-pélvico (PPS) entre machos e fêmeas, não foram observadas por Hazin et al. (1991). Entretanto, Legat \& Vooren (2004) verificaram que a proporção da variável, espaço peitoral-pélvico (PPS), foi 4\% maior nas fêmeas do que nos machos. Sendo assim, estes autores sugeriram que essa diferença significativa entre os 
sexos poderia ser considerada como uma característica sexual secundária relacionada às funções dos órgãos reprodutivos. Segundo Bass 1973, a distância relativa entre o espaço peitoral-pélvico é maior nas fêmeas do que nos machos, sendo esta uma característica específica encontrada nos tubarões da ordem Carcharhiniformes. A única diferença encontrada por Hazin op cit foi no tamanho da nadadeira peitoral de machos que seriam $10 \%$ maior do que nas fêmeas, fato que não foi constatado nos embriões analisados neste trabalho.

Embora a obtenção das variáveis morfométricas do presente estudo tenha sido feita com a máxima acuidade, devemos considerar de acordo com Francis (2006) que a principal fonte de variabilidade na obtenção das medidas corpóreas depende da metodologia empregada na mensuração das mesmas. Segundo Kuhry \& Marcus (1977), em uma relação estrutural como na equação alométrica, a variância residual ou variabilidade é composta por erros na mensuração e pela dispersão biológica, que se refletem nas irregularidades do crescimento do indivíduo.

De acordo com Mollet \& Cailliet (1996), a equação alométrica raramente foi aplicada em estudos sobre a morfometria dos elasmobrânquios, com exceção da relação comprimento-peso. No entanto, alguns autores como von Bertalanffy (1960), Gould (1966) e Ricker (1979) já haviam proposto que ela fosse a equação mais adequada para a caracterização deste grupo de peixes.

Mesmo considerando a falta de estudos anteriores sobre a quantificação do crescimento relativo em elasmobrânquios, foi possível a comparação de alguns resultados com os da literatura correlata. Entretanto, 
esse é o primeiro estudo da alometria em embriões de P.glauca, onde observamos e quantificamos a alometria ao longo do desenvolvimento ontogenético.

Garrick (1960) observou a tendência de mudanças com o crescimento das dimensões proporcionais em seis gêneros da ordem Squaliformes. Este autor verificou que havia características qualitativas comuns em diversas espécies de tubarões, incluindo a presença de crescimento acelerado (alometria positiva) no tronco comparado com a região da cabeça e da cauda, que apresentaram uma taxa de crescimento mais lenta (alometria negativa). Essa tendência de crescimento acelerado também foi observada para as variáveis morfométricas, comprimento do tronco e espaço entre dorsais, que compõe a região do tronco dos embriões do tubarão-azul (Figura 14).

Por outro lado, segundo Garrick (op cit), mudanças no crescimento longitudinal das dimensões na região da cabeça são relativamente extensas e tendem a ser mascaradas por ocorrerem em pequena escala, quando analisadas em relação ao comprimento total. De fato, observamos que as variáveis que compõe a região da cabeça crescem de acordo com uma alometria negativa sendo que tais alterações são mais visíveis durante 0 desenvolvimento ontogenético dos embriões do que nos indivíduos adultos.

De acordo com Fish \& Shannahan (2000), as variações encontradas na forma das nadadeiras peitorais e sua função na flutuação, estão intimamente associadas com a ecologia dos tubarões. Uma característica comum entre os tubarões oceânicos que derivam seguindo ou aproveitando correntes marítimas é a presença de nadadeiras peitorais alongadas, como as observadas em Prionace glauca e Carcharhinus longimanus, consideradas como 
maximizadoras hidrodinâmicas da flutuação durante cruzeiros de baixa velocidade (Moss, 1984).

Enquanto que as nadadeiras peitorais crescem em um ritmo mais acelerado, a segunda dorsal e a anal, quando presentes, são geralmente as menores nadadeiras encontradas nos tubarões. Em geral, é observada ainda a existência de uma relação inversa entre o tamanho e a taxa de crescimento de todas as nadadeiras e a superfície ventral da cabeça (Thomson \& Simanek, 1977). Diante dos resultados obtidos, podemos afirmar a existência dessa relação inversa já que praticamente todas as variáveis morfométricas que compõe a nadadeira peitoral, a primeira dorsal e a caudal apresentaram crescimento alométrico positivo, enquanto que os caracteres que compõe a região ventral da cabeça apresentam crescimento alométrico negativo.

O crescimento alométrico positivo foi encontrado na maior parte das variáveis morfométricas da nadadeira peitoral e caudal dos embriões, que fazem parte das estruturas utilizadas como centro de ajuste das forças gravitacionais, permitindo aos indivíduos uma boa flutuação, agilidade e boa velocidade de locomoção após seu nascimento. De acordo com Thomson \& Simanek (1977), esse padrão de crescimento dessas estruturas é característico para o tubarão-azul, incluindo-o no grupo dos grandes predadores e migradores.

Bass (1973) também observou que geralmente, entre os tubarões da família Carcharhinidae, ocorre uma taxa de crescimento acelerado na primeira nadadeira dorsal seguida por uma desaceleração com o aumento no comprimento do indivíduo. Do mesmo modo, Mollet et al. (1996) verificaram que a altura máxima da nadadeira dorsal ocorre após o nascimento, 
produzindo uma aparente alometria positiva no crescimento da variável morfométrica, altura da primeira nadadeira dorsal (D1H). Após o crescimento dessa nadadeira tornar-se estável, os autores ainda observaram que sua taxa de crescimento sofre uma desaceleração.

De fato, verificamos que o crescimento da variável (D1H) apresentou alometria positiva, durante a formação ontogenética da estrutura nos embriões. Dessa forma, podemos esperar o mesmo padrão de variação no crescimento da primeira nadadeira dorsal, encontrado por Bass (1973) e Mollet et al. (1996).

De acordo com Casselman (1983), a avaliação da idade dos peixes por meio de estruturas calcificadas deve utilizar diferentes técnicas no tratamento e na análise da estrutura etária. Embora no presente estudo tenha-se usado as principais metodologias propostas em Cailliet et al. (1983a), Cailliet \& Goldman (2004) e Goldman (2005), não foi possível visualizar qualquer tipo de marca que pudesse estar relacionada ao crescimento do embrião. Da mesma forma, Stevens (1975) não encontrou marcas de crescimento ao analisar a vértebra de um embrião a termo de P.glauca.

Entretanto, Campana (com. pess. ${ }^{2}$ ) atribui esses fatos a composição da vértebra por hidroxiapatita, uma substância metabolicamente inerte, que diferentemente dos teleósteos, que possuem otólitos compostos por carbonato de cálcio, não se deposita diariamente.

Através da relação linear encontrada entre o raio da vértebra e o comprimento total dos embriões, atendemos a principal suposição de Smith (1983), que justificou a utilização dos métodos da proporção direta e da

\footnotetext{
${ }^{2}$ Dr. Steven E. Campana. Pesquisador Científico. Bedford Institute of Oceanography - Divisão de Ecologia Populacional. Dartmouth, Nova Scotia - Canadá. campanas@mar.dfo-mpo.gc.ca
} 
modificada de Dahl-Lea. Essa relação também foi apontada por Parsons (1983b) como uma característica importante e um potencial indicador da idade.

Ao mesmo tempo, a possibilidade de quebra da linearidade, abordada por Stevens (1975) e Aires-da-Silva (1996), durante a fase intrauterina, não foi observada. No entanto, não podemos excluir a plausibilidade da nãolinearidade da relação entre o raio da vértebra e o comprimento total nos indivíduos com tamanhos inferiores a $120 \mathrm{~mm}$, não contemplados na amostra.

Não foram observadas diferenças significativas entre os sexos, para a regressão linear entre o raio da vértebra e o comprimento total do embrião, atendendo a uma das premissas para a realização do estudo de idade e crescimento em peixes (Campana, 2001). Dessa forma, a idade, os parâmetros de crescimento e o ajuste dos modelos, foram estimados para machos e fêmeas em conjunto.

Apesar dos métodos aplicados terem apresentado resultados semelhantes, o fato do ajuste linear da relação entre a estrutura e o comprimento total dos embriões não ter passado através de sua origem, justificou a escolha do método da proporção modificada de Dahl-Lea, proposto por Francis (1990), incorporando os valores do intercepto e da inclinação na parametrização da equação.

De acordo com Cailliet \& Tanaka (1990), não devemos ignorar a variação individual do tamanho com a idade ou da idade em um determinado tamanho, portanto não podemos considerar que os parâmetros de crescimento sejam representados apenas por uma única curva ou linha de crescimento.

De certa forma, uma grande variedade de modelos de crescimento pode ser ajustada aos dados de comprimento-idade nos elasmobrânquios. 
Entre os modelos de crescimento mais aplicados, o de von Bertalanffy (1938) tem sido utilizado freqüentemente para descrever o crescimento em indivíduos adultos, enquanto que a curva de Gompertz (1825) representaria melhor o crescimento larval e juvenil (Cailliet \& Goldman, 2004; Goldman, 2005).

Embora tenha sido criticada durante anos, a função de von Bertalanffy vem se mantendo como a mais utilizada, pois considera que o crescimento está baseado na premissa biológica de que as dimensões de um organismo em qualquer momento dependeriam apenas da resultante de duas forças opostas, o anabolismo e o catabolismo (Cailliet \& Goldman, op cit).

De fato, o modelo de von Bertalanffy sempre foi utilizado para a estimativa dos parâmetros da curva de crescimento do tubarão-azul, desde Aasen (1966), Stevens (1975), Cailliet et al (1983b), Tanaka (1990), Nakano (1994), Aires-da-Silva (1996), Henderson et al. (2001), Skomal \& Natanson (2003), Lessa et al. (2004), Manning \& Francis (2005) até Montealegre-Quijano (2007). No entanto, alguns outros modelos também foram utilizados, como Richards e Schnute por Lessa et al. (op cit) e variações de Schnute por Manning \& Francis (op cit).

Cailliet et al. (2006) sugerem a utilização de vários modelos para avaliar as características do crescimento de uma determinada espécie, considerando que nem todas as espécies seguem a mesma função matemática. Desse modo, o presente trabalho atendeu a recomendação deste autor ao utilizar mais de um modelo na estimação dos parâmetros da curva de crescimento para os embriões de P.glauca.

De acordo com Pratt \& Casey (1990), são raros os estudos que utilizaram o ajuste de curvas de crescimento para a fase intrauterina. Parsons 
(1983a) evidenciou através da análise de regressão polinomial, que o aumento do comprimento nos embriões de Rhizoprionodon terraenovae aproximava-se de uma curva sigmóide, a qual considerou ser uma curva de crescimento embrionário.

Ketchen (1972) apresentou uma curva de crescimento para a fase intrauterina de Squalus acanthias, baseada nas observações das médias e dos intervalos de determinados tamanhos. Logo após, Holden (1974) considerou que todos os tubarões deveriam ter uma taxa de crescimento constante, entre $0,10-0,20 / a n o$, e utilizou esse intervalo para extrapolar valores das taxas de crescimento embrionário de Cetorhinus maximus, Galeorhinus australis e Squalus acanthias. De acordo com Cailliet et al. (1983a), as curvas de crescimento apresentadas por estes autores foram originadas a partir da extrapolação das taxas de crescimento embrionário, entretanto, elas não substituem a análise da taxa de crescimento baseada na determinação da idade, devendo ser utilizadas somente como uma medida provisória (Francis, 1981).

Os modelos não-lineares, logístico, de von Bertalanffy e de Gompertz apresentaram um bom ajuste aos dados de comprimento-idade para a fase do crescimento intrauterino do tubarão-azul, se opondo ao crescimento embrionário linear sugerido por Pratt (1979). Devemos considerar que todos esses modelos não-lineares foram elaborados com base na estimativa da idade de cada embrião e estão de acordo com a proposição de Francis (op. cit.); no entanto o mesmo procedimento não foi realizado por Pratt (op. cit.) que simplesmente utilizou a relação entre os meses de captura e o comprimento furcal dos embriões. 
Entre os parâmetros de crescimento, o comprimento assintótico $\left(\mathrm{L}_{\infty}\right)$ apresentou um valor médio específico para cada um dos modelos de crescimento e foi comparado com os comprimentos de nascimento observados na literatura correlata. Dessa forma, a aplicação do modelo logístico levou à obtenção de um valor de $L_{\infty}$ semelhante ao proposto por Cadenat \& Blache (1981 in Snelson et al. 2008), Nakano \& Nagasawa (1996) e Cailliet et al. (1983b); já o modelo de von Bertalanffy originou um valor de $L_{\infty}$ próximo ao estimado por Skomal \& Natanson (2003), Lessa et al. (2004) e MontealegreQuijano (2007) e o modelo de Gompertz apresentou um valor que coincidiu com as estimativas sugeridas por Bigelow \& Schroeder (1948), Strasburg (1958), Stevens (1975), Pratt (1979) e Aires-da-Silva (1996).

Os valores do parâmetro de crescimento to estimados para os modelos de Gompertz e logístico indicam que o intervalo entre o $4^{\circ}$ e $05^{\circ}$ mês de gestação, apresentaria uma diminuição na taxa de crescimento absoluto marcada pelo ponto de inflexão da curva. De acordo com Pratt (1979) e Legat \& Vooren (2008), este intervalo na gestação está relacionado a uma mudança nutricional dos embriões de P.glauca, dada pelo esgotamento de vitelo e da formação do cordão placentário através do qual as mães passariam a fornecer alimento aos embriões.

Por outro lado, a estimativa do parâmetro to calculado através do modelo de von Bertalanffy, indicou que a idade ou o tempo no qual os embriões teriam teoricamente um comprimento igual a zero, seria de aproximadamente 51 dias. De acordo com Legat \& Vooren (2008) o primeiro estágio do desenvolvimento embrionário do tubarão-azul, seria representado por embriões fusiformes com cerca de 16 a $27 \mathrm{~mm}$ de comprimento. Entretanto, mesmo 
considerando a falta de estudos e a ausência de classes de comprimento inferiores a $120 \mathrm{~mm}$, não podemos descartar a plausibilidade da estimativa encontrada pelo modelo de von Bertalanffy, sendo necessário uma reavaliação que englobe as mesmas classes de comprimento encontradas no primeiro estágio do desenvolvimento embrionário por Legat \& Vooren (op. cit.).

As taxas de crescimento $(k)$, obtidas através dos modelos logístico e de Gompertz, foram maiores do que as encontradas para as curvas de crescimento dos adultos de P.glauca por Steven (1975), Cailliet et al. (1983b), Tanaka et al. (1990), Nakano (1994), Aires-da-Silva (1996), Henderson et al. (2001), Skomal \& Natanson (2003), Lessa et al. (2004), Manning \& Francis (2005) e Montealegre-Quijano (2007). Por outro lado, do modelo de von Bertalanffy resultou a menor taxa de crescimento, que coincidiu com o valor encontrado por Lessa et al. (op. cit.) e ficou um pouco acima da observada por Steven (op. cit.), Aires-da-Silva (op. cit.) e Henderson et al. (op. cit.).

Segundo Holden (1974), a taxa de crescimento intrauterino teria o mesmo valor da observada nos indivíduos de vida livre. No entanto, Pratt \& Casey (1990) consideraram incoerente esta suposição de Holden (op. cit.) e afirmaram que o crescimento embrionário ocorreria de maneira diferente da observada nos indivíduos adultos. Casey et al. (1985) também sugeriram que o crescimento em embriões de Carcharhinus plumbeus, ocorreria em diferentes estágios ou stanzas de crescimento, utilizando o conceito proposto por Ricker (1979).

De acordo com Burnham \& Anderson (2002 in Araya \& Cubillos, 2006), a utilização do critério de seleção de Akaike (AIC) é uma boa escolha quando se pretende encontrar um modelo mais parcimonioso para explicar a variação 
observada nos dados. No entanto, não é possível maximizar todos os atributos de um modelo especifico simultaneamente, porque muitas vezes, a parcimônia, a precisão, a exatidão e o contexto biológico, não são atributos independentes (Araya \& Cubillos, op. cit.).

Francis (1996) propõe que o método mais natural, para comparação e escolha das diferentes curvas e taxas de crescimento, seria aquele que mais se aproxima do tamanho assintótico. De acordo com Katsanevakis (2006), o princípio da parcimônia implica na seleção de um modelo que contenha o menor número possível de parâmetros e possa representar de maneira adequada os dados; no entanto, este autor considera a existência de certo grau de incerteza na escolha de um modelo, pois muitas vezes uma componente existente na variância causaria uma superestimação de precisão, quando ignorada.

Embora o modelo de Gompertz tenha sido escolhido para representar a curva de crescimento dos embriões de P.glauca, ele não apresentou um $w_{\mathrm{i}}>$ 90\% que justificaria seu uso como uma escolha incontestável, segundo Katsanevakis \& Maravelias (2008). De acordo com estes autores, quando o modelo de Gompertz é o primeiro a ser selecionado, normalmente o modelo de von Bertalanffy é o segundo na classificação realizada pelos critérios de AIC. De fato, essa proposição dos autores foi verificada no presente estudo, indicando esse "rank" na seleção.

Dessa forma, devemos avaliar cuidadosamente os parâmetros fornecidos pelos modelos de crescimento, pois a escolha de apenas um modelo deve considerar a existência dos diversos efeitos individuais, a 
heterogeneidade e as interações que são geralmente desconhecidas nos sistemas biológicos (Katsanevakis, 2006).

Levando em conta as considerações apresentadas anteriormente, julgamos mais adequados os parâmetros obtidos através do modelo de Gompertz para representar a curva de crescimento intrauterino de P.glauca. 


\section{Considerações Finais}

Levando em conta os objetivos que nortearam este estudo, podemos tecer as seguintes considerações:

1- Os caracteres morfométricos analisados foram adequados para diagnosticar e quantificar mudanças corpóreas que ocorrem ao longo do crescimento dos embriões do tubarão-azul, Prionace glauca, destacando-se a presença de alometria negativa nas dimensões da região da cabeça, de alometria positiva nos caracteres das nadadeiras e isometria em apenas $5 \%$ das variáveis corpóreas.

2- As relações métricas entre as vértebras e o tamanho dos embriões apresentaram correspondência linear, mostrando-se adequadas para serem utilizadas na descrição do crescimento e potencial indicador da idade dos mesmos.

3- Embora a idade real dos embriões não tenha sido estabelecida, pois não foram detectadas marcas nas vértebras dos embriões, estas estruturas foram apropriadas para esclarecer a questão da quebra de linearidade entre o raio da vértebra e o comprimento total dos indivíduos durante sua fase intrauterina, permitindo que fosse estimada uma idade "esperada" de cada embrião, para o que foi utilizando como indicador "de idade" o raio da vértebra correspondente à birthmark, e um período de gestação de 12 meses e a aplicação do conceito da proporção direta de Dahl-Lea. 
4- A utilização desta metodologia, visando esclarecer como se processa esta fase do crescimento nunca havia sido empregada, e mostrou-se coerente com resultados encontrados na literatura correlata sobre o desenvolvimento embrionário da espécie.

5- Embora, até o momento, os modelos de crescimento logístico, de Gompertz e de von Bertalanffy só tenham sido utilizados na literatura para descrever a curva de crescimento após o nascimento dos indivíduos, eles também foram adequados para representar as curvas de crescimento embrionário.

6- Ainda que o modelo de Gompertz tenha sido escolhido com base nos menores valores obtidos de Akaike e por apresentar parâmetros de crescimento mais adequados à fase de desenvolvimento da espécie e também coerência com os dados disponíveis na literatura, fica o questionamento sobre sua aplicação e a escolha do melhor modelo para descrever esta fase da vida de P.glauca e dos elasmobrânquios, em geral.

7- Finalmente, acreditamos que o objetivo principal do estudo a análise do crescimento relativo e da idade dos embriões do tubarãoazul foi cumprido com êxito. Levando em conta que este estudo apresenta abordagem e metodologia inéditas, esperamos que ele venha a contribuir significativamente para novas discussões e outros estudos sobre o crescimento embrionário dos elasmobrânquios. 


\section{Referências Bibliográficas}

AASEN, O. 1966. Blahaien, Prionace glauca (Linnaeus, 1758). Fisken Og Havet, v.1, p. 1-16.

AIRES-DA-SILVA, A. M. C. 1996. Contribuição para o conhecimento da idade e crescimento da tintureira, Prionace glauca (Carcharhinidae), no Atlântico Norte. Relatório de Estágio do Curso de Licenciatura em Biologia Marinha e Pescas. Universidade do Algarve, Unidade de Ciências e Tecnologias dos Recursos Aquáticos, $73 \mathrm{p}$.

AMORIM, A. F. 1992. Estudos da biologia da pesca e reprodução do caçãoazul, Prionace glauca, L. 1758, capturado no sudeste e sul do Brasil. Tese de doutorado. Universidade Estadual Paulista, Instituto de Biociências do Campus de Rio Claro, 205 p.

AMORIM, A. F., ARFELLI, C. A. \& FAGUNDES, L. 1998. Pelagic elasmobranchs caught by longliners off southern Brazil during 1974-1997, an overview. Mar. Freshw. Res., v. 49 (7), p. 621-632.

APPLEGATE, S. P., A survey of shark hard parts. In: GILBERT, P.W., MATHEWSON, R.F., RALL, D.P., (eds). Sharks, Skates and Rays. Maryland: Johns Hopkins Press, p. 33-76.

ARAYA, M. \& CUBILLOS, L. A. 2006. Evidence of two-phases growth in elasmobranchs. Environ. Biol. Fish., v.77, p. 293-300. 
AZEVEDO, V. G. 2003. Aspectos biológica e dinâmica das capturas do tubarão-azul (Prionace glauca) realizada pela frota espinheleira de Itajaí SC, Brasil. Dissertação de Mestrado. Universidade de São Paulo, Departamento de Oceanografia Biológica, 160 p.

BABCOCK, E. A. 2008. Recreational fishing for pelagic sharks worldwide. In: CAMHI, M. D., PIKITCH, E. K. \& BABCOCK, E. A., (eds). Sharks of the open ocean: biology, fisheries \& conservation. Oxford: Blackwell Publishing, p. $193-204$.

BASS, A. J. 1973. Analysis and description of variation in the proportional dimensions of scyliorhinid, carcharhinid and sphyrnid sharks. Bull. / S. Afr. Assoc. Mar. Biol. Res., Investigational Report 32, 28 p.

BAUM, J. K., MYERS, R. A., KEHLER, D. G., WORM, B., HARLEY, S. J. \& DOHERTY, P. A. 2003. Collapse and conservation of shark populations in the northwest Atlantic. Science, v.299, p. 389-392.

BERKELEY, S. A., CHAPMAN, C. \& SOGARD, S. M. 2004. Maternal size as a determinant of larval growth and survival in a marine fish, Sebastes melanops. Ecology, v.85, p. 1258-1264.

BERTALANFFY, L. V. 1938. A quantitative theory of organic growth. Hum. Biol., v.10, p. 181-213.

BERTALANFFY, L. V. 1960. Principles and theory of growth. In: NOWINSKI, W. W., (ed). Fundamental aspects of normal and malignant growth. New York: Elsevier, p. 137-259. 
BIGELOW, H. B. \& SCHROEDER, W. C. 1948. Sharks. In: TEE-VAN, J., BReder, C., HILdebrand, S., PARR, A. \& SCHROEder, W., (eds). Fishes of the western north Atlantic: lancelets, cyclostomes, and sharks. New Haven: Sears Foundation for Marine Research, p. 59-546.

BONFIL, R. 1994. Overview of world elasmobranch fisheries. FAO Fish. Tech. Pap., v.341, 119 p.

BOOKSTEIN, F. L., CHERNOFF, B., ELDER, R. L., HUMPHRIES, J. M. SMITH, G. R. \& STRAUSS, R. E. 1985. Morphometrics in evolutionary biology, the geometry of size and shape change with examples from fishes. Michigan: Acad. Nat. Sci. Philadelphia Spec. Pub., 15. 277 p.

BOOKSTEIN, F. L. 1986. Size and shape spaces for landmark in two dimensions. Stat. Sci., v.1 (2), p. 181-222.

BOOKSTEIN, F. L. 1999. Morphometric tools for landmark data. New York: Cambridge University Press. 435 p.

BRANSTETTER, S. 1987. Age and growth validation of newborn sharks held in laboratory aquaria, with comments on the life history of the Atlantic sharpnose shark, Rhizoprionodon terraenovae. Copeia, v.2, p. 291-300.

BROTHERS, E. B., PRINCE, E. D. \& LEE, D. W. 1983. Age and growth of the young-of-the-year bluefin tuna, Thunnus thynnus, from otoliths microstructure. In: PRINCE, E. D. \& PULOS, L. M., (eds). Proceedings of the international workshop on age determination in oceanic pelagic fishes: tunas, billfishes, and sharks, NOAA Tech. Rep., NMFS 8. p. 49-59. 
BURNHAM, K. P. \& ANDERSON, D. R. 2002. Model selection and multimodel inference: A practical information-theoretic approach. $2^{\text {nd }}$. edition. New York: Springer. 488 p.

CAILLIET, G. M., MARTIN, L. K., KUSHER, D., WOLF, P. \& WELDEN, B. A. 1983a. Techniques for enhancing vertebral bands in age estimation of California elasmobranch. In: PRINCE, E. D. \& PULOS, L. M., (eds). Proceedings of the international workshop on age determination in oceanic pelagic fishes: tunas, billfishes, and sharks, NOAA Tech. Rep., NMFS 8. p. 157-165.

CAILLIET, G. M., MARTIN, L. K., HARVEY, J. T., KUSHER, D. \& WELDEN, B.A. 1983b. Preliminary studies on the age and growth of blue, Prionace glauca, common thresher, Alopias vulpinis, and shortfin mako, Isurus oxyrinchus, sharks from California waters. In: PRINCE, E. D. \& PULOS, L. M., (eds). Proceedings of the international workshop on age determination in oceanic pelagic fishes: tunas, billfishes, and sharks. NOAA Tech. Rep., NMFS 8. p. 179-199.

CAILLIET, G. M. 1990. Elasmobranchs age determination and verification: an updated review. In: PRATT JR, H. L., GRUBER, S. H. \& TAINUCHI, T., (eds). Elasmobranchs as living resources: advances in the biology, ecology, systematics and the status of the fisheries. NOAA Tech. Rep., NMFS 90. p. 157-165.

CAILLIET, G. M. \& TANAKA, S. 1990. Recommendations for research needed to better understand the age and growth of elasmobranchs. In: PRATT JR, 
H. L., GRUBER, S. H. \& TAINUCHI, T., (eds). Elasmobranchs as living resources: advances in the biology, ecology, systematics and the status of the fisheries. NOAA Tech. Rep., NMFS 90. p. 505-507.

CAILLIET, G. M. \& GOLDMAN, K. J. 2004. Age determination and validation in chondrichthyan fishes. In: CARRIER, J., MUSIK, J. A. \& HEITHAUS, M. R., (eds). Biology of sharks and their relatives. Florida: CRC Press LLC, p. 339447.

CAILLIET, G. M., SMITH, W. D., MOLLET, H. F. \& GOLDMAN, K. J. 2006. Age and growth studies of chondrichthyan fishes: the need for consistency in terminology, verification, validation, and growth function fitting. Environ. Biol. Fish., v.77, p. 211-228.

CAMHI, M. D., FORDHAM, S. V. \& FLOWER, S. L. 2008. Domestic and international management for pelagic sharks. In: CAMHI, M. D., PIKITCH, E. K. \& BABCOCK, E. A., (eds). Sharks of the open ocean: biology, fisheries \& conservation. Oxford: Blackwell Publishing, p. 418-444.

CAMPANA, S. E. 2001. Accuracy, precision and quality control in age determination, including a review of the use and abuse of age validations methods. J. Fish Biol., v.59, p. 197-242.

CAREY, F. G. \& SCHAROLD, J. V. 1990. Movements of Blue Sharks (Prionace glauca) in depth and course. Mar. Biol., v.106, p. 329-342.

CARLANDER, K. D. 1969. Handbook of freshwater fishery biology. Ames: lowa Univ. Press. 752 p. 
CARVALHO, M. R. 1996. Higher-level elasmobranch phylogeny, basal squaleans, and paraphyly. In: STIASSNY, M., PARENTI, L. R \& JOHSON G. D., (eds). Interrelationship of fishes. San Diego: Academic Press, 35-46 p.

CASEY, J. G, PRATT JR, H. J. \& STILLWELL, C. E. 1985. Age and growth of the sandbar shark (Carcharhinus plumbeus) from the western north Atlantic. Can. J. Fish. Aquat. Sci., v.42, p. 963-975.

CASSELMAN, J. M. 1983. Age and growth assessments of fish from their calcified structures - techniques and tools. In: PRINCE, E. D. \& PULOS, L. M., (eds). Proceedings of the international workshop on age determination in oceanic pelagic fishes: tunas, billfishes, and sharks. NOAA Tech. Rep., NMFS 8. p. 1-17.

CASTRO, B. M., LORENZZETTI, J. A. A, SILVEIRA, I. C. A. A. \& MIRANDA, L. B. 2006. Estrutura termohalina e circulação na região entre o Cabo de São Tomé (RJ) e o Chuí (RS). In: ROSSI-WONGTSCHOWSKI, C. L. D. \& MADUREIRA, L. S. P., (eds). O ambiente oceanográfico da plataforma continental e do talude na região sudeste-sul do Brasil. São Paulo: Edusp, p.11-120.

CASTRO, J. A. \& MEJUTO, J. 1995. Reproductive parameters of blue shark, Prionace glauca, and other sharks in the Gulf of Guinea. Mar. Freshw. Res., v.46, p. $967-973$.

CASTRO, J. I., WOODLEY, C. M. \& BRUDEK, R. L. 1999. A preliminary evaluation of the status of shark species. FAO Fish. Tech. Pap., v.380, 72 p. 
CLARKE, M. W \& IRVINE, S. E. 2006. Terminology for the ageing of chondrichthyan fish using dorsal-fin spines. Environ. Biol. Fish., v.77, p. 273277.

CLEMENT, J. G., 1992. Re-examination of the fine structure of endoskeletal mineralization in chondricthyes: implications for growth, ageing and calcium homeostasis. Aust. J. Mar. Freshw. Res., v.43, p. 157-181.

COMPAGNO, L. J. V. 1977. Phyletic relationships of living sharks and rays. Amer. Zool., v.17, p. 303-322.

COMPAGNO, L. J. V. 1984. Sharks of the World: An annotated and illustrated catalogue of shark species known to date. Carcharhiniformes. FAO Fish Synop., 125, v.4, p. 251-655.

COMPAGNO, L. J. V. 1999. Endoskeleton. In: HAMLETT, W. C., (ed). Sharks, Skates, and Rays. Baltimore: The Johns Hopkins Univ. Press, p. 69-92.

COMPAGNO, L., DANDO, M. \& FLOWER, S. 2005. Sharks of the world. Oxford: Princeton University Press, 368 p.

DA SILVA JR, C. L., KAMPEL, M., DE ARAUJO, C. E. S. \& STECH, J. L. 1996. Observação da penetração do ramo costeiro da corrente das Malvinas na costa sul-sudeste do Brasil a partir de imagens AVHRR. In: KRUG, T., (ed). VIII Simpósio brasileiro de sensoriamento remoto. Salvador: INPE, p. 787793. Disponível em: http://urlib.net/dpi.inpe.br/lise/2004/08.25.13.20 
DEAN, M. N., CHIOU, W. A. \& SUMMERS, A. P., 2005. Morphology and ultrastructure of prismatic cartilage calcification. Microsc. Microanal., v.11, p. 1196-1197.

DEAN, M. N. \& SUMMERS, A. P. 2006. Mineralized cartilage in the skeleton of chondrichthyan fishes. Zool., v.109, p. 164-186.

DE VRIES, D. A., GRIMES, C. B., LANG, K. L. \& WHITE, D. B. 1990. Age and growth of king and Spanish mackerel larvae and juveniles from the Gulf of Mexico and U.S. south Atlantic Bight. Environ. Biol. Fish., v.29, p. 135-143.

DOS SANTOS, R. A. \& HAIMOVICI, M. 2001. Cephalopods in the diet of marine mammals stranded or incidentally caugh along southeastern and southern Brazil (21-34º S). Fish. Res., v.52, p. 99-112.

FISH, F. E. \& SHANNAHAN, L. D. 2000. The role of the pectoral fins in body trim of sharks. J. Fish Biol., v.56, p. 1062-1073.

FRANCIS, M. P. 1981. Von Bertalanffy growth rates in species of Mustelus (Elasmobranchii: Triakidae). Copeia, v.1, p. 189-192.

FRANCIS, R. I. I. C. 1990. Back-calculation of fish length: a critical review. J. Fish Biol., v.36, p. 883-902.

FRANCIS, R. I. I. C. 1996. Do herring grow faster than orange roughy? Fish. Bull., v.94, p. 783-786.

FRANCIS, M. P. 2006. Morphometric minefields-towards a measurement standard for chondrichthyan fishes. Environ. Biol. Fish., v.77, p. 407- 421. 
GALLAGHER, M. J \& NOLAN, C. P. 1999. A novel method for the estimation of age and growth in rajids using caudal thorns. Can. J. Fish. Aquat. Sci., v.56, p. $1590-1599$.

GALLAGHER, M. J., GREEN, M. J. \& NOLAN, C. P. 2006. The potential use of caudal thorns as a non-invasive ageing structure in the thorny skate (Amblyraja radiata Donovan, 1808). Environ. Biol. Fish., v.77, p. 265-272.

GARRICK, J. A. F. 1960. Studies on New Zealand elasmobranchii. Part XII The species of Squalus from New Zealand, and a general account and key to the New Zealand squaloidea. Trans. R. Soc. N.Z., v.88 (3), p. 519-557.

GOLDMAN, K. J. 2005. Age and growth of elasmobranch fishes. In: MUSICK, J. A \& BONFIL, R., (eds). Management techniques for elasmobranch fisheries. FAO Fish Tech. Pap., v.474. p. 76-102.

GOMPERTZ, B. 1825. On the nature of the function expressive of the law of human mortality and on a new mode of determining the value of life contingences. Phil. Trans. R. Soc. London., v.115, p. 515-585.

GOULD, S. J. 1966. Allometry and size in ontogeny and phylogeny. Biol. Rev., v. 41 , p. $587-640$.

GUBANOV, Y. P. \& GRIGOR'YEV. 1975. Observations on the distribution and biology of the blue shark Prionace glauca (Carcharhinidae) of the Indian Ocean. J. Ichthyol., v.15 (1), p. 37-43.

HAIMOVICI, M. \& PEREZ, J. A. A. 1991. Coastal cephalopod fauna off southern Brazil. Bull. Mar. Sci., v.49, p. 221-230. 
HAIMOVICI, M., MARTINS, A. S., FIGUEIREDO, J. L. \& VIEIRA, P. C. 1994. Demersal bony fish of the outer shelf and upper slope of the southern Brazil subtropical convergence ecosystem. Mar. Ecol., Prog. Ser., v.108 (1-2), p. 59-77.

HARVEY, J. T. 1989. Food habits, seasonal, abundance, size, and sex of the blue shark, Prionace glauca, in Monterey Bay, California. Calif. Fish Game., v.75 (1), p. 33-44.

HAZIN, F. H. V., LESSA, R., ISHINO, M., OTSUKA, K. \& KIHARA, K. 1991. Morphometric description of the blue shark, Prionace glauca, from the southwestern equatorial Atlantic. J. Tokyo Univ. Fish., v.78 (2), p. 137-144.

HAZIN, F. H. V. 1993. Fisheries-Oceanographical study on tunas, billfishes, and sharks in the southwestern equatorial Atlantic Ocean. Ph.D. thesis. Tokyo University of Fisheries, Doctoral Course of Marine Science and Technology, $286 \mathrm{p}$.

HAZIN, F. H. V., BOECKMAN, C. E., LEAL, E. C., LESSA, R. P. T., KIHARA, K. \& OTSUKA, K. 1994a. Distribution and relative abundance of the blue shark, Prionace glauca, in the southwestern equatorial Atlantic Ocean. Fish. Bull., v.92 (2), p. 474-480.

HAZIN, F. H. V., KIHARA, K., OTSUKA, K., BOECKMAN, C. E. \& LEAL, E. C. 1994b. Reproduction of the blue shark, Prionace glauca, in the southwestern equatorial Atlantic Ocean. Fish. Bull., v.60 (5), p. 487-491. 
HAZIN, F. H. V., ZAGAGLIA, J. R., BROADHURST, M. K., TRAVASSOS, P. E. P., \& BEZERRA, T. R. Q. 1998. Review of a small-scale pelagic longline fishery off northeastern Brazil. Mar. Fish. Rev., v.60 (3), p. 1-8.

HAZIN, F. H. V., PINHEIRO, P. B. \& BROADHURST, M. K. 2000. Further notes on reproduction of the blue shark, Prionace glauca, and a postulated migratory pattern in the south Atlantic Ocean. Cienc. Cul., v.52 (2), p. 114120.

HAZIN, F. H. V., BROADHURST, M. K., AMORIM, A. F., ARFELLI, C. A. \& DOMINGO, A. 2008. Catches of pelagic sharks by subsurface longline fisheries in the south Atlantic Ocean during the last century: A review of available data with emphasis on Uruguay e Brazil. In: CAMHI, M. D., PIKITCH, E. K. \& BABCOCK, E. A., (eds). Sharks of the open ocean: biology, fisheries \& conservation. Oxford: Blackwell Publishing, p. 213-229.

HENDERSON, A. C., FLANNERY, K. \& DUNNE, J., 2001. Observations on the biology and ecology of the blue shark in the north-east Atlantic. J. Fish Biol., v.58, p. 1347-1358.

HINTZE, J. 2007. NCSS and GESS. NCSS, LLC. Kaysville, Utah. www.ncss.com.

HOENIG, J. M. \& BROWN, C. A. 1988. A simple technique for staining growth bands in elasmobranch vertebrae. Bull. Mar. Sci., v.42 (2), p. 334-337. 
HOLDEN, M. J. \& MEADOWS, P. S. 1962. The structure of the spine (Squalus acanthias) and its use for age determination. J. Mar. Biol. Assoc. U.K., v.42, p. $179-197$.

HOLDEN, M. J. \& VINCE, M. R. 1973. Age validation studies on the centra of Raja clavata using tetracycline. J. Cons. Int. Explor. Mer., v.35, p. 13-17.

HOLDEN, M. J. 1974. Problems in the rational exploitation of elasmobranch populations and some suggested solutions. In: JONES, F. R. H., (ed). Sea fisheries research. London: Elek, p. 117-137.

HUGHES, G. M., PERRY, S. F. \& PIIPER, J. 1986. Morphometry of the gills of the elasmobranch Scyliorhinus stellaris in relation to body size. J. Exp. Biol., v.121, p. 27-42.

HUXLEY, J. S. 1932. Problems of relative growth. 1993 edition. London: Johns Hopkins University Press. $360 \mathrm{p}$.

ICCAT. 2006a. Task I database. Disponível na Internet via www.iccat.es/accesingdb.html. Consulta feita no dia 20 de dezembro de 2008.

ICCAT. 2006b. Report for biennial period, 2004-05 Part II (2005). Annual Report, v.3, p. 10-14.

ICCAT. 2007. Report for biennial period, 2006-07 Part I (2006). SCRS Report, v.2, p. $152-155$. 
ICCAT. 2008. Report of the shark stock assessments meeting. Report SCRS /2008/17, p.1-89.

INSIGHTFUL, CORP. 2007. S-Plus 8.0 for Windows. Enterpriser Developer.

IUCN. 2006. IUCN Red list of threatened species. Disponível na Internet via www.iucnredlist.org. Consulta feita no dia 20 de dezembro de 2008.

JENKINS, G. P. \& DAVIS, T. L. O. 1990. Age, growth rate, and growth trajectory determined from otolith microstructure of southern bluefin tuna Thunnus maccoyii larvae. Mar. Ecol., Prog. Ser., v.63, p. 93-104.

JONES, B. C. \& GEEN, G. H. 1977. Morphometric changes in an elasmobranch (Squalus acanthias) after preservation. Can. J. Zool., v.55 (6), 1060-1062.

KATSANEVAKIS, S. 2006. Modelling fish growth: Model selection, multi-model inference and model selection uncertainty. Fish. Res., v.81, p. 229-235.

KATSANEVAKIS, S. \& MARAVELIAS, C. D. 2008. Modelling fish growth: multimodel inference as a better alternative to a priori using von Bertalanffy equation. Fish Fish., v.9, p. 178-187.

KEMP, N. E., 1977. Calcification of endoskeleton in elasmobranchs. Am. Zool., v. 17, p. $932-932$.

KETCHEN, K. S. 1972. Size at maturity, fecundity, and embryonic growth of the spiny dogfish (Squalus acanthias) in British Columbia waters. J. Fish. Res. Boar. Can., v.29, p. 1717-1723. 
KOHLER, N. E., TURNER, P. A., HOEY, J. J., NATANSON, L. J. \& BRIGGS, R. 2002. Tag and recapture data for three pelagic shark species: blue shark (Prionace glauca), Shortfin mako (Isurus oxyrinchus), and porbeagle (Lamna nasus) in the north Atlantic Ocean. Collect. Vol. Sci. Pap. ICCAT, v.54 (4), p. 1231-1260.

KUBODERA, T., WATANABE, H. \& ICHII, T. 2007. Feeding habits of the blue shark, Prionace glauca, and salmon shark, Lama ditropis, in the transition region of the western North Pacific. Rev. Fish. Biol. Fishe., v.17 (2-3), p. 111-124.

KUHRY, B. \& MARCUS, L. F. 1977. Bivariate linear models in biometry. Syst. Zool., v.26 (2), p. 201-209.

LA MARCA, M. J. 1966. A simple technique for demonstrating calcified annuli in the vertebrae of large elasmobranchs. Copeia, v.2, p. 351-352.

LASS, H. U. \& MOHRHOLZ, V. 2008. On the interaction between the subtropical gyre and the subtropical cell on the shelf of the SE Atlantic. J. Mar. Syst., v.74 (1-2), p. 1-43.

LEGAT, J. F. A. \& VOOREN, C. M. 2004. Reproductive cycle and migration of the blue shark (Prionace glauca) in south Atlantic Ocean. In: IV International Congress on the Biology of Fish. Manaus: Anais, p. 25-35.

LEGAT, J. F. A. \& VOOREN, C. M. 2008. Caracterização da morfologia uterina e das fases de desenvolvimento embrionário do tubarão-azul, Prionace glauca (Linnaeus, 1758). Arq. Cienc. Mar, v.41 (2), p. 14-20. 
LELE, S. \& RICHTSMEIER, J. T. 2001. An invariant approach to statistical analysis of shapes. London: Chapman and Hall-CRC Press. 308 p.

LESSA, R. P. T. 1988. Biometria de tubarões costeiros aplicada ao controle de desembarques no norte do Brasil, Maranhão. Cienc. Cul., v.40 (9), p. 892-897.

LESSA, R. P., PAGLERANI, R. B \& SANTANA, F. M. 1999a. Biology and morphometry of the oceanic whitetip shark, Carcharhinus longimanus (Carcharhinidae), off north-eastern Brazil. Cybium, v.23 (4), p. 353-368.

LESSA, R. P., SANTANA, F. M. \& PAGLERANI, R. B. 1999b. Age and growth and stock structure of the oceanic whitetip shark Carcharhinus longimanus, off northeastern Brazil. Fish. Res., v.42, p. 21-30.

LESSA, R. P. \& SANTANA, F. M. 2004. Crescimento embrionário e em vida livre do tubarão azul, Prionace glauca no Atlântico Sudoeste Equatorial. In: IV Reunião da Sociedade Brasileira para o Estudo de Elasmobrânquios. Recife: Livro de resumos, p. 104.

LESSA, R. P., SANATANA, F. M., HAZIN, F. H. 2004. Age and growth of the blue shark Prionace glauca (Linnaeus, 1758) off northeastern Brazil. Fish. Res., v.66, p. 19-30.

LESSA, R. P., SANTANA, F. M. \& NETO, P. D. 2006. A critical appraisal of marginal increment analysis for assessing temporal periodicity in band formation among tropical sharks. Environ. Biol. Fish., v.77, p. 309-315. 
MANNING, M. J. \& FRANCIS, M. P. 2005. Age and growth of blue shark (Prionace glauca) from the New Zealand Exclusive Economic Zone. Wellington: New Zealand Fisheries Assessment Report 2005/26. 52 p.

MARCUS, L. F.1990. Traditional morphometrics. In: ROHLF, F. J. \& BOOKSTEIN, F. L., (eds). Proceedings of the Michigan Morphometrics Workshop. Michigan: Univ. Michigan Museum of Zoology, p. 77-122.

MARShalL, A. D., PIERCE, S. J. \& BenNET, M. B. 2008. Morphological measurements of manta rays (Manta birostris) with a description of a fetus from the east coast of southern Africa. Zootaxa, v.1717, p. 24-30.

McFARLANE, G. A., KING, J. R. \& SAUNDERS, M. W. 2002. Preliminary study on the use of neural arches in the age determination of bluntnose sixgill sharks (Hexanchus griseus). Fish. Bull., v.100 (4), p. 861-864.

MICROSOFT, 2007. Microsoft ${ }^{\circledR}$ Access 2007. Microsoft Corporation.

MOLLET, H. F. \& CAILLIET, G. M. 1996. Using allometry to predict body mass from linear measurements of the white shark. In: KLIMLEY, A. P. \& AINLEY, A. D., (eds). Great white sharks, the biology of Carcharodon carcharias. San Diego: Academic Press, p. 81-89.

MOLLET, H. F., CAILLIET, G. M., KLIMLEY, A. P., EBERT, D. A., TESTI, A. D. \& COMPAGNO, L. J. V. 1996. A review of length validation methods and protocols to measure large white sharks. In: KLIMLEY, A. P. \& AINLEY, A. D., (eds). Great white sharks, the biology of Carcharodon carcharias. San Diego: Academic Press, p. 91-108. 
MONTEALEGRE-QUIJANO, S. 2007. Biologia populacional do tubarão-azul Prionace glauca (Linnaeus, 1758) (Carcharhinidae), na região sudoeste do Oceano Atlântico. Tese de Doutorado. Universidade Federal do Rio Grande, Departamento de Oceanografia Biológica, 189 p.

MONTEIRO, L. R. \& DOS REIS, S. F. 2005. Princípios de morfometria geométrica. Ribeirão Preto: Editora Holos. 198 p.

MOSS, S. A. 1977. Skeletal tissues in sharks. Am. Zool., v.17, p. 335-342.

MOSS, S. A. 1984. Sharks: An introduction for the amateur naturalist. Englewood Cliff NJ: Prentice Hall Inc. 246 p.

NAKANO, H. 1994. Age, reproduction and migration of blue shark in the north Pacific Ocean. Bull. Natl. Res. Inst. Far Seas Fish., v.31, p. 141-256.

NAKANO, H. \& NAGASAWA, K. 1996. Distribution of pelagic elasmobranch caught by salmon research gillnets in the north Pacific. Fish. Sci., v.62, p. 860-865.

NAKANO, H. \& SEIKI, M. P. 2003. Synopsis of biological data on blue shark Prionace glauca Linnaeus. Bull. / Fish. Res. Agency, v.6, p. 18-25.

NAKANO, H. \& STEVENS, J. D. 2008. The biology and ecology of the blue shark, Prionace glauca. In: CAMHI, M. D., PIKITCH, E. K. \& BABCOCK, E. A., (eds). Sharks of the open ocean: biology, fisheries \& conservation. Oxford: Blackwell Publishing, p. $140-151$. 
NASA. 2009. National Aeronautics and Space Administration. Hurricane data analysis tool. Disponível na Internet via www.disc.sci.gsfc.nasa.gov. Consulta feita no dia 19 de fevereiro de 2009.

OFFICER, R. A., GASON, A. S, WALKER, T. I. \& CLEMENT, J. G. 1996. Sources of variation in counts of growth increments in vertebrae from gummy shark, Mustelus antarticus, and school shark, Galeorhinus galeus: implications for age determination. Can. J. Fish. Aquat. Sci., v.53, p. 17651777.

ØRVIG, T. 1951. Histological studies of placoderms and fossil elasmobranchs. I: The endoskeleton, with remarks on the hard tissues of lower vertebrates in general. Ark. Zool., v.2, p. 321-454.

PARSONS, G. R. 1983a. The reproductive biology of the atlantic sharpnose shark, Rhizoprionodon terranovae (Richardson). Fish. Bull., v.81 (1), p. 61 73.

PARSONS, G. R. 1983b. An examination of the vertebral rings of the atlantic sharpnose shark, Rhizoprionodon terranovae. Northeast Gulf Sci., v.6 (1), 63-66.

PAULA, G. 2004. Modelos de regressão com apoio computacional. São Paulo: Instituto de Matemática e Estatística da Universidade de São Paulo. $245 p$.

PORTER, M. E., BELTRÁN, J. L., KOOB, T. J. \& SUMMERS, A. P. 2006. Material properties and biochemical composition of mineralized vertebral 
cartilage in seven elasmobranch species (chondricthyes). J. Exp. Biol., v.209, p. $2920-2928$.

PORTER, M. E., KOOB, T. J. \& SUMMERS, A. P. 2007. The contribution of mineral to the material properties of vertebral cartilage from the smooth hound shark Mustelus californicus. J. Exp. Biol., v.210 (19), p. 3319-3327.

PRATT, H. L. 1979. Reproduction in the blue shark, Prionace glauca. Fish. Bull., v.77 (3), p. 445-470.

PRATT, H. L. Jr. \& CASEY, J. G. 1990. Shark reproductive strategies as a limiting factor in directed fisheries, with a review of Holden's method of estimating growth parameters. NOAA Tech. Rep. NMFS 90. p. 97-109.

QUEIROZ, N., LIMA, F. P., MAIA, A., RIBEIRO, P. A., CORREIA, J. P. \& SANTOS, A. A. 2005. Movement of blue shark, Prionace glauca, in the north-east Atlantic based on mark-recapture data. J. Mar. Biol. Ass. U.K., v.85, p. $1107-1112$.

RADTKE, R. L. 1983. Otolith formation and increment deposition in laboratoryreared skipjack tuna, Euthynnus pelamis, larvae. In: PRINCE, E. D. \& PULOS, L. M., (eds). Proceedings of the international workshop on age determination in oceanic pelagic fishes: tunas, billfishes, and sharks. NOAA Tech. Rep. NMFS 8. p. 99-103.

RIBOT-CARBALLAL, M. C., GALVÁN-MAGAÑA, F. \& QUIÑÓNESVELÁSQUEZ, C. 2005. Age and growth of the shortfin mako shark, Isurus 
oxyrinchus, from the western coast of Baja California Sur, Mexico. Fish. Res., v.76, p. 14-21.

RICKER, W. E. 1979. Growth rate and models. In: HOAR, W. S.; RANDALL, D. J., BERTT, J. R., (eds). Fish physiology. London: Academic Press, p. 677743.

RINCÓN, G., LESSA, R. P. \& FREITAS, J. 2000. Crescimento embrionário do tubarão azul, Prionace glauca, no nordeste do Brasil. In: II Reunião da Sociedade Brasileira para o Estudo de Elasmobrânquios. Santos: Livro de resumos, p. 56 .

SANTOS, R. A. \& HAIMOVICI, M. 2001. Cephalopods in the diet of marine mammals stranded or incidentally caught along southeastern and southern Brazil (21-34º). Fish. Res., v.52, p. 99-112.

SCHLUESSEL, V., BENNET, M. B., BLECKMANN, H., BLOMBERG, S. \& COLLIN, S. R. Morphometric and ultrastructural comparison of the olfactory system in elasmobranchs: the significance of structure-function relationships based on phylogeny and ecology. J. Morphol., v.269 (11), p. 1365-1386.

SEBER, G. A. F. \& WILD, C. J. 1989. Nonlinear Regression. New York: John Wiley. $768 p$.

SKOMAL, G. B. \& NATANSON, L. J. 2003. Age and growth of the blue shark (Prionace glauca) in the north Atlantic Ocean. Fish. Bull., v.101, p. 627-639.

SMITH, C. L. 1983. Summary of round table discussions on back calculation. In: PRINCE, E. D. \& PULOS, L. M., (eds). Proceedings of the international 
workshop on age determination in oceanic pelagic fishes: tunas, billfishes, and sharks. NOAA Tech. Rep., NMFS 8. p. 45-47.

SNELSON JR, F. F., BURGESS, G. H. \& ROMAN, B. L. 2008. The reproductive biology of pelagic elasmobranch. In: CAMHI, M. D., PIKITCH, E. K. \& BABCOCK, E. A., (eds). Sharks of the open ocean: biology, fisheries \& conservation. Oxford: Blackwell Publishing, p. 24-53.

SPONAUGLE, S., DENIT, K.L., LUTHY, S. A., SERAFY, J. E. \& COWEN, R. K. 2005. Growth variation in larval Makaira nigricans. J. Fish Biol., v.66, p. 822835.

STEVENS, J. D. 1975. Vertebral rings as a means of the age determination in the blue shark (Prionace glauca). J. Mar. Biol. Ass. U.K., v.55, p. 657-665.

STEVENS, J. D. 1976. First results of shark tagging in the north-east Atlantic, 1972-1975. J. Mar. Biol. Ass. U.K., v.56, p. 929-937.

STRASBURG, D. W. 1958. Distribution, abundance, and habits of pelagic sharks in the central Pacific Ocean. Fish. Bull., v.58 (138), p. 335-361.

STRAUSS, R. E. 1993. The study of allometry since Huxley. In: Problems of Relative Growth. London: Johns Hopkins University Press, p. xlvii-Ixxv.

TANAKA, S. 1990. Age and growth studies on the calcified structures of newborn sharks in laboratory aquaria using tetracycline. In: PRATT JR, H. L., GRUBER, S. H. \& TANIUCHI, T., (eds). Elasmobranchs as living resources: Advances in the biology, ecology, systematics and the status of the fisheries. NOAA Tech. Rep., NMFS 90. p. 189-202. 
TANAKA, S., CAILLIET, G. M., YUDIN, K. G. 1990. Differences in growth of the blue shark, Prionace glauca: technique or population. In: PRATT JR, H. L., GRUBER, S. H. \& TANIUCHI, T., (eds). Elasmobranchs as living resources: advances in the biology, ecology, systematics and the status of the fisheries. NOAA Tech. Rep. NMFS 90. p. 177-187.

TAKASUKA, A. \& AOKI, I. 2006. Environmental determinants of growth rates for larval japanese anchovy Engraulis japonicus in different waters. Fish. Ocean., v.15 (2), p. 139-149.

THOMPSON, D. W. 1966. On growth and form. Abridge edition. London: Cambridge University Press. 346 p.

THOMSON, K. S. \& SIMANEK, D. E. 1977. Body form and locomotion in sharks. Amer. Zool., v.17, p. 343-354.

TORRES, B., MOREY, G. \& TOMÁS, J. 2005. Interpretation of vertebral growth marks as annuli in the sandbar shark Carcharhinus plumbeus: analysis of vertebrae of captive specimens. J. Mar. Biol. Ass. U.K., v.85, p. 1167-1170.

UNIVALI/CTTMar, 2008. GEP - Sistema Integrado de Estatística Pesqueira (2000 a 2008). Disponível na Internet via www.siaiacad04.univali.br. Consulta feita no dia 16 de dezembro de 2008.

VANNUCCINI, S. 1999. Shark utilization, marketing and trade. Rome: FAO Fish. Tech. Pap., v.389, 470 p. 
VASKE JR. T. \& RINCÓN, G. F. 1998. Conteúdo estomacal dos tubarões azuis (Prionace glauca) e anequim (Isurus oxyrinchus) em águas oceânicas no sul do Brasil. Rev. Bras. Biol., v. 58 (3), p. 443-450.

WOURMS, J. P. 1977. Reproduction and development in condrichthyan fishes. Amer. Zool., v.17, p. 379-410.

ZAR, J. H. 1999. Bioestatistical Analysis. 4" edition. New Jersey: Prentice-Hall. $662 p$.

ZELDITCH, M. L., SWIDERSKI, D. Z., SHEETS, D. H. \& FINK, W. Z. 2004. Geometric Morphometrics for Biologists. Elsevier: Academic Press. 443 p. 
Tabela 1. Medidas morfométricas usadas no estudo, com suas abreviações correspondentes (Compagno, 1984). Todas as medidas foram tomadas com precisão de $0,01 \mathrm{~mm}$ com exceção das medidas marcadas com asterístico $\left(^{*}\right)$, que foram tomadas com precisão de $1 \mathrm{~mm}$.

\begin{tabular}{|c|c|c|c|}
\hline \multirow{2}{*}{$\frac{\text { Local de medição }}{\text { Comprimento do corpo }}$} & \multicolumn{3}{|c|}{ Abreviações Nome } \\
\hline & LT & * & Comprimento total \\
\hline & LF & * & Comprimento furcal \\
\hline & PRC & * & Comprimento pré-caudal \\
\hline & TRL & & Comprimento do tronco \\
\hline & PD1 & & Comprimento inicial da primeira nadadeira dorsal \\
\hline & PD2 & & Comprimento inicial da segunda nadadeira dorsal \\
\hline & PAL & & Comprimento pré-anal \\
\hline & PP1 & & Comprimento pré-peitoral \\
\hline & PP2 & & Comprimento pré-pélvico \\
\hline & PCA & & Espaço pélvico-caudal \\
\hline & IDS & & Espaço entre dorsais \\
\hline & DCS & & Espaço dorsal-caudal \\
\hline & PPS & & Espaço peitoral-pélvico \\
\hline \multirow{5}{*}{ Altura do corpo } & $\mathrm{HDH}$ & & Altura da cabeça \\
\hline & TRH & & Altura do tronco \\
\hline & $\mathrm{ABH}$ & & Altura do abdomen \\
\hline & TAH & & Altura da cauda \\
\hline & $\mathrm{CPH}$ & & Altura do pedúnculo da nadadeira caudal \\
\hline \multirow[t]{4}{*}{ Largura do corpo } & HDW & & Largura da cabeça \\
\hline & ABW & & Largura do abdomen \\
\hline & TAW & & Largura da cauda \\
\hline & CPW & & Largura do pedúnculo da nadadeira caudal \\
\hline \multirow[t]{12}{*}{ Cabeça } & HDL & & Comprimento da cabeça \\
\hline & РОВ & & Comprimento pré-orbital \\
\hline & POR & & Comprimento pré-oral \\
\hline & EYL & & Comprimento do olho \\
\hline & EYH & & Altura do olho \\
\hline & ING & & Comprimento entre as fendas branquiais \\
\hline & $\mathrm{MOL}$ & & Comprimento da boca \\
\hline & MOW & & Largura da boca \\
\hline & INO & & Espaço interorbital \\
\hline & INW & & Espaço internasal \\
\hline & GS1 & & Altura da primeira fenda branquial \\
\hline & GS5 & & Altura da quinta fenda branquial \\
\hline \multirow[t]{4}{*}{ Nadadeira Caudal } & CDM & & Comprimento do lobo superior \\
\hline & CPV & & Comprimento do lobo inferior \\
\hline & CPU & & Comprimento da margem interna do lobo superior \\
\hline & CTR & & Comprimento do terminal do lobo superior \\
\hline \multirow[t]{6}{*}{ Nadadeira Dorsal } & D1A & & Comprimento da margem anterior da primeira nadadeira dorsal \\
\hline & D1H & & Altura da primeira nadadeira dorsal \\
\hline & D1P & & Comprimento da margem posterior da primeira nadadeira dorsal \\
\hline & D1B & & Comprimento da base da primeira nadadeira dorsal \\
\hline & D1L & & Comprimento da primeira nadadeira dorsal \\
\hline & D1I & & Comprimento da margem interna da primeira nadadeira dorsal \\
\hline \multirow[t]{4}{*}{ Nadadeira Peitoral } & P1A & & Comprimento da margem anterior da nadadeira peitoral \\
\hline & $\mathrm{P} 1 \mathrm{~B}$ & & Comprimento da base da nadadeira peitoral \\
\hline & P1P & & Comprimento da margem posteior da nadadeira peitoral \\
\hline & P1I & & Comprimento da margem interna da nadadeira peitoral \\
\hline
\end{tabular}


Tabela 2. Descrição estatística das variáveis morfométricas, para a amostra total. Descrição das medidas na Tabela 1.

\begin{tabular}{|c|c|c|c|c|c|c|c|c|}
\hline \multirow{2}{*}{$\begin{array}{l}\text { Variáveis } \\
\text { Morfométricas }\end{array}$} & \multirow{2}{*}{ Mínimo } & \multirow{2}{*}{ Máximo } & \multirow{2}{*}{ Média } & \multirow{2}{*}{$\begin{array}{l}\text { Desvio } \\
\text { Padrão }\end{array}$} & \multicolumn{3}{|c|}{ p-valor (normalidade) } & \multirow{2}{*}{$\mathrm{N}$} \\
\hline & & & & & Simetria $\left(z_{s}\right)$ & Curtose $\left(z_{k}\right)$ & Omnibus $\left(\mathrm{K}^{2}\right)$ & \\
\hline LT & 120,00 & 432,00 & 270,78 & 69,39 & 0,8583 & 0,0001 & 0,0005 & 83 \\
\hline PRC & 88,00 & 315,00 & 196,51 & 49,02 & 0,8636 & 0,0008 & 0,0037 & 83 \\
\hline TRL & 51,48 & 213,89 & 126,21 & 33,87 & 0,7533 & 0,0237 & 0,0738 & 83 \\
\hline LF & 98,00 & 349,00 & 220,33 & 56,34 & 0,7443 & 0,0000 & 0,0001 & 83 \\
\hline POB & 13,01 & 37,37 & 26,06 & 6,15 & 0,5692 & 0,0000 & 0,0000 & 83 \\
\hline INW & 6,66 & 18,85 & 12,15 & 2,81 & 0,8710 & 0,0001 & 0,0007 & 83 \\
\hline INO & 16,05 & 36,89 & 27,50 & 4,75 & 0,2753 & 0,0265 & 0,0470 & 83 \\
\hline EYL & 9,03 & 15,45 & 11,79 & 1,51 & 0,9237 & 0,0074 & 0,0276 & 83 \\
\hline $\mathrm{EYH}$ & 5,19 & 10,52 & 8,19 & 0,95 & 0,0767 & 0,2760 & 0,1154 & 74 \\
\hline $\mathrm{HDL}$ & 36,52 & 101,11 & 70,30 & 15,45 & 0,3263 & 0,0000 & 0,0000 & 83 \\
\hline MOL & 5,09 & 17,70 & 11,71 & 3,46 & 0,2529 & 0,0000 & 0,0000 & 83 \\
\hline MOW & 8,97 & 26,69 & 17,40 & 3,84 & 0,8343 & 0,0052 & 0,0198 & 83 \\
\hline POR & 13,88 & 42,67 & 28,84 & 6,88 & 0,6760 & 0,0000 & 0,0002 & 83 \\
\hline HDW & 10,99 & 35,11 & 22,43 & 6,49 & 0,5055 & 0,0000 & 0,0000 & 83 \\
\hline $\mathrm{HDH}$ & 8,25 & 37,61 & 20,66 & 6,72 & 0,2598 & 0,0094 & 0,0182 & 83 \\
\hline ING & 7,14 & 18,87 & 12,82 & 2,87 & 0,6445 & 0,0003 & 0,0015 & 81 \\
\hline GS1 & 2,35 & 10,18 & 5,63 & 1,17 & 0,0087 & 0,0031 & 0,0004 & 69 \\
\hline GS5 & 2,09 & 7,27 & 3,93 & 1,01 & 0,0005 & 0,0332 & 0,0003 & 69 \\
\hline TRH & 10,20 & 31,40 & 22,29 & 5,03 & 0,0659 & 0,2669 & 0,0995 & 73 \\
\hline PD1 & 49,69 & 148,66 & 103,03 & 22,13 & 0,3764 & 0,0001 & 0,0004 & 81 \\
\hline PD2 & 75,00 & 263,00 & 170,54 & 40,89 & 0,4369 & 0,0004 & 0,0014 & 81 \\
\hline IDS & 19,42 & 76,90 & 45,65 & 12,78 & 0,9283 & 0,0090 & 0,0328 & 81 \\
\hline DCS & 7,58 & 33,27 & 18,96 & 5,34 & 0,7605 & 0,0551 & 0,1516 & 80 \\
\hline D1A & 8,77 & 33,37 & 21,95 & 6,44 & 0,1889 & 0,0000 & 0,0000 & 80 \\
\hline D1H & 5,86 & 18,93 & 12,02 & 3,40 & 0,5206 & 0,0001 & 0,0004 & 80 \\
\hline D1P & 7,23 & 22,69 & 12,91 & 2,97 & 0,5194 & 0,3934 & 0,5645 & 80 \\
\hline D1B & 8,09 & 29,38 & 18,20 & 4,89 & 0,4295 & 0,0002 & 0,0007 & 80 \\
\hline D1I & 3,76 & 14,00 & 9,01 & 2,85 & 0,2287 & 0,0000 & 0,0000 & 80 \\
\hline D1L & 12,15 & 41,89 & 27,33 & 7,42 & 0,1353 & 0,0000 & 0,0000 & 79 \\
\hline $\mathrm{ABH}$ & 8,89 & 25,94 & 17,89 & 4,42 & 0,7984 & 0,0005 & 0,0023 & 71 \\
\hline ABW & 6,06 & 21,04 & 13,55 & 3,39 & 0,5623 & 0,1851 & 0,3514 & 72 \\
\hline PAL & 75,00 & 260,00 & 167,80 & 40,63 & 0,6405 & 0,0001 & 0,0002 & 83 \\
\hline PP1 & 31,37 & 101,49 & 66,80 & 15,70 & 0,4077 & 0,0000 & 0,0000 & 83 \\
\hline PP2 & 61,00 & 207,00 & 137,65 & 32,38 & 0,5592 & 0,0000 & 0,0001 & 83 \\
\hline PPS & 23,06 & 91,48 & 57,93 & 15,36 & 0,8263 & 0,0000 & 0,0001 & 83 \\
\hline PCA & 21,32 & 89,26 & 49,17 & 13,33 & 0,2607 & 0,4995 & 0,4230 & 83 \\
\hline TAH & 6,59 & 23,12 & 14,37 & 3,05 & 0,7112 & 0,6336 & 0,8335 & 69 \\
\hline TAW & 5,36 & 21,56 & 11,99 & 2,76 & 0,2185 & 0,0643 & 0,0847 & 69 \\
\hline $\mathrm{CPH}$ & 4,13 & 12,91 & 8,58 & 1,65 & 0,6434 & 0,1420 & 0,3057 & 69 \\
\hline CPW & 3,20 & 10,56 & 6,75 & 1,29 & 0,4651 & 0,3711 & 0,5134 & 69 \\
\hline CDM & 31,77 & 115,88 & 73,11 & 19,37 & 0,8522 & 0,0001 & 0,0003 & 83 \\
\hline CPV & 10,25 & 46,62 & 28,73 & 8,74 & 0,4573 & 0,0000 & 0,0000 & 83 \\
\hline CPU & 15,28 & 54,14 & 33,74 & 9,90 & 0,4374 & 0,0000 & 0,0001 & 83 \\
\hline CTR & 7,80 & 27,30 & 17,63 & 5,42 & 0,5496 & 0,0000 & 0,0000 & 83 \\
\hline $\mathrm{P} 1 \mathrm{~A}$ & 14,40 & 60,85 & 38,22 & 11,31 & 0,3598 & 0,0000 & 0,0000 & 83 \\
\hline P1B & 6,20 & 15,72 & 10,56 & 2,43 & 0,5547 & 0,0000 & 0,0000 & 83 \\
\hline $\mathrm{P} 1 \mathrm{P}$ & 9,98 & 44,48 & 28,92 & 8,95 & 0,2919 & 0,0000 & 0,0000 & 83 \\
\hline P1I & 3,46 & 16,80 & 10,11 & 2,96 & 0,9420 & 0,0009 & 0,0040 & 83 \\
\hline
\end{tabular}


Tabela 3. Descrição estatística das variáveis morfométricas, para fêmeas. Descrição das medidas na Tabela 1.

\begin{tabular}{|c|c|c|c|c|c|c|c|c|}
\hline \multirow{2}{*}{$\begin{array}{c}\text { Variáveis } \\
\text { Morfométricas }\end{array}$} & \multirow{2}{*}{ Mínimo } & \multirow{2}{*}{ Máximo } & \multirow{2}{*}{ Média } & \multirow{2}{*}{$\begin{array}{l}\text { Desvio } \\
\text { Padrão }\end{array}$} & \multicolumn{3}{|c|}{ p-valor (normalidade) } & \multirow{2}{*}{$N$} \\
\hline & & & & & Simetria $\left(\mathrm{Z}_{\mathrm{s}}\right)$ & Curtose $\left(z_{k}\right)$ & Omnibus $\left(\mathrm{K}^{2}\right)$ & \\
\hline LT & 172,00 & 380,00 & 261,9 & 67,90 & 0,7870 & 0,0000 & 0,0000 & 42 \\
\hline PRC & 123,00 & 274,00 & 190,0 & 47,32 & 0,8152 & 0,0000 & 0,0000 & 42 \\
\hline TRL & 74,34 & 182,06 & 121,8 & 32,41 & 0,5823 & 0,0000 & 0,0001 & 42 \\
\hline LF & 137,00 & 308,00 & 212,6 & 55,29 & 0,7567 & 0,0000 & 0,0000 & 42 \\
\hline POB & 16,81 & 36,93 & 25,3 & 6,14 & 0,8070 & 0,0000 & 0,0001 & 42 \\
\hline INW & 7,88 & 16,71 & 11,7 & 2,67 & 0,7180 & 0,0001 & 0,0000 & 42 \\
\hline INO & 16,05 & 36,89 & 26,9 & 4,77 & 0,5149 & 0,3233 & 0,4966 & 42 \\
\hline EYL & 9,24 & 14,52 & 11,7 & 1,51 & 0,9369 & 0,0002 & 0,0009 & 42 \\
\hline $\mathrm{EYH}$ & 5,19 & 10,52 & 8,1 & 1,03 & 0,2342 & 0,2345 & 0,2430 & 39 \\
\hline HDL & 48,66 & 91,94 & 68,2 & 15,24 & 0,7867 & 0,0000 & 0,0000 & 42 \\
\hline $\mathrm{MOL}$ & 6,47 & 16,56 & 11,2 & 3,41 & 0,7588 & 0,0000 & 0,0000 & 42 \\
\hline MOW & 11,80 & 23,05 & 16,9 & 3,50 & 0,9056 & 0,0000 & 0,0000 & 42 \\
\hline POR & 18,49 & 38,68 & 27,8 & 6,67 & 0,9197 & 0,0000 & 0,0000 & 42 \\
\hline HDW & 11,83 & 33,00 & 21,6 & 6,46 & 0,9412 & 0,0000 & 0,0000 & 42 \\
\hline $\mathrm{HDH}$ & 9,42 & 27,61 & 19,7 & 6,30 & 0,3627 & 0,0000 & 0,0000 & 42 \\
\hline ING & 8,31 & 17,05 & 12,4 & 2,67 & 0,9417 & 0,0002 & 0,0009 & 40 \\
\hline GS1 & 3,87 & 7,53 & 5,6 & 0,93 & 0,5576 & 0,3546 & 0,5486 & 33 \\
\hline GS5 & 2,56 & 5,73 & 3,9 & 0,85 & 0,2828 & 0,3953 & 0,3914 & 33 \\
\hline TRH & 11,48 & 28,78 & 21,7 & 5,08 & 0,2024 & 0,1167 & 0,1296 & 36 \\
\hline PD1 & 70,33 & 134,86 & 100,7 & 21,72 & 0,8224 & 0,0000 & 0,0000 & 40 \\
\hline PD2 & 109,00 & 227,00 & 166,1 & 39,89 & 0,7662 & 0,0000 & 0,0000 & 40 \\
\hline IDS & 26,67 & 63,10 & 43,8 & 12,23 & 0,9343 & 0,0000 & 0,0000 & 40 \\
\hline DCS & 11,32 & 26,59 & 18,3 & 5,12 & 0,8950 & 0,0000 & 0,0000 & 40 \\
\hline D1A & 12,15 & 29,12 & 21,1 & 6,31 & 0,5947 & 0,0000 & 0,0000 & 40 \\
\hline $\mathrm{D} 1 \mathrm{H}$ & 5,94 & 17,67 & 11,5 & 3,40 & 0,7673 & 0,0000 & 0,0002 & 40 \\
\hline D1P & 7,23 & 17,51 & 12,5 & 2,84 & 0,4889 & 0,0778 & 0,1662 & 40 \\
\hline D1B & 9,95 & 25,85 & 17,3 & 4,64 & 0,7612 & 0,0000 & 0,0000 & 40 \\
\hline D1I & 4,46 & 14,00 & 8,7 & 2,97 & 0,9766 & 0,0000 & 0,0000 & 40 \\
\hline D1L & 13,56 & 36,96 & 26,3 & 7,27 & 0,3999 & 0,0000 & 0,0000 & 39 \\
\hline $\mathrm{ABH}$ & 11,09 & 24,50 & 17,5 & 3,98 & 0,8084 & 0,0311 & 0,0950 & 35 \\
\hline ABW & 7,03 & 18,52 & 13,1 & 3,17 & 0,3389 & 0,0244 & 0,0503 & 35 \\
\hline PAL & 110,00 & 228,00 & 162,5 & 39,69 & 0,9374 & 0,0000 & 0,0000 & 42 \\
\hline PP1 & 44,02 & 89,76 & 64,8 & 15,48 & 0,8682 & 0,0000 & 0,0000 & 42 \\
\hline PP2 & 90,00 & 186,00 & 134,2 & 31,87 & 0,9580 & 0,0000 & 0,0000 & 42 \\
\hline PPS & 38,08 & 87,60 & 56,9 & 15,57 & 0,6854 & 0,0000 & 0,0000 & 42 \\
\hline PCA & 30,92 & 72,05 & 47,1 & 12,40 & 0,4525 & 0,0001 & 0,0005 & 42 \\
\hline TAH & 9,35 & 17,71 & 13,9 & 2,58 & 0,1810 & 0,0143 & 0,0203 & 33 \\
\hline TAW & 7,67 & 15,84 & 11,4 & 2,24 & 0,5194 & 0,0790 & 0,1737 & 33 \\
\hline $\mathrm{CPH}$ & 5,94 & 10,42 & 8,4 & 1,28 & 0,0856 & 0,2781 & 0,1267 & 33 \\
\hline CPW & 4,12 & 8,46 & 6,6 & 1,15 & 0,3498 & 0,3712 & 0,4331 & 33 \\
\hline CDM & 47,19 & 102,65 & 71,1 & 19,13 & 0,5387 & 0,0000 & 0,0000 & 42 \\
\hline CPV & 14,31 & 40,65 & 27,5 & 8,66 & 0,8825 & 0,0000 & 0,0000 & 42 \\
\hline CPU & 20,44 & 51,50 & 32,7 & 9,92 & 0,2338 & 0,0028 & 0,0056 & 42 \\
\hline CTR & 9,36 & 25,69 & 16,9 & 5,41 & 0,8375 & 0,0000 & 0,0000 & 42 \\
\hline $\mathrm{P} 1 \mathrm{~A}$ & 21,73 & 53,36 & 36,8 & 11,11 & 0,7431 & 0,0000 & 0,0000 & 42 \\
\hline P1B & 6,25 & 13,95 & 10,3 & 2,34 & 0,8329 & 0,0000 & 0,0000 & 42 \\
\hline $\mathrm{P} 1 \mathrm{P}$ & 15,42 & 40,11 & 27,7 & 8,86 & 0,8016 & 0,0000 & 0,0000 & 42 \\
\hline P1I & 5,84 & 14,64 & 9,9 & 2,87 & 0,8845 & 0,0000 & 0,0000 & 42 \\
\hline
\end{tabular}


Tabela 4. Descrição estatística das variáveis morfométricas, para machos. Descrição das medidas na Tabela 1.

\begin{tabular}{|c|c|c|c|c|c|c|c|c|}
\hline \multirow{2}{*}{$\begin{array}{c}\text { Variáveis } \\
\text { Morfométricas }\end{array}$} & \multirow{2}{*}{ Mínimo } & \multirow{2}{*}{ Máximo } & \multirow{2}{*}{ Média } & \multirow{2}{*}{$\begin{array}{l}\text { Desvio } \\
\text { Padrão }\end{array}$} & \multicolumn{3}{|c|}{ p-valor (normalidade) } & \multirow{2}{*}{$\mathrm{N}$} \\
\hline & & & & & Simetria $\left(z_{s}\right)$ & Curtose $\left(z_{k}\right)$ & Omnibus $\left(\mathrm{K}^{2}\right)$ & \\
\hline LT & 120,00 & 432,00 & 279,88 & 70,55 & 0,5576 & 0,4875 & 0,6616 & 41 \\
\hline PRC & 88,00 & 315,00 & 203,17 & 50,42 & 0,5644 & 0,6017 & 0,7391 & 41 \\
\hline TRL & 51,48 & 213,89 & 130,75 & 35,12 & 0,8554 & 0,8287 & 0,9608 & 41 \\
\hline LF & 98,00 & 349,00 & 228,27 & 56,97 & 0,4046 & 0,3974 & 0,4939 & 41 \\
\hline POB & 13,01 & 37,37 & 26,85 & 6,15 & 0,2698 & 0,2355 & 0,2691 & 41 \\
\hline INW & 6,66 & 18,85 & 12,59 & 2,92 & 0,4734 & 0,2733 & 0,4244 & 41 \\
\hline INO & 18,81 & 35,95 & 28,11 & 4,71 & 0,3192 & 0,0761 & 0,1263 & 41 \\
\hline EYL & 9,03 & 15,45 & 11,91 & 1,52 & 0,9416 & 0,6099 & 0,8756 & 41 \\
\hline $\mathrm{EYH}$ & 6,17 & 9,71 & 8,30 & 0,85 & 0,2271 & 0,8988 & 0,4782 & 35 \\
\hline HDL & 36,52 & 101,11 & 72,42 & 15,56 & 0,2136 & 0,2260 & 0,2218 & 41 \\
\hline MOL & 5,09 & 17,70 & 12,24 & 3,48 & 0,1451 & 0,0155 & 0,0185 & 41 \\
\hline MOW & 8,97 & 26,69 & 17,94 & 4,13 & 0,5129 & 0,4549 & 0,6107 & 41 \\
\hline POR & 13,88 & 42,67 & 29,87 & 7,02 & 0,5234 & 0,3730 & 0,5486 & 41 \\
\hline HDW & 10,99 & 35,11 & 23,30 & 6,49 & 0,2769 & 0,0758 & 0,1144 & 41 \\
\hline $\mathrm{HDH}$ & 8,25 & 37,61 & 21,61 & 7,08 & 0,2865 & 0,6446 & 0,5095 & 41 \\
\hline ING & 7,14 & 18,87 & 13,23 & 3,03 & 0,4180 & 0,1416 & 0,2445 & 41 \\
\hline GS1 & 2,35 & 10,18 & 5,67 & 1,36 & 0,0266 & 0,0113 & 0,0035 & 36 \\
\hline GS5 & 2,09 & 7,27 & 3,93 & 1,14 & 0,0018 & 0,0421 & 0,0010 & 36 \\
\hline TRH & 10,20 & 31,40 & 22,81 & 5,00 & 0,1278 & 0,8977 & 0,3111 & 37 \\
\hline PD1 & 49,69 & 148,66 & 105,27 & 22,56 & 0,2649 & 0,5107 & 0,4327 & 41 \\
\hline PD2 & 75,00 & 263,00 & 174,90 & 41,87 & 0,3577 & 0,5889 & 0,5661 & 41 \\
\hline IDS & 19,42 & 76,90 & 47,48 & 13,19 & 0,9057 & 0,6867 & 0,9154 & 41 \\
\hline DCS & 7,58 & 33,27 & 19,65 & 5,53 & 0,8748 & 0,9209 & 0,9828 & 40 \\
\hline D1A & 8,77 & 33,37 & 22,81 & 6,53 & 0,1357 & 0,0565 & 0,0533 & 40 \\
\hline D1H & 5,86 & 18,93 & 12,51 & 3,37 & 0,5023 & 0,1899 & 0,3381 & 40 \\
\hline D1P & 7,34 & 22,69 & 13,36 & 3,06 & 0,2097 & 0,1512 & 0,1625 & 40 \\
\hline D1B & 8,09 & 29,38 & 19,06 & 5,03 & 0,2807 & 0,3245 & 0,3440 & 40 \\
\hline D1I & 3,76 & 12,72 & 9,26 & 2,74 & 0,0615 & 0,0274 & 0,0153 & 40 \\
\hline D1L & 12,15 & 41,89 & 28,30 & 7,53 & 0,1375 & 0,1343 & 0,1082 & 40 \\
\hline $\mathrm{ABH}$ & 8,89 & 25,94 & 18,30 & 4,83 & 0,6896 & 0,0131 & 0,0426 & 36 \\
\hline ABW & 6,06 & 21,04 & 13,98 & 3,57 & 0,7624 & 0,6483 & 0,8609 & 37 \\
\hline PAL & 75,00 & 260,00 & 173,24 & 41,34 & 0,4051 & 0,5677 & 0,6006 & 41 \\
\hline PP1 & 31,37 & 101,49 & 68,87 & 15,84 & 0,2656 & 0,3432 & 0,3434 & 41 \\
\hline PP2 & 61,00 & 207,00 & 141,17 & 32,91 & 0,3435 & 0,5579 & 0,5378 & 41 \\
\hline PPS & 23,06 & 91,48 & 59,01 & 15,26 & 0,4551 & 0,5117 & 0,6100 & 41 \\
\hline PCA & 21,32 & 89,26 & 51,28 & 14,06 & 0,5129 & 0,6241 & 0,7160 & 41 \\
\hline TAH & 6,59 & 23,12 & 14,78 & 3,41 & 0,7855 & 0,5277 & 0,7894 & 36 \\
\hline TAW & 5,36 & 21,56 & 12,51 & 3,10 & 0,3870 & 0,1086 & 0,1898 & 36 \\
\hline $\mathrm{CPH}$ & 4,13 & 12,91 & 8,71 & 1,94 & 0,7972 & 0,3076 & 0,5750 & 36 \\
\hline CPW & 3,20 & 10,56 & 6,91 & 1,40 & 0,4984 & 0,2260 & 0,3821 & 36 \\
\hline CDM & 31,77 & 115,88 & 75,13 & 19,65 & 0,7237 & 0,3542 & 0,6116 & 41 \\
\hline CPV & 10,25 & 46,62 & 29,98 & 8,76 & 0,3152 & 0,3698 & 0,4039 & 41 \\
\hline CPU & 15,28 & 54,14 & 34,80 & 9,90 & 0,9653 & 0,0847 & 0,2260 & 41 \\
\hline CTR & 7,80 & 27,30 & 18,35 & 5,41 & 0,2669 & 0,0125 & 0,0238 & 41 \\
\hline $\mathrm{P} 1 \mathrm{~A}$ & 14,40 & 60,85 & 39,77 & 11,45 & 0,2693 & 0,2489 & 0,2794 & 41 \\
\hline P1B & 6,20 & 15,72 & 10,85 & 2,51 & 0,4393 & 0,0799 & 0,1599 & 41 \\
\hline P1P & 9,98 & 44,48 & 30,13 & 8,99 & 0,1743 & 0,0990 & 0,1019 & 41 \\
\hline $\mathrm{P} 1 \mathrm{I}$ & 3,46 & 16,80 & 10,36 & 3,06 & 0,7549 & 0,4712 & 0,7346 & 41 \\
\hline
\end{tabular}


Tabela 5. Estatística descritiva das proporções, para a amostra total. Todos os valores referem-se à percentagem do comprimento total $(\mathrm{LT})$. Descrição das medidas na Tabela 1.

\begin{tabular}{|c|c|c|c|c|c|c|c|c|}
\hline \multirow{2}{*}{$\begin{array}{c}\text { Variáveis } \\
\text { Morfométricas }\end{array}$} & \multirow{2}{*}{ Mínimo } & \multirow{2}{*}{ Máximo } & \multirow{2}{*}{ Média } & \multirow{2}{*}{$\begin{array}{l}\text { Desvio } \\
\text { Padrão }\end{array}$} & \multicolumn{3}{|c|}{ p-valor (normalidade) } & \multirow{2}{*}{$\mathrm{N}$} \\
\hline & & & & & Simetria $\left(\mathrm{z}_{\mathrm{s}}\right)$ & Curtose $\left(z_{k}\right)$ & Omnibus $\left(\mathrm{K}^{2}\right)$ & \\
\hline PRC & 68,47 & 75,94 & 72,72 & 1,26 & 0,6760 & 0,0724 & 0,1824 & 83 \\
\hline TRL & 42,90 & 49,51 & 46,48 & 1,33 & 0,8685 & 0,5895 & 0,8528 & 83 \\
\hline LF & 77,68 & 84,12 & 81,37 & 1,33 & 0,3622 & 0,6713 & 0,6034 & 83 \\
\hline POB & 8,11 & 10,99 & 9,70 & 0,62 & 0,9160 & 0,4014 & 0,6993 & 83 \\
\hline INW & 3,82 & 5,55 & 4,53 & 0,32 & 0,8623 & 0,0484 & 0,1405 & 83 \\
\hline INO & 8,00 & 15,68 & 10,46 & 1,52 & 0,0041 & 0,2716 & 0,0088 & 83 \\
\hline EYL & 3,34 & 7,53 & 4,53 & 0,79 & 0,0020 & 0,0803 & 0,0018 & 83 \\
\hline EYH & 1,76 & 5,14 & 3,17 & 0,76 & 0,0428 & 0,1177 & 0,0378 & 74 \\
\hline $\mathrm{HDL}$ & 23,41 & 30,43 & 26,23 & 1,37 & 0,6481 & 0,6328 & 0,8039 & 83 \\
\hline MOL & 3,41 & 5,38 & 4,28 & 0,43 & 0,4398 & 0,1617 & 0,2787 & 83 \\
\hline MOW & 5,31 & 7,72 & 6,51 & 0,52 & 0,6003 & 0,5305 & 0,7161 & 83 \\
\hline POR & 9,43 & 11,90 & 10,72 & 0,56 & 0,9259 & 0,3941 & 0,6925 & 83 \\
\hline HDW & 6,33 & 9,58 & 8,22 & 0,71 & 0,3129 & 0,9556 & 0,6000 & 83 \\
\hline $\mathrm{HDH}$ & 4,39 & 9,36 & 7,52 & 1,15 & 0,0001 & 0,1145 & 0,0002 & 83 \\
\hline ING & 3,90 & 5,95 & 4,76 & 0,43 & 0,0281 & 0,8138 & 0,0874 & 81 \\
\hline GS1 & 1,41 & 2,70 & 2,00 & 0,29 & 0,1071 & 0,5565 & 0,2297 & 69 \\
\hline GS5 & 0,81 & 2,06 & 1,40 & 0,30 & 0,8538 & 0,0081 & 0,0295 & 69 \\
\hline TRH & 6,18 & 9,76 & 7,97 & 0,91 & 0,8124 & 0,0126 & 0,0434 & 73 \\
\hline PD1 & 34,41 & 41,81 & 38,21 & 1,96 & 0,6180 & 0,0002 & 0,0008 & 81 \\
\hline PD2 & 58,73 & 67,57 & 62,78 & 1,77 & 0,8957 & 0,4309 & 0,7270 & 81 \\
\hline IDS & 14,26 & 18,56 & 16,64 & 0,87 & 0,7627 & 0,9592 & 0,9542 & 81 \\
\hline DCS & 5,93 & 7,88 & 6,89 & 0,44 & 0,9980 & 0,0943 & 0,2466 & 80 \\
\hline D1A & 6,19 & 10,07 & 7,94 & 0,78 & 0,0686 & 0,8492 & 0,1871 & 80 \\
\hline D1H & 3,13 & 5,18 & 4,37 & 0,42 & 0,3560 & 0,6840 & 0,6012 & 80 \\
\hline D1P & 3,54 & 6,20 & 4,78 & 0,58 & 0,2947 & 0,9584 & 0,5768 & 80 \\
\hline D1B & 5,29 & 8,01 & 6,64 & 0,58 & 0,7196 & 0,9601 & 0,9364 & 80 \\
\hline D1I & 2,31 & 4,01 & 3,24 & 0,39 & 0,2038 & 0,3036 & 0,2627 & 80 \\
\hline D1L & 7,88 & 11,92 & 9,89 & 0,75 & 0,4693 & 0,3801 & 0,5237 & 79 \\
\hline $\mathrm{ABH}$ & 3,49 & 8,18 & 6,33 & 0,82 & 0,0216 & 0,0577 & 0,0118 & 71 \\
\hline ABW & 3,32 & 7,20 & 4,83 & 0,73 & 0,0550 & 0,0924 & 0,0385 & 72 \\
\hline PAL & 57,14 & 67,04 & 62,21 & 1,73 & 0,6498 & 0,2153 & 0,4186 & 83 \\
\hline PP1 & 21,89 & 27,47 & 24,83 & 1,15 & 0,5746 & 0,6727 & 0,7813 & 83 \\
\hline PP2 & 46,36 & 55,87 & 51,14 & 1,87 & 0,9105 & 0,4953 & 0,7876 & 83 \\
\hline PPS & 19,22 & 23,70 & 21,36 & 0,95 & 0,4191 & 0,4372 & 0,5335 & 83 \\
\hline PCA & 16,03 & 20,66 & 18,13 & 0,91 & 0,6352 & 0,1257 & 0,2767 & 83 \\
\hline TAH & 3,74 & 6,00 & 5,05 & 0,50 & 0,1548 & 0,7824 & 0,3485 & 69 \\
\hline TAW & 3,20 & 5,17 & 4,21 & 0,47 & 0,5166 & 0,5011 & 0,6462 & 69 \\
\hline $\mathrm{CPH}$ & 1,37 & 3,93 & 3,05 & 0,41 & 0,2173 & 0,6009 & 0,4074 & 69 \\
\hline CPW & 1,68 & 3,34 & 2,40 & 0,35 & 0,8255 & 0,5516 & 0,8175 & 69 \\
\hline CDM & 24,20 & 29,76 & 26,96 & 1,01 & 0,0970 & 0,1011 & 0,0658 & 83 \\
\hline CPV & 8,32 & 12,25 & 10,46 & 0,89 & 0,0012 & 0,2491 & 0,0028 & 83 \\
\hline CPU & 10,42 & 14,31 & 12,37 & 0,89 & 0,9775 & 0,5110 & 0,8054 & 83 \\
\hline CTR & 5,16 & 7,94 & 6,43 & 0,57 & 0,4852 & 0,7634 & 0,7491 & 83 \\
\hline P1A & 11,76 & 15,88 & 13,96 & 0,99 & 0,1085 & 0,7507 & 0,2623 & 83 \\
\hline P1B & 3,31 & 5,17 & 3,94 & 0,33 & 0,0872 & 0,0461 & 0,0317 & 83 \\
\hline P1P & 7,27 & 12,62 & 10,50 & 1,00 & 0,0507 & 0,5474 & 0,1236 & 83 \\
\hline P1I & 2,88 & 4,42 & 3,70 & 0,31 & 0,2716 & 0,3290 & 0,3393 & 83 \\
\hline
\end{tabular}


Tabela 6. Comparação entre as proporções das variáveis morfométricas de fêmeas e machos, aplicando o Teste 't de Student - para duas amostras independentes". Descrição das medidas na Tabela 1. $\left(\mathrm{s}^{*}\right)=$ Variáveis significativas.

\begin{tabular}{|c|c|c|c|c|c|c|c|c|c|c|c|}
\hline \multirow{2}{*}{$\begin{array}{c}\text { Variáveis } \\
\text { Morfométricas }\end{array}$} & \multicolumn{4}{|c|}{ Fêmeas } & \multicolumn{4}{|c|}{ Machos } & \multirow[b]{2}{*}{$t$} & \multirow{2}{*}{ p-valor } & \multirow{2}{*}{ Significâncię } \\
\hline & Média & Mínimo & Máximo & Desvio Padrão & Média & Mínimo & Máximo & Desvio Padrão & & & \\
\hline PRC & 72,75 & 70,51 & 75,94 & 1,35 & 72,68 & 68,47 & 74,48 & 1,17 & 0,2311 & 0,8178 & ns \\
\hline TRL & 46,45 & 43,22 & 49,50 & 1,30 & 46,52 & 42,90 & 49,51 & 1,36 & $-0,2609$ & 0,7948 & ns \\
\hline LF & 81,16 & 77,68 & 84,12 & 1,47 & 81,59 & 79,06 & 83,50 & 1,14 & $-1,4912$ & 0,1400 & ns \\
\hline POB & 9,72 & 8,11 & 10,99 & 0,64 & 9,67 & 8,63 & 10,84 & 0,60 & 0,3817 & 0,7037 & ns \\
\hline INW & 4,52 & 3,82 & 5,32 & 0,30 & 4,54 & 3,88 & 5,55 & 0,34 & $-0,2017$ & 0,8407 & ns \\
\hline HDL & 26,30 & 23,65 & 29,01 & 1,35 & 26,16 & 23,41 & 30,43 & 1,41 & 0,4643 & 0,6437 & ns \\
\hline MOL & 4,23 & 3,41 & 5,19 & 0,44 & 4,34 & 3,50 & 5,38 & 0,43 & $-1,1583$ & 0,2501 & ns \\
\hline MOW & 6,54 & 5,31 & 7,72 & 0,54 & 6,47 & 5,46 & 7,54 & 0,50 & 0,6776 & 0,5000 & ns \\
\hline POR & 10,69 & 9,43 & 11,90 & 0,59 & 10,74 & 9,80 & 11,82 & 0,54 & $-0,3521$ & 0,7257 & ns \\
\hline HDW & 8,17 & 6,33 & 9,58 & 0,74 & 8,28 & 6,73 & 9,54 & 0,68 & $-0,6765$ & 0,5007 & ns \\
\hline GS1 & 2,03 & 1,50 & 2,62 & 0,28 & 1,96 & 1,41 & 2,70 & 0,30 & 0,9951 & 0,3233 & ns \\
\hline PD2 & 62,86 & 58,93 & 67,57 & 1,93 & 62,70 & 58,73 & 66,67 & 1,62 & 0,4126 & 0,6810 & ns \\
\hline IDS & 16,41 & 14,26 & 17,94 & 0,87 & 16,86 & 15,44 & 18,56 & 0,83 & $-2,3959$ & 0,0190 & $S^{*}$ \\
\hline DCS & 6,85 & 5,93 & 7,72 & 0,46 & 6,92 & 6,18 & 7,88 & 0,43 & $-0,6659$ & 0,5074 & ns \\
\hline D1A & 7,87 & 6,19 & 10,07 & 0,80 & 8,00 & 6,70 & 9,81 & 0,77 & $-0,7480$ & 0,4567 & ns \\
\hline $\mathrm{D} 1 \mathrm{H}$ & 4,32 & 3,13 & 5,13 & 0,44 & 4,42 & 3,62 & 5,18 & 0,39 & $-1,1656$ & 0,2474 & ns \\
\hline D1P & 4,76 & 3,71 & 6,20 & 0,57 & 4,81 & 3,54 & 6,12 & 0,60 & $-0,4205$ & 0,6753 & ns \\
\hline $\mathrm{D} 1 \mathrm{~B}$ & 6,54 & 5,29 & 7,89 & 0,61 & 6,74 & 5,66 & 8,01 & 0,55 & $-1,5882$ & 0,1163 & ns \\
\hline D1I & 3,23 & 2,51 & 4,01 & 0,40 & 3,24 & 2,31 & 3,94 & 0,38 & $-0,1162$ & 0,9078 & ns \\
\hline D1L & 9,78 & 7,88 & 11,77 & 0,78 & 9,99 & 8,75 & 11,92 & 0,72 & $-1,2032$ & 0,2326 & ns \\
\hline PAL & 62,29 & 58,59 & 67,04 & 1,67 & 62,14 & 57,14 & 65,85 & 1,80 & 0,3873 & 0,6996 & ns \\
\hline PP1 & 24,88 & 21,89 & 27,47 & 1,27 & 24,77 & 22,31 & 26,23 & 1,03 & 0,4613 & 0,6459 & ns \\
\hline PP2 & 51,55 & 47,61 & 55,87 & 1,76 & 50,72 & 46,36 & 54,65 & 1,91 & 2,0616 & 0,0425 & $S^{*}$ \\
\hline PPS & 21,66 & 19,78 & 23,70 & 0,92 & 21,05 & 19,22 & 23,11 & 0,90 & 3,0339 & 0,0032 & $S^{*}$ \\
\hline PCA & 18,01 & 16,03 & 20,45 & 0,94 & 18,26 & 16,38 & 20,66 & 0,87 & $-1,2851$ & 0,2024 & ns \\
\hline ТАН & 5,01 & 3,74 & 5,98 & 0,53 & 5,08 & 4,11 & 6,00 & 0,49 & $-0,5921$ & 0,5559 & ns \\
\hline TAW & 4,11 & 3,29 & 5,17 & 0,43 & 4,30 & 3,20 & 5,11 & 0,50 & $-1,7076$ & 0,0924 & ns \\
\hline $\mathrm{CPH}$ & 3,07 & 2,36 & 3,93 & 0,39 & 3,03 & 1,37 & 3,69 & 0,43 & 0,4015 & 0,6893 & ns \\
\hline CPW & 2,39 & 1,76 & 3,28 & 0,34 & 2,41 & 1,68 & 3,34 & 0,36 & $-0,2742$ & 0,7848 & ns \\
\hline $\mathrm{CDM}$ & 27,13 & 24,20 & 29,76 & 1,14 & 26,79 & 25,33 & 28,69 & 0,84 & 1,5403 & 0,1277 & ns \\
\hline $\mathrm{CPU}$ & 12,39 & 10,54 & 14,31 & 0,96 & 12,36 & 10,42 & 13,97 & 0,83 & 0,1605 & 0,8729 & ns \\
\hline CTR & 6,37 & 5,17 & 7,47 & 0,58 & 6,48 & 5,16 & 7,94 & 0,57 & $-0,8539$ & 0,3957 & ns \\
\hline P1A & 13,88 & 12,21 & 15,88 & 1,03 & 14,05 & 11,76 & 15,62 & 0,95 & $-0,8092$ & 0,4208 & ns \\
\hline P1P & 10,42 & 8,79 & 12,62 & 0,97 & 10,57 & 7,27 & 12,24 & 1,05 & $-0,7001$ & 0,4859 & ns \\
\hline P1I & 3,74 & 3,04 & 4,41 & 0,28 & 3,66 & 2,88 & 4,42 & 0,33 & 1,1204 & 0,2659 & ns \\
\hline
\end{tabular}


Tabela 7. Comparação entre as proporções das variáveis morfométricas de fêmeas e machos, aplicando o Teste de "Wilcoxon Rank". Descrição das medidas na Tabela 1.

\begin{tabular}{|c|c|c|c|c|c|c|c|c|c|c|c|}
\hline \multirow{2}{*}{$\begin{array}{c}\text { Variáveis } \\
\text { Morfométricas }\end{array}$} & \multicolumn{4}{|c|}{ Fêmeas } & \multicolumn{4}{|c|}{ Machos } & \multirow{2}{*}{$W$} & \multirow{2}{*}{ p-valor } & \multirow{2}{*}{ Significância } \\
\hline & Média & Mínimo & Máximo & Desvio Padrão & Média & Mínimo & Máximo & Desvio Padrão & & & \\
\hline INO & 10,56 & 8,00 & 13,91 & 1,53 & 10,35 & 8,07 & 15,68 & 1,52 & 1813 & 0,5466 & ns \\
\hline EYL & 4,63 & 3,42 & 6,16 & 0,73 & 4,44 & 3,34 & 7,53 & 0,85 & 1921 & 0,1548 & ns \\
\hline EYH & 3,25 & 1,76 & 4,6 & 0,82 & 3,08 & 2,10 & 5,14 & 0,69 & 1531 & 0,4639 & ns \\
\hline $\mathrm{HDH}$ & 7,45 & 5,17 & 9,36 & 1,13 & 7,59 & 4,39 & 8,96 & 1,18 & 1672 & 0,4066 & ns \\
\hline ING & 4,74 & 3,9 & 5,68 & 0,44 & 4,77 & 4,15 & 5,95 & 0,42 & 1606 & 0,7530 & ns \\
\hline GS5 & 1,43 & 0,81 & 1,87 & 0,27 & 1,37 & 0,93 & 2,06 & 0,31 & 1238 & 0,3238 & ns \\
\hline TRH & 7,99 & 6,18 & 9,76 & 0,95 & 7,95 & 6,27 & 9,43 & 0,88 & 1345 & 0,8910 & ns \\
\hline PD1 & 38,4 & 34,74 & 41,81 & 2,02 & 38,03 & 34,41 & 41,41 & 1,91 & 1725 & 0,4268 & ns \\
\hline $\mathrm{ABH}$ & 6,37 & 4,62 & 7,63 & 0,65 & 6,30 & 3,49 & 8,18 & 0,97 & 1279 & 0,8326 & ns \\
\hline ABW & 4,78 & 3,64 & 6,19 & 0,66 & 4,87 & 3,32 & 7,20 & 0,81 & 1280 & 0,9821 & ns \\
\hline CPV & 10,35 & 8,32 & 12,25 & 0,95 & 10,58 & 8,54 & 11,84 & 0,82 & 1621 & 0,1954 & ns \\
\hline P1B & 3,96 & 3,3 & 4,66 & 0,31 & 3,91 & 3,31 & 5,17 & 0,34 & 1869 & 0,3430 & $\mathrm{~ns}$ \\
\hline
\end{tabular}


Tabela 8. Resultados das regressões lineares para os valores das variáveis morfométricas logaritmizadas; valores do teste $t$ e seu $\mathrm{p}$-valor, aplicado para testar a significância do coeficiente alométrico $(b)$ em relação à isometria $(b=1)$.Descrição das medidas na Tabela 1. $\left(\mathrm{s}^{*}\right)=$ Variáveis significativas.

\begin{tabular}{|c|c|c|c|c|c|}
\hline Relações & Regressões & $r^{2}$ & $t$ & p-valor & Significâncie \\
\hline PRC $\times$ LT & $\log P R C=-0,0448+0,9613^{*} \log L T$ & 0,9947 & $-4,96$ & 0,00000 & ns \\
\hline TRL $x$ LT & $\log T R L=-0,4072+1,0309{ }^{*} \log L T$ & 0,9899 & 2,66 & 0,00466 & ns \\
\hline LF $x$ LT & $\log L F=-0,0715+0,9924{ }^{*} \log L T$ & 0,9951 & $-0,97$ & 0,16639 & $\mathrm{~s}^{*}$ \\
\hline POB x LT & $\log P O B=-0,7543+0,8924 * \log \mathrm{LT}$ & 0,9439 & $-4,45$ & 0,00001 & ns \\
\hline INW x LT & $\log I N W=-1,0000+0,8571{ }^{*} \log L T$ & 0,9426 & $-6,08$ & 0,00000 & ns \\
\hline INO $\times$ LT & $\log I N O=0,0029+0,5913^{*} \log L T$ & 0,7778 & $-11,64$ & 0,00000 & ns \\
\hline EYL x LT & $\log E Y L=0,0484+0,4216 * \log L T$ & 0,7875 & $-23,80$ & 0,00000 & ns \\
\hline EYH $\times$ LT & $\log E Y H=0,4166+0,2041 * \log L T$ & 0,1935 & $-16,21$ & 0,00000 & ns \\
\hline HDL x LT & $\log \mathrm{HDL}=-0,1927+0,8388 * \log \mathrm{LT}$ & 0,9748 & $-10,75$ & 0,00000 & ns \\
\hline MOL x LT & $\log \mathrm{MOL}=-1,7231+1,1460 * \log \mathrm{LT}$ & 0,9188 & 3,86 & 0,00011 & ns \\
\hline MOW x LT & $\log M O W=-0,7121+0,8038 * \log L T$ & 0,9313 & $-8,07$ & 0,00000 & ns \\
\hline POR x LT & $\log P O R=-0,7532+0,9102 * \log L T$ & 0,9642 & $-4,61$ & 0,00001 & ns \\
\hline HDW x LT & $\log H D W=-1,3707+1,1096{ }^{*} \log L T$ & 0,9281 & 3,20 & 0,00100 & ns \\
\hline $\mathrm{HDH} \times \mathrm{LT}$ & $\log \mathrm{HDH}=-1,7512+1,2573{ }^{*} \log \mathrm{LT}$ & 0,8305 & 4,08 & 0,00005 & ns \\
\hline ING $\times$ LT & $\log I N G=-0,9021+0,8257{ }^{*} \log L T$ & 0,9000 & $-5,62$ & 0,00000 & ns \\
\hline GS1 $\times$ LT & $\log G S 1=-0,9131+0,6765 * \log L T$ & 0,6612 & $-5,46$ & 0,00000 & ns \\
\hline GS5 x LT & $\log$ GS5 $=-0,8523+0,5862 * \log L T$ & 0,3727 & $-4,45$ & 0,00002 & ns \\
\hline TRH $\times$ LT & $\log T R H=-0,7924+0,8734 * \log L T$ & 0,8075 & $-2,50$ & 0,00733 & ns \\
\hline PD1 x LT & Log PD1 $=-0,0130+0,8326$ * Log LT & 0,9853 & $-14,56$ & 0,00000 & ns \\
\hline PD2 x LT & $\log P D 2=-0,0584+0,9409 * \log L T$ & 0,9901 & $-5,58$ & 0,00000 & ns \\
\hline IDS x LT & $\log$ IDS $=-0,9675+1,0775 * \log L T$ & 0,9729 & 3,84 & 0,00013 & ns \\
\hline DCS $x$ LT & $\log D C S=-1,3665+1,0841 * \log L T$ & 0,9588 & 3,31 & 0,00071 & ns \\
\hline D1A $x$ LT & $\log D 1 A=-1,4935+1,1613^{*} \log L T$ & 0,9287 & 4,43 & 0,00002 & ns \\
\hline $\mathrm{D} 1 \mathrm{H} \times \mathrm{LT}$ & $\log \mathrm{D} 1 \mathrm{H}=-1,5518+1,0787^{*} \log \mathrm{LT}$ & 0,8990 & 1,92 & 0,02899 & ns \\
\hline D1P x LT & $\log \mathrm{D} 1 \mathrm{P}=-0,8144+0,7896{ }^{*} \log \mathrm{LT}$ & 0,7920 & $-4,59$ & 0,00001 & ns \\
\hline D1B $\times$ LT & $\log \mathrm{D} 1 \mathrm{~B}=-1,2251+1,0187{ }^{*} \log \mathrm{LT}$ & 0,9018 & 0,49 & 0,31247 & $\mathrm{~s}^{*}$ \\
\hline D1I $\times$ LT & $\log D 1 I=-2,1196+1,2587^{*} \log L T$ & 0,9166 & 6,02 & 0,00000 & ns \\
\hline D1L x LT & $\log \mathrm{D} 1 \mathrm{~L}=-1,2277+1,0914 * \log \mathrm{LT}$ & 0,9410 & 2,94 & 0,00217 & ns \\
\hline $\mathrm{ABH} \times \mathrm{LT}$ & $\log A B H=-0,8773+0,8669 * \log L T$ & 0,7284 & $-2,09$ & 0,02018 & ns \\
\hline ABW $x$ LT & Log ABW $=-1,0098+0,8722 * \log L T$ & 0,7001 & $-1,87$ & 0,03256 & ns \\
\hline PAL $\times$ LT & $\log P A L=-0,0612+0,9403 * \log L T$ & 0,9907 & $-5,91$ & 0,00000 & ns \\
\hline PP1 x LT & $\log \mathrm{PP} 1=-0,3770+0,9054{ }^{*} \log \mathrm{LT}$ & 0,9739 & $-5,73$ & 0,00000 & ns \\
\hline PP2 x LT & $\log P P 2=-0,0695+0,9081 * \log L T$ & 0,9861 & $-7,66$ & 0,00000 & ns \\
\hline PPS $\times$ LT & $\log P P S=-0,7218+1,0212{ }^{*} \log L T$ & 0,9735 & 1,13 & 0,13013 & $s^{*}$ \\
\hline PCA x LT & $\log P C A=-0,7609+1,0078 * \log L T$ & 0,9696 & 0,39 & 0,34733 & $\mathrm{~s}^{*}$ \\
\hline TAH $\times$ LT & $\log \mathrm{TAH}=-0,8517+0,8171^{*} \log \mathrm{LT}$ & 0,8239 & $-3,96$ & 0,00009 & ns \\
\hline TAW $\times$ LT & $\log$ TAW $=-1,0029+0,8462 * \log L T$ & 0,7884 & $-2,87$ & 0,00275 & ns \\
\hline $\mathrm{CPH} \times \mathrm{LT}$ & $\log \mathrm{CPH}=-0,6842+0,6578 * \log \mathrm{LT}$ & 0,6441 & $-5,73$ & 0,00000 & ns \\
\hline CPW $\times$ LT & $\log C P W=-0,7647+0,6483^{*} \log L T$ & 0,6466 & $-6,00$ & 0,00000 & ns \\
\hline CDM $\times$ LT & $\log C D M=-0,5973+1,0114 * \log L T$ & 0,9812 & 0,74 & 0,23209 & $\mathrm{~s}^{*}$ \\
\hline CPV x LT & $\log C P V=-1,4920+1,2114 * \log L T$ & 0,9611 & 7,80 & 0,00000 & ns \\
\hline CPU x LT & $\log C P U=-1,0897+1,0750 * \log L T$ & 0,9453 & 2,61 & 0,00535 & ns \\
\hline CTR x LT & $\log C T R=-1,6764+1,1997{ }^{*} \log \mathrm{LT}$ & 0,9543 & 6,84 & 0,00000 & ns \\
\hline $\mathrm{P} 1 \mathrm{~A} \times \mathrm{LT}$ & $\log P 1 A=-1,2830+1,1766{ }^{*} \log L T$ & 0,9741 & 8,29 & 0,00000 & ns \\
\hline P1B x LT & $\log P 1 B=-1,0456+0,8507{ }^{*} \log \mathrm{LT}$ & 0,9122 & $-5,10$ & 0,00000 & ns \\
\hline $\mathrm{P} 1 \mathrm{P} \times \mathrm{LT}$ & $\log P 1 P=-1,5626+1,2408 * \log L T$ & 0,9624 & 8,82 & 0,00000 & ns \\
\hline P1I $x$ LT & $\log P 11=-1,7349+1,1248 * \log L T$ & 0,9401 & 3,95 & 0,00008 & ns \\
\hline
\end{tabular}


Tabela 9. Análise de covariância (ANCOVA), valores do teste $t$ e seu p-valor aplicado para verificar diferenças significativas no coeficiente alométrico (b) e no intercepto (a) entre machos e fêmeas. gl: graus de liberdade. Descrição das medidas na Tabela 1.

\begin{tabular}{|c|c|c|c|c|c|c|c|c|}
\hline \multirow{2}{*}{$\begin{array}{c}\text { Variáveis } \\
\text { Morfométricas }\end{array}$} & \multicolumn{4}{|c|}{$\mathrm{b}$} & \multicolumn{4}{|c|}{$a$} \\
\hline & $t$ & gl & $\mathrm{p}$-valor & ificância & $t$ & $\mathrm{gl}$ & $\mathrm{p}$-valor & Significância \\
\hline PRC & 1,48 & 79 & 0,1428 & ns & 0,09 & 80 & 0,9285 & ns \\
\hline TRL & 1,90 & 79 & 0,0612 & ns & 0,28 & 80 & 0,7814 & ns \\
\hline LF & $-0,61$ & 79 & 0,5458 & ns & 1,32 & 80 & 0,1910 & ns \\
\hline POB & $-0,63$ & 79 & 0,5329 & ns & 0,26 & 80 & 0,7959 & ns \\
\hline INW & 0,21 & 79 & 0,8338 & ns & 1,42 & 80 & 0,1602 & ns \\
\hline INO & $-0,40$ & 79 & 0,6895 & ns & 0,39 & 80 & 0,7011 & ns \\
\hline EYL & $-0,84$ & 79 & 0,4029 & ns & $-0,36$ & 80 & 0,7228 & ns \\
\hline EYH & 1,18 & 70 & 0,2420 & ns & 0,61 & 71 & 0,5467 & ns \\
\hline $\mathrm{HDL}$ & $-0,53$ & 79 & 0,5992 & ns & 0,59 & 80 & 0,5589 & ns \\
\hline MOL & $-0,53$ & 79 & 0,6003 & ns & 0,84 & 80 & 0,4031 & ns \\
\hline MOW & 1,12 & 79 & 0,2671 & ns & 0,69 & 80 & 0,4933 & ns \\
\hline POR & $-0,10$ & 79 & 0,9206 & ns & 0,92 & 80 & 0,3592 & ns \\
\hline HDW & $-0,59$ & 79 & 0,5554 & ns & 0,47 & 80 & 0,6432 & ns \\
\hline $\mathrm{HDH}$ & 0,54 & 79 & 0,5875 & ns & 0,13 & 80 & 0,8966 & ns \\
\hline ING & 1,07 & 77 & 0,2901 & ns & 1,21 & 78 & 0,2318 & ns \\
\hline GS1 & 1,75 & 65 & 0,0853 & ns & $-0,84$ & 66 & 0,4015 & ns \\
\hline GS5 & 0,63 & 65 & 0,5303 & ns & $-0,71$ & 66 & 0,4773 & ns \\
\hline TRH & $-0,60$ & 69 & 0,5496 & ns & 0,14 & 70 & 0,8877 & ns \\
\hline PD1 & 0,23 & 77 & 0,8202 & ns & 0,28 & 78 & 0,7806 & ns \\
\hline PD2 & 0,73 & 77 & 0,4672 & ns & 0,35 & 78 & 0,7279 & ns \\
\hline IDS & 0,24 & 77 & 0,8092 & ns & 2,36 & 78 & 0,0209 & s \\
\hline DCS & 0,30 & 76 & 0,766 & ns & 0,55 & 77 & 0,5817 & ns \\
\hline D1A & 0,06 & 76 & 0,9535 & ns & 0,32 & 77 & 0,7468 & ns \\
\hline D1H & $-1,38$ & 76 & 0,1732 & ns & 1,10 & 77 & 0,2767 & ns \\
\hline D1P & $-0,67$ & 76 & 0,5069 & ns & 0,99 & 77 & 0,3273 & ns \\
\hline D1B & 0,55 & 76 & 0,5851 & ns & 1,60 & 77 & 0,1147 & ns \\
\hline D1I & $-1,30$ & 76 & 0,1985 & ns & $-0,53$ & 77 & 0,6005 & ns \\
\hline D1L & $-0,55$ & 75 & 0,5820 & ns & 0,97 & 76 & 0,3352 & ns \\
\hline $\mathrm{ABH}$ & 0,15 & 67 & 0,8830 & ns & $-0,32$ & 68 & 0,7465 & ns \\
\hline ABW & $-0,20$ & 68 & 0,8428 & ns & 0,66 & 69 & 0,5117 & ns \\
\hline PAL & $-0,06$ & 79 & 0,9527 & ns & 0,75 & 80 & 0,4533 & ns \\
\hline PP1 & $-0,22$ & 79 & 0,8266 & ns & 0,53 & 80 & 0,5994 & ns \\
\hline PP2 & $-0,07$ & 79 & 0,9407 & ns & $-1,42$ & 80 & 0,1587 & ns \\
\hline PPS & $-0,29$ & 79 & 0,7728 & ns & $-3,49$ & 80 & 0,0008 & $\mathrm{~s}$ \\
\hline PCA & 1,40 & 79 & 0,1660 & ns & 1,25 & 80 & 0,2167 & ns \\
\hline TAH & 1,82 & 65 & 0,0734 & ns & 1,04 & 66 & 0,3025 & ns \\
\hline TAW & 1,16 & 65 & 0,2502 & ns & 1,89 & 66 & 0,0629 & ns \\
\hline $\mathrm{CPH}$ & 1,21 & 65 & 0,2300 & ns & $-0,21$ & 66 & 0,8352 & ns \\
\hline CPW & 0,49 & 65 & 0,6280 & ns & 0,64 & 66 & 0,5254 & ns \\
\hline CDM & 0,19 & 79 & 0,8471 & ns & $-1,49$ & 80 & 0,1404 & ns \\
\hline CPV & $-0,51$ & 79 & 0,6142 & ns & 0,61 & 80 & 0,5404 & ns \\
\hline CPU & $-0,77$ & 79 & 0,4462 & ns & $-0,23$ & 80 & 0,8149 & ns \\
\hline CTR & $-0,83$ & 79 & 0,4109 & ns & 0,05 & 80 & 0,9633 & ns \\
\hline $\mathrm{P} 1 \mathrm{~A}$ & $-0,29$ & 79 & 0,7737 & ns & 0,28 & 80 & 0,7824 & ns \\
\hline P1B & 0,20 & 79 & 0,8386 & ns & $-0,15$ & 80 & 0,8834 & ns \\
\hline P1P & $-0,21$ & 79 & 0,8370 & ns & 0,14 & 80 & 0,8858 & ns \\
\hline P1I & 0,83 & 79 & 0,4092 & ns & $-1,71$ & 80 & 0,0903 & ns \\
\hline
\end{tabular}


Tabela 10. Média e o desvio padrão das idades entre os métodos aplicados da proporção direta e da modificada de Dahl-Lea, por classes de comprimento total $(\mathrm{mm}) . \mathrm{N}=$ número de indivíduos.

\begin{tabular}{|c|c|c|c|c|}
\hline \multirow{2}{*}{$\begin{array}{c}\text { Classes de } \\
\text { Comprimento Total }(\mathrm{mm})\end{array}$} & \multicolumn{2}{|c|}{ Dahl - Lea } & \multirow{2}{*}{$\begin{array}{l}\text { Desvio } \\
\text { Padrão }\end{array}$} & \multirow{2}{*}{$\mathrm{N}$} \\
\hline & Direta & Modificada & & \\
\hline $120-150$ & 2,10 & 3,51 & 1,00 & 1 \\
\hline $150-180$ & 3,30 & 4,54 & 0,88 & 3 \\
\hline $180-210$ & 3,86 & 5,02 & 0,82 & 27 \\
\hline $210-240$ & 4,20 & 5,32 & 0,79 & 1 \\
\hline $240-270$ & 5,71 & 6,60 & 0,63 & 1 \\
\hline $270-300$ & 6,10 & 6,94 & 0,60 & 16 \\
\hline $300-330$ & 6,48 & 7,27 & 0,56 & 17 \\
\hline $330-360$ & 8,22 & 8,76 & 0,38 & 11 \\
\hline $360-390$ & 8,61 & 9,09 & 0,34 & 3 \\
\hline $390-420$ & 9,61 & 9,95 & 0,24 & 2 \\
\hline $420-450$ & 10,51 & 10,72 & 0,15 & 1 \\
\hline
\end{tabular}

Tabela 11. Análise da regressão não linear. Ajuste do modelo Logístico, com o cálculo dos Intervalos de Confiança de $95 \%$ para os parâmetros do modelo. LT - Comprimento Total; idade esperada dos embriões em meses, a partir do método modificado da proporção direta de Dahl-Lea.

\begin{tabular}{cccc}
\multicolumn{2}{c}{ Modelo Logístico LT $=\mathrm{L}_{\infty}\left(1+\operatorname{Exp}\left(-\mathrm{k}\left(\text { idade }-\mathrm{t}_{0}\right)\right)\right)^{\wedge}(-1)$} \\
\hline \multirow{2}{*}{$\begin{array}{c}\text { Parâmetros } \\
\text { Estimados }\end{array}$} & Média & \multicolumn{2}{c}{ Intervalo de Confiança } \\
\cline { 3 - 4 } & & Inf.95\% & Sup.95\% \\
\hline $\mathrm{L}^{\infty}$ & 420,56 & 387,88 & 453,23 \\
$\mathrm{k}$ & 0,48 & 0,39 & 0,56 \\
$\mathrm{t}_{0}$ & 5,23 & 4,89 & 5,58 \\
\hline
\end{tabular}


Tabela 12. Análise da regressão não linear. Ajuste do modelo de von Bertalanffy, com o cálculo dos Intervalos de Confiança de $95 \%$ para os parâmetros do modelo. LT Comprimento Total; idade esperada dos embriões em meses, a partir do método modificado da proporção direta de Dahl-Lea.

\begin{tabular}{cccc}
\multicolumn{2}{c}{ Modelo de von Bertalanffy $\mathrm{LT}=\mathrm{L}_{\infty}\left(1-\operatorname{Exp}\left(-\mathrm{k}\left(\right.\right.\right.$ idade $\left.\left.\left.-\mathrm{t}_{0}\right)\right)\right)$ ) } \\
\hline \multirow{2}{*}{$\begin{array}{c}\text { Parâmetros } \\
\text { Estimados }\end{array}$} & Média & \multicolumn{2}{c}{ Intervalo de Confiança } \\
\cline { 3 - 4 } & & Inf.95\% & Sup.95\% \\
\hline $\mathrm{L}^{\infty}$ & 562,22 & 426,67 & 698,18 \\
$\mathrm{k}$ & 0,15 & 0,08 & 0,22 \\
$\mathrm{t}_{0}$ & 1,97 & 1,38 & 2,55 \\
\hline
\end{tabular}

Tabela 13. Análise da regressão não linear. Ajuste do modelo de Gompertz, com o cálculo dos Intervalos de Confiança de $95 \%$ para os parâmetros do modelo. LT - Comprimento Total; idade esperada dos embriões em meses, a partir do método modificado da proporção direta de Dahl-Lea.

\begin{tabular}{cccc}
\multicolumn{2}{c}{ Modelo de Gompertz $\mathrm{LT}=\mathrm{L}_{\infty}\left(\operatorname{Exp}\left(-\operatorname{Exp}\left(-\mathrm{k}\left(\right.\right.\right.\right.$ idade $\left.\left.\left.\left.-\mathrm{t}_{0}\right)\right)\right)\right)$} \\
\hline \multirow{2}{*}{$\begin{array}{c}\text { Parâmetros } \\
\text { Estimados }\end{array}$} & \multirow{2}{*}{ Média } & \multicolumn{2}{c}{ Intervalo de Confiança } \\
\cline { 3 - 4 } & & Inf.95\% & Sup.95\% \\
\hline $\mathrm{L}_{\infty}$ & 457,19 & 404,95 & 509,35 \\
$\mathrm{k}$ & 0,31 & 0,24 & 0,39 \\
$\mathrm{t}_{0}$ & 4,40 & 4,08 & 4,72 \\
\hline
\end{tabular}

Tabela 14. Média dos parâmetros de crescimento obtidos pelos modelos de crescimento Logístico, von Bertalanffy e Gompertz, e comparação entre os modelos através dos critérios de informação de Akaike (AIC, $\Delta_{i}$ e $w_{i}$ ) e da soma dos quadrados dos erros (SQE).

\begin{tabular}{|c|c|c|c|c|c|c|c|}
\hline \multirow{2}{*}{$\begin{array}{l}\text { Modelos de } \\
\text { Crescimento }\end{array}$} & \multicolumn{3}{|c|}{ Parâmetros } & \multicolumn{3}{|c|}{ Critérios Akaike } & \multirow{2}{*}{ SQE } \\
\hline & $L^{\infty}$ & $\mathrm{k}$ & $t_{0}$ & AIC & $\Delta_{\mathrm{i}}$ & $w_{\mathrm{i}}(\%)$ & \\
\hline Logistico & 420,56 & 0,48 & 5,23 & 713,04 & 0,99 & 26,66 & 23751 \\
\hline von Bertalanffy & 562,22 & 0,15 & 1,97 & 712,83 & 0,78 & 29,61 & 23691 \\
\hline Gompertz & 457,19 & 0,31 & 4,40 & 712,05 & 0,00 & 43,73 & 23469 \\
\hline
\end{tabular}




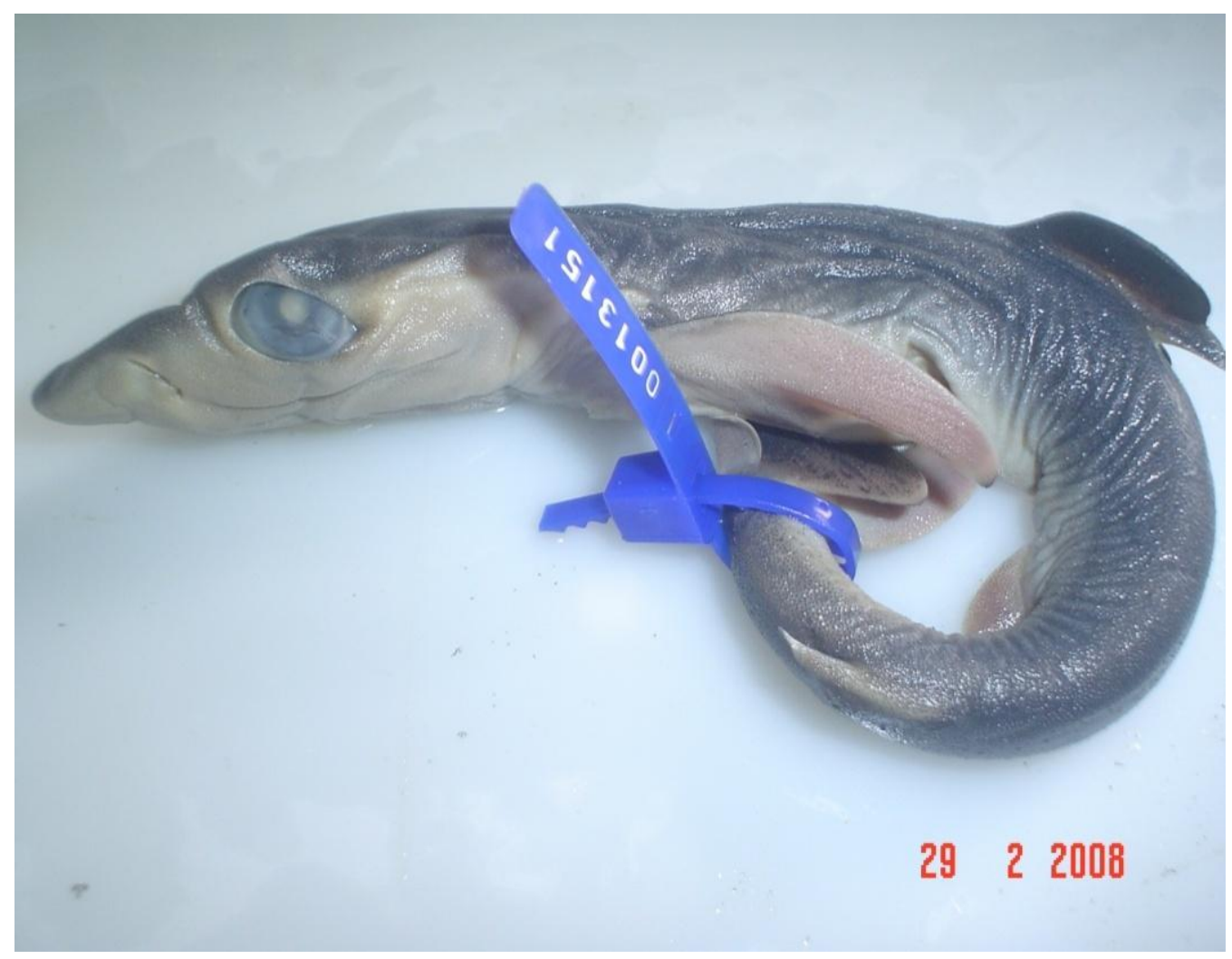

Figura 1: Exemplar de embrião de Prionace glauca (LT - 299,00 mm).

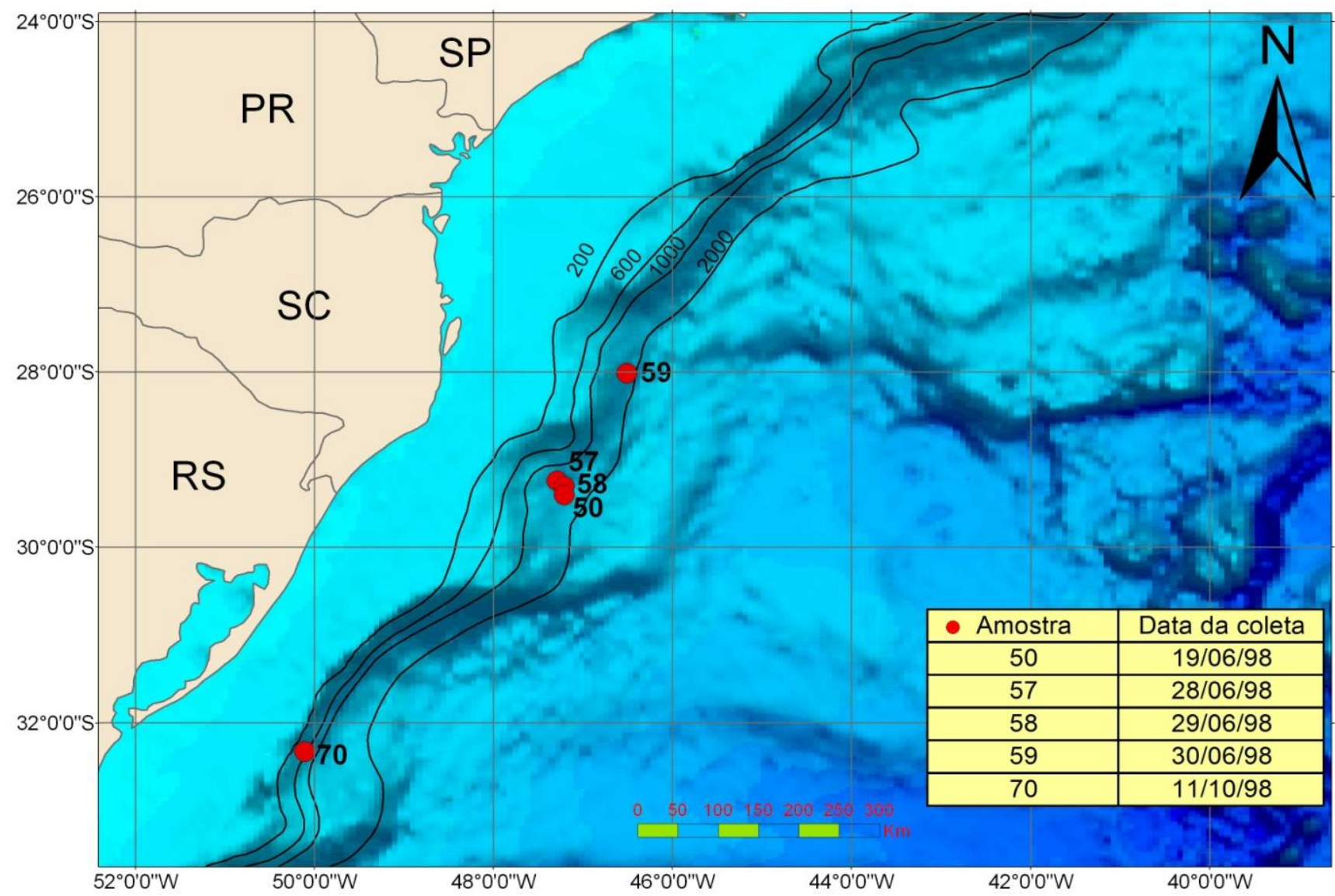

Figura 2: Localização dos pontos de captura das fêmeas com embriões durante a prospecção. 


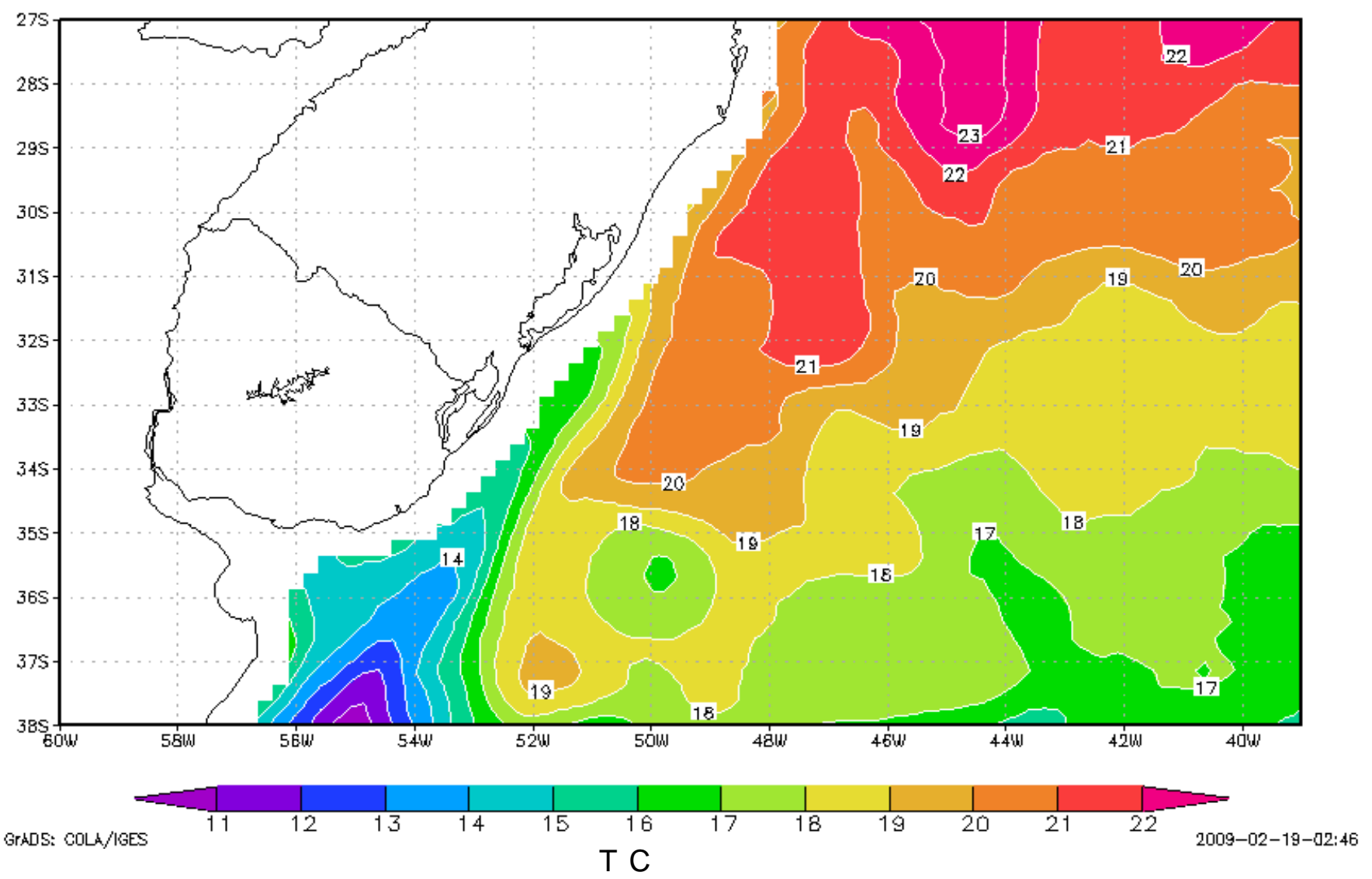

Figura 3a: Plot da temperatura média na superfície (TSM) para a Região Sudeste-Sul do Brasil para junho de 1998 (Nasa, 2009).

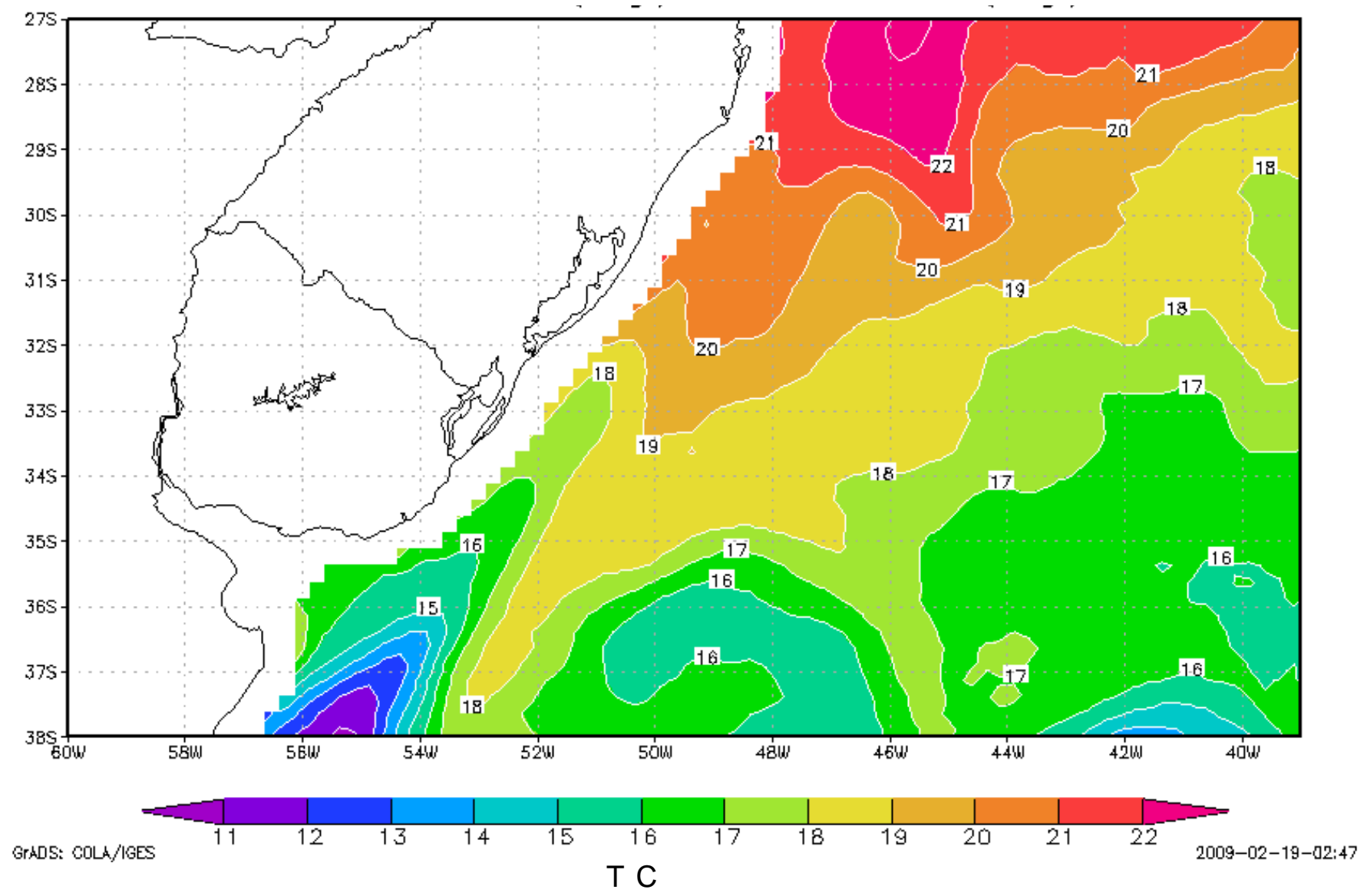

Figura 3b: Plot da temperatura média na superfície (TSM) para a Região Sudeste-Sul do Brasil para outubro de 1998 (Nasa, 2009). 


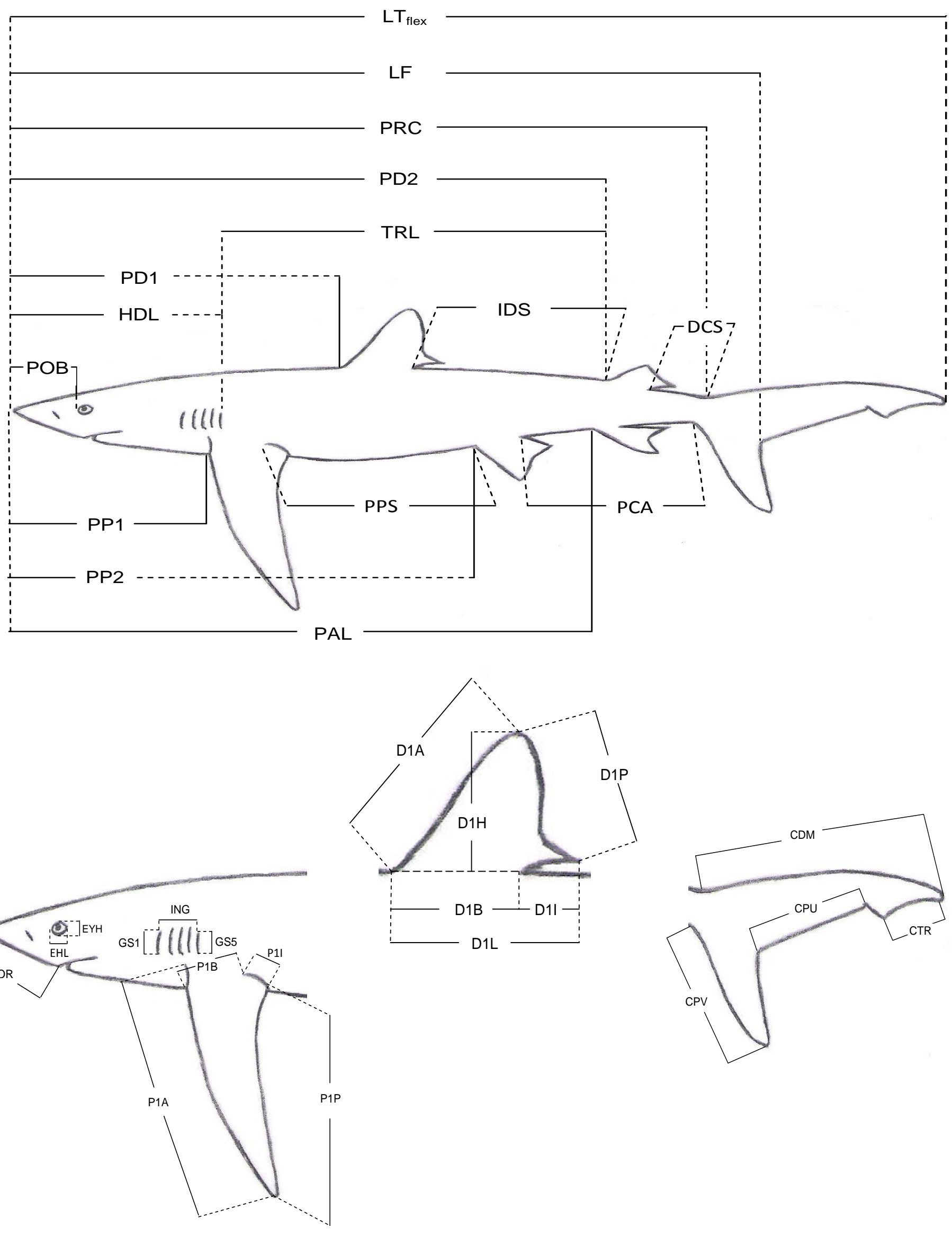

Figura 4a: Medidas analisadas. Descrição das medidas no texto. 

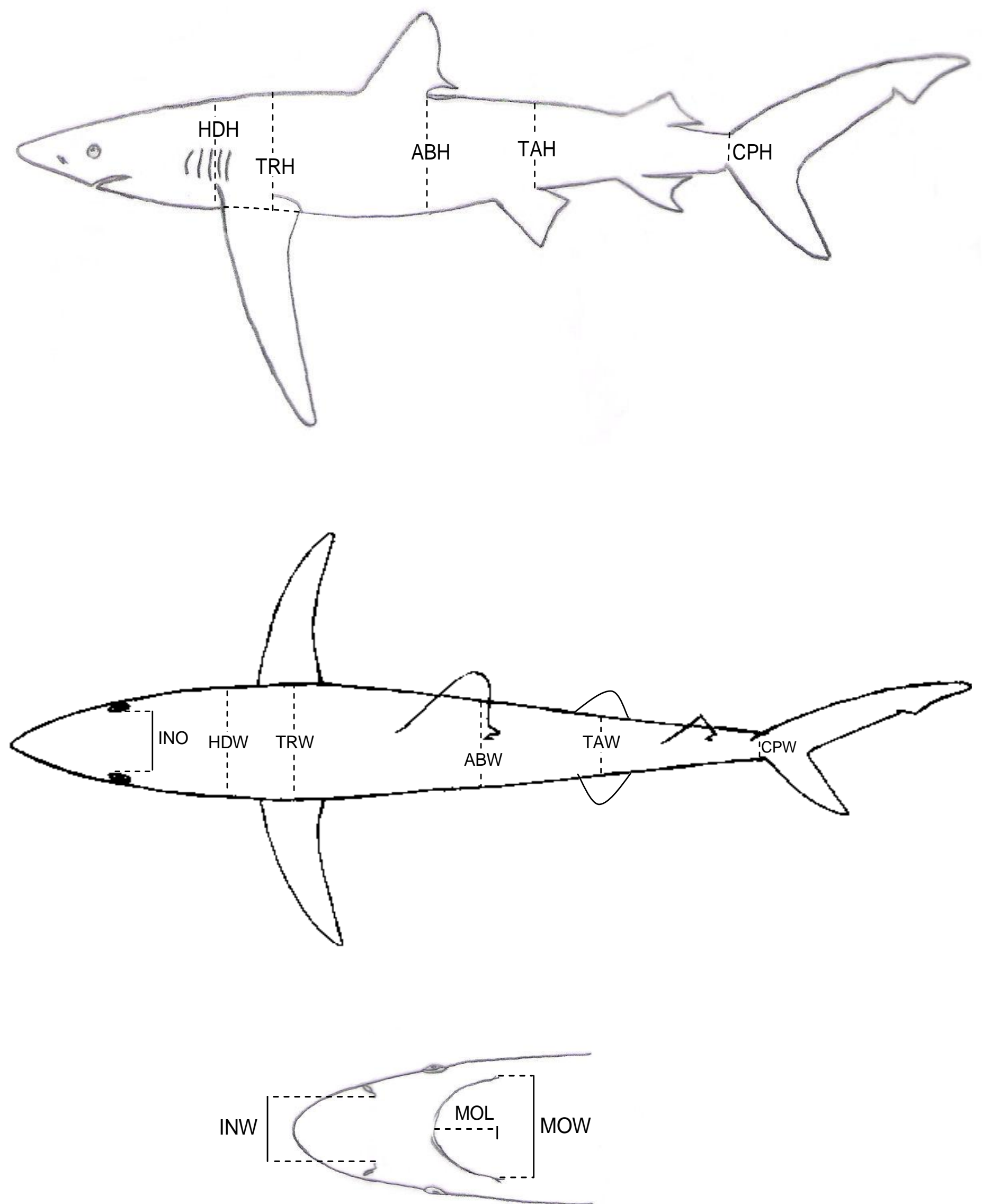

Figura 4b: (continuação) Medidas analisadas. Descrição das medidas no texto. 
A separação do

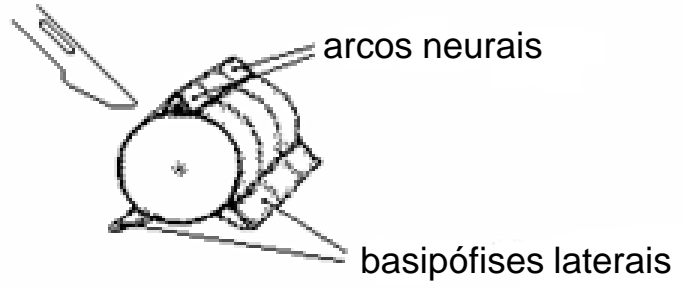

B centra vertebrais prontos para emblocamento

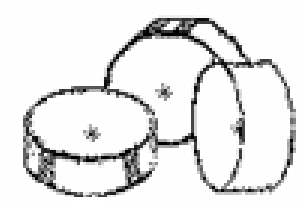

C

centra vertebral seccionado sagitalmente pronto para obtenção do raio

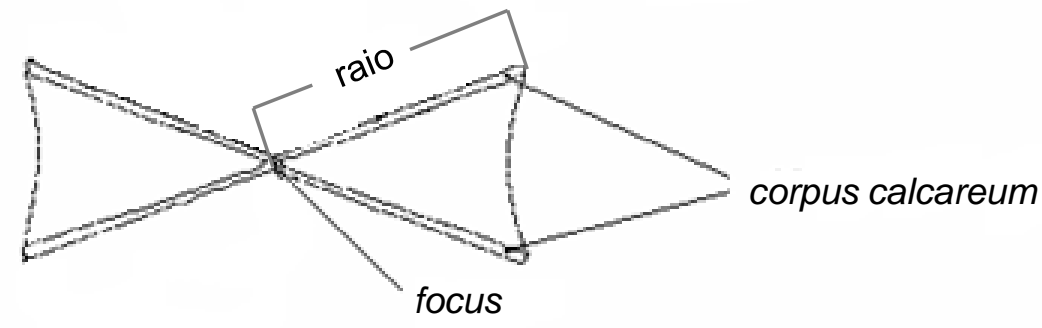

Figura 5a: Representação esquemática das etapas (A, B e C) na preparação dos "centrum" vertebrais de Prionace glauca. Fonte: Aires-da-Silva, (1996).
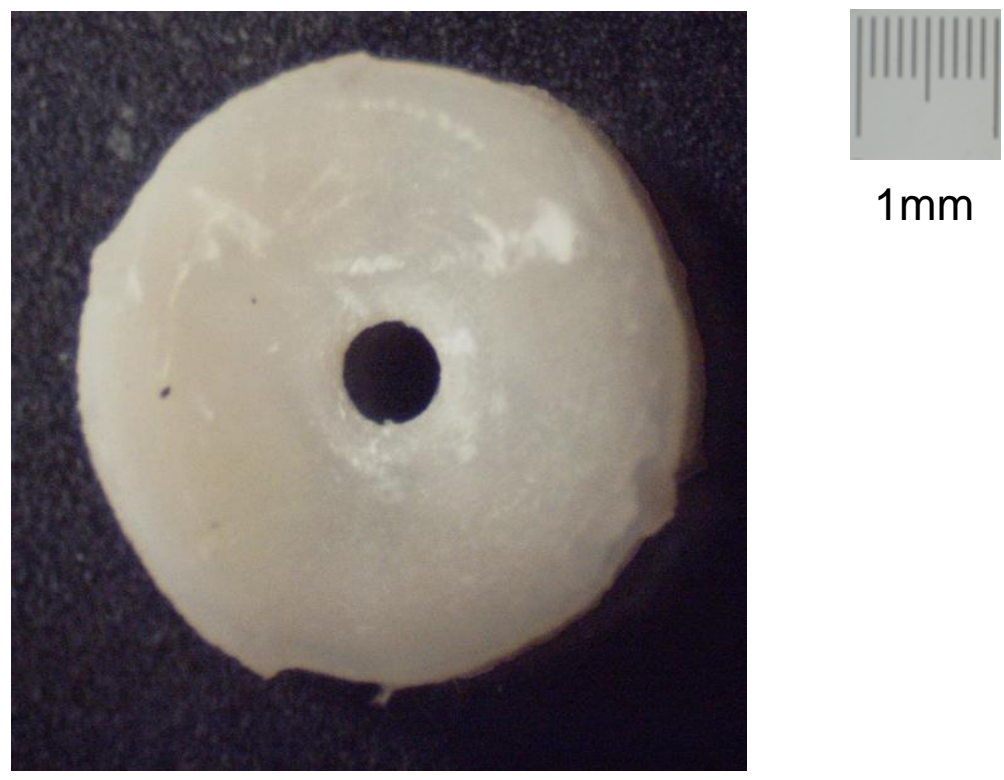

$1 \mathrm{~mm}$

Figura 5b:Centrum vertebral pré-processado com aumento de 1,5X. 


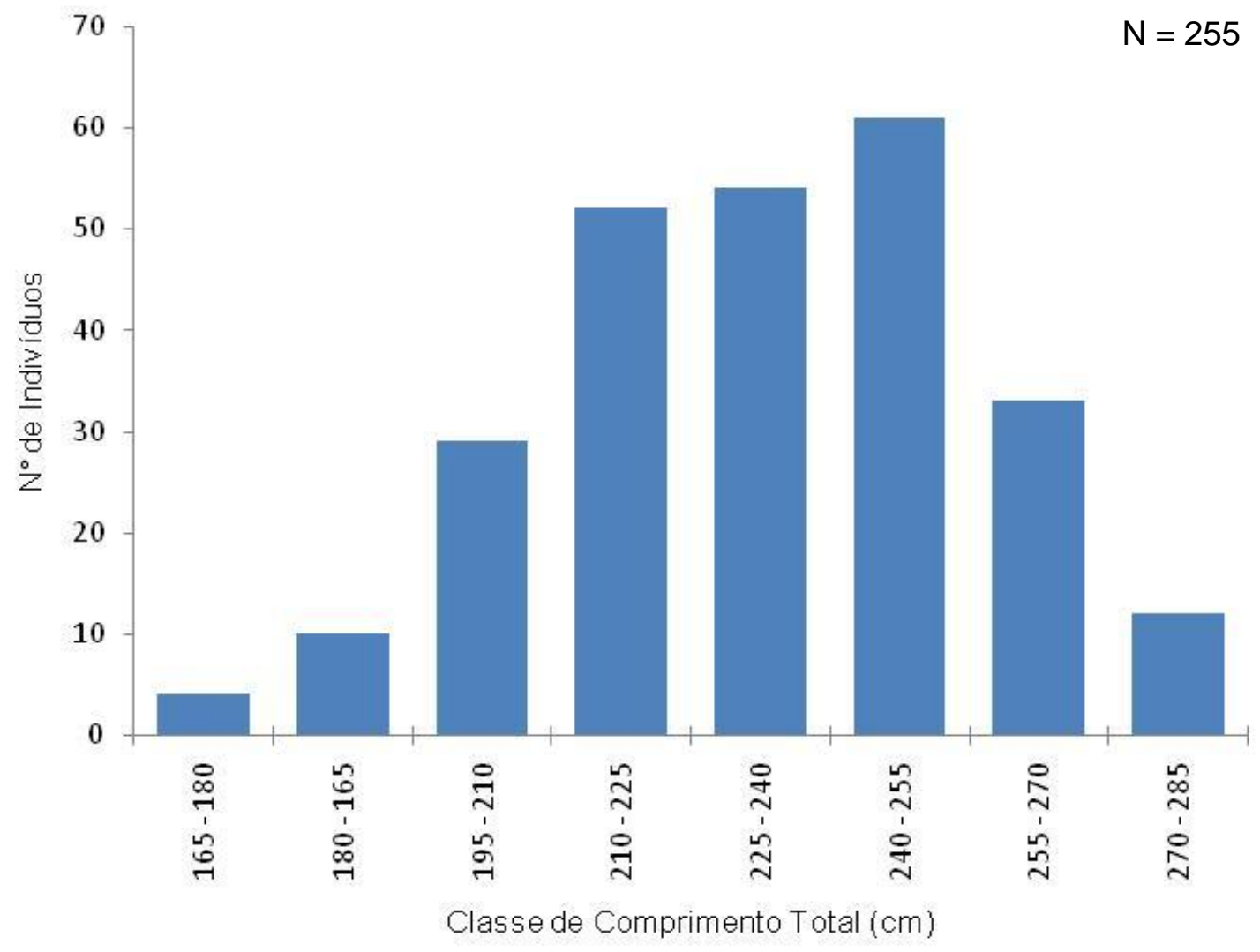

Figura 6: Frequência dos indivíduos adultos por classe de comprimento $(\mathrm{cm})$, para a amostra total.

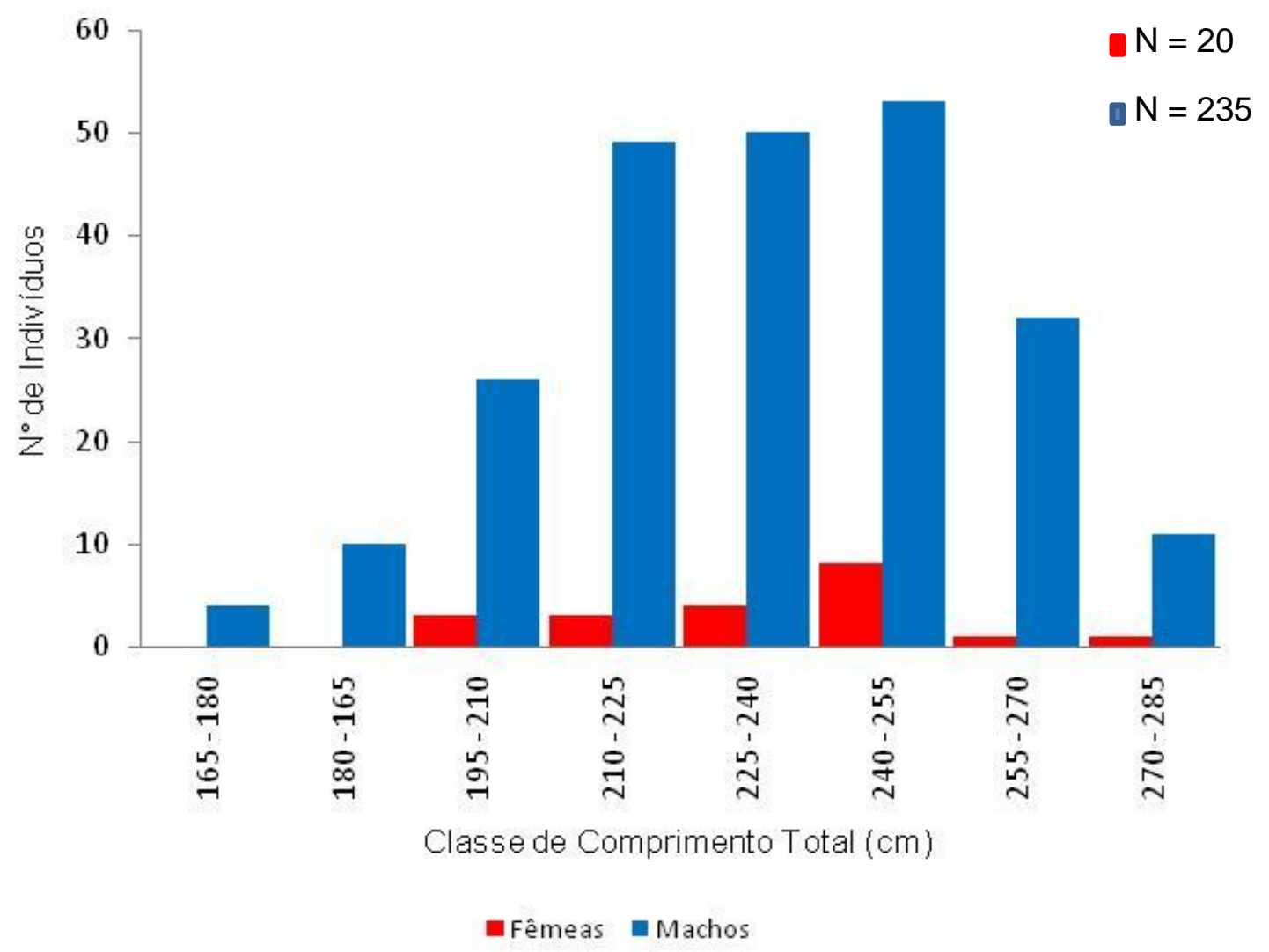

Figura 7: Frequência de machos e fêmeas adultos por classe de comprimento $(\mathrm{cm})$. 


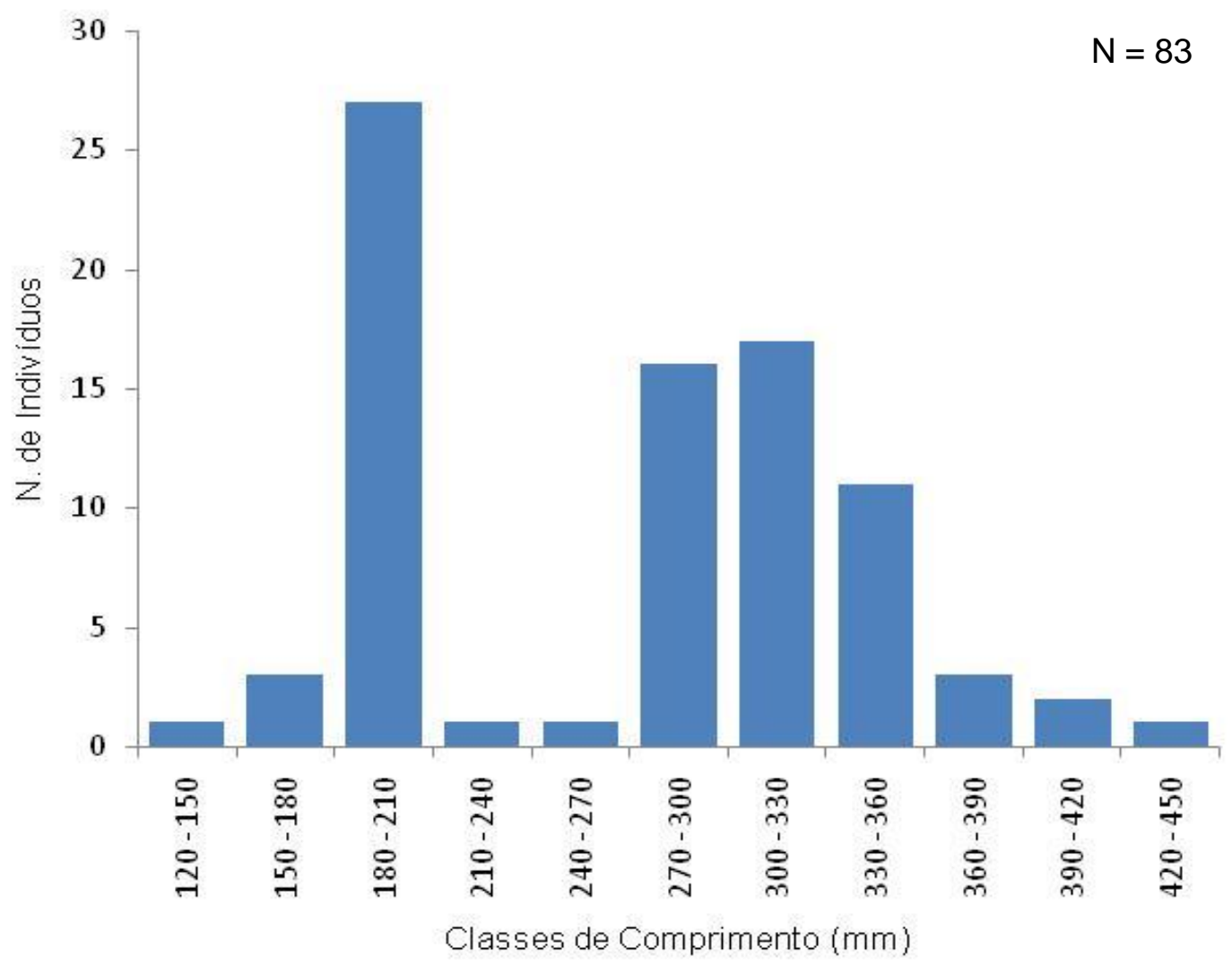

Figura 8: Frequência dos embriões por classe de comprimento (mm), para a amostra total.

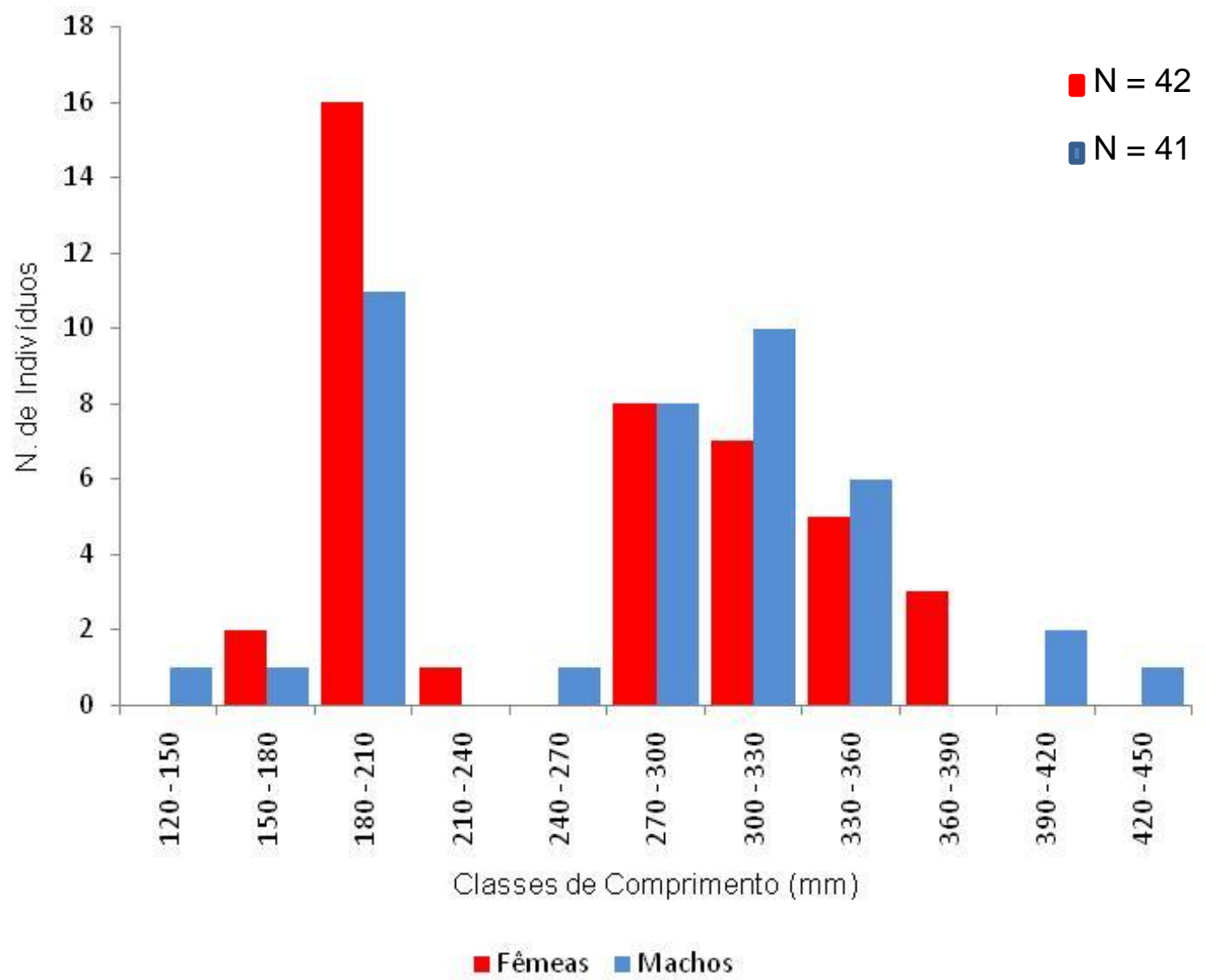

Figura 9: Frequência de embriões machos e fêmeas por classe de comprimento ( $\mathrm{mm})$. 


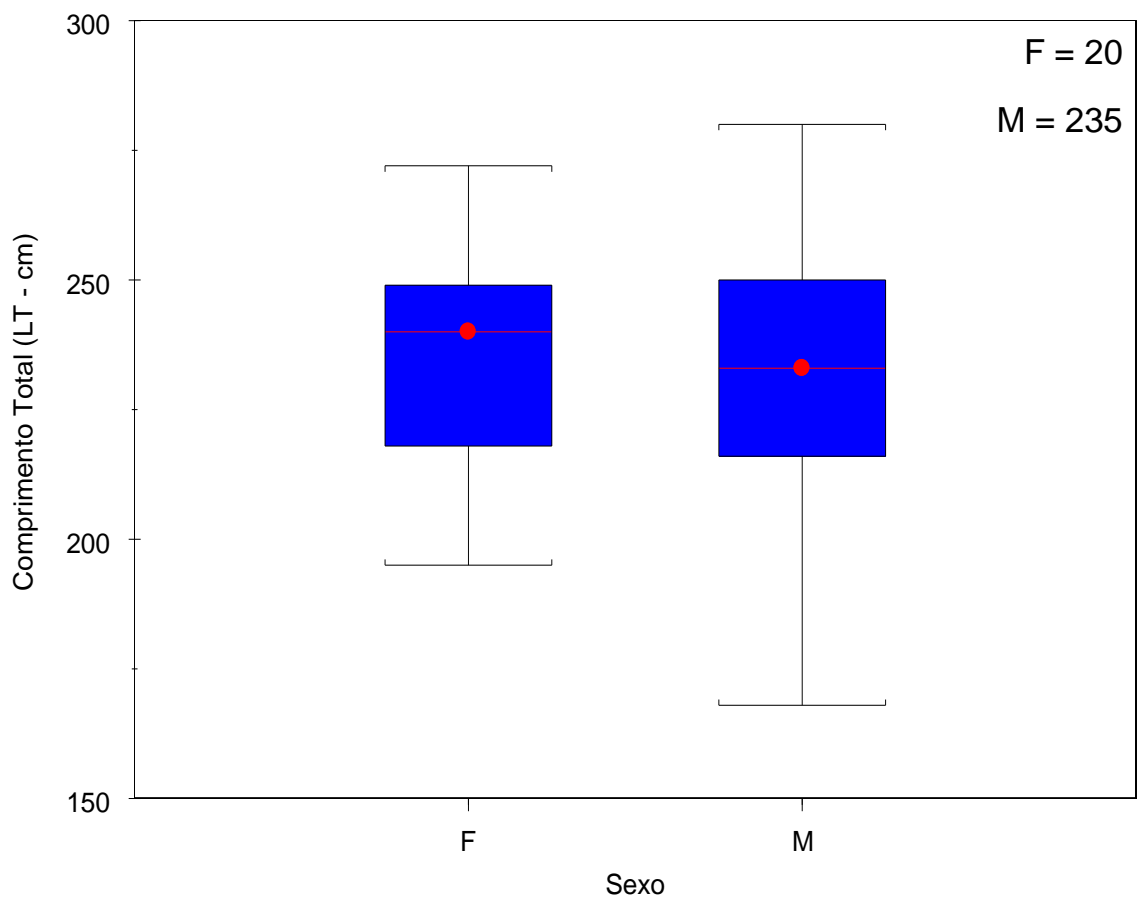

Figura 10: Box Plot da distribuição da variável Comprimento Total $(\mathrm{cm})$ para os indivíduos adultos, por sexo. ( $\mathrm{F}$ - Fêmeas ; $\mathrm{M}$ - Machos).

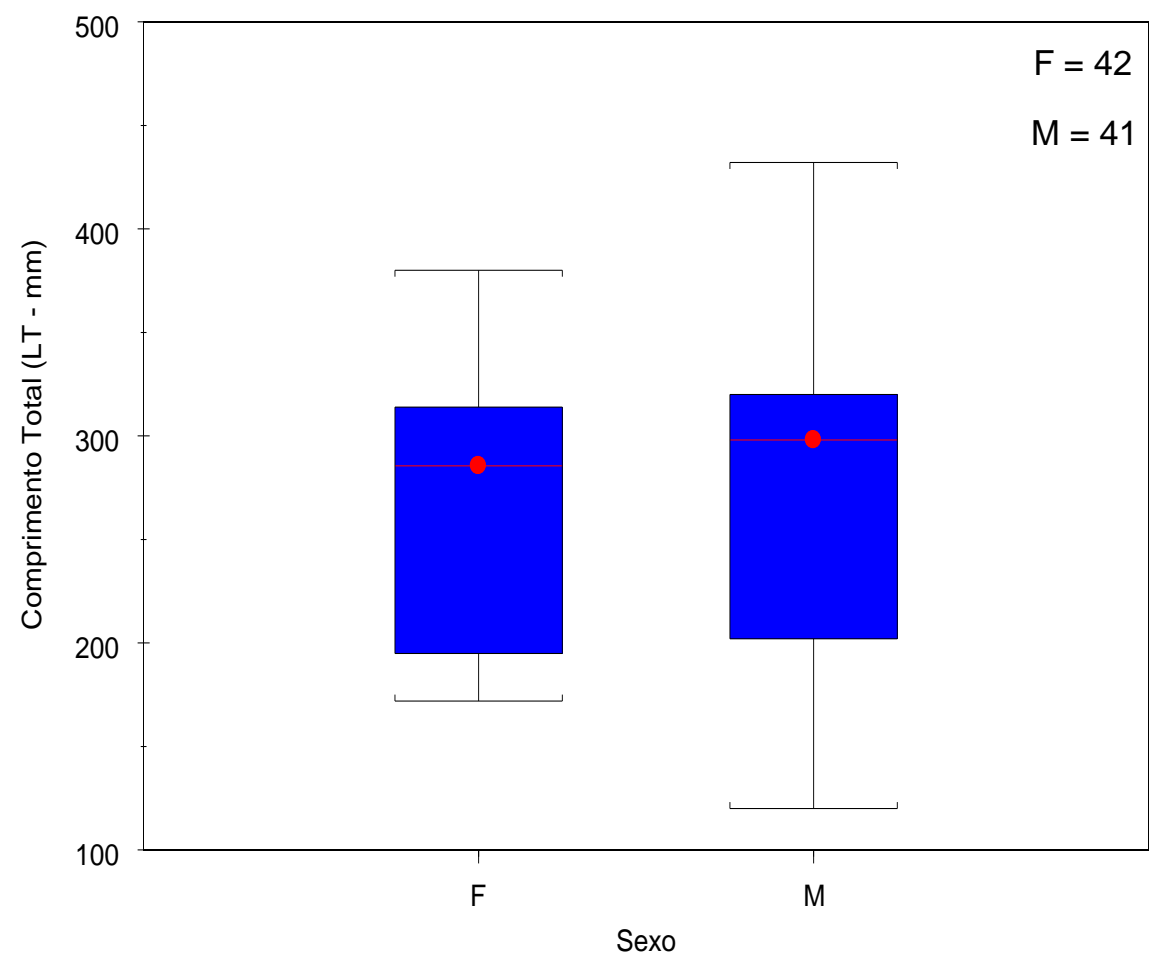

Figura 11: Box Plot da distribuição da variável Comprimento Total ( $\mathrm{mm})$ para os embriões,por sexo. (F - Fêmeas ; $M$ - Machos). 

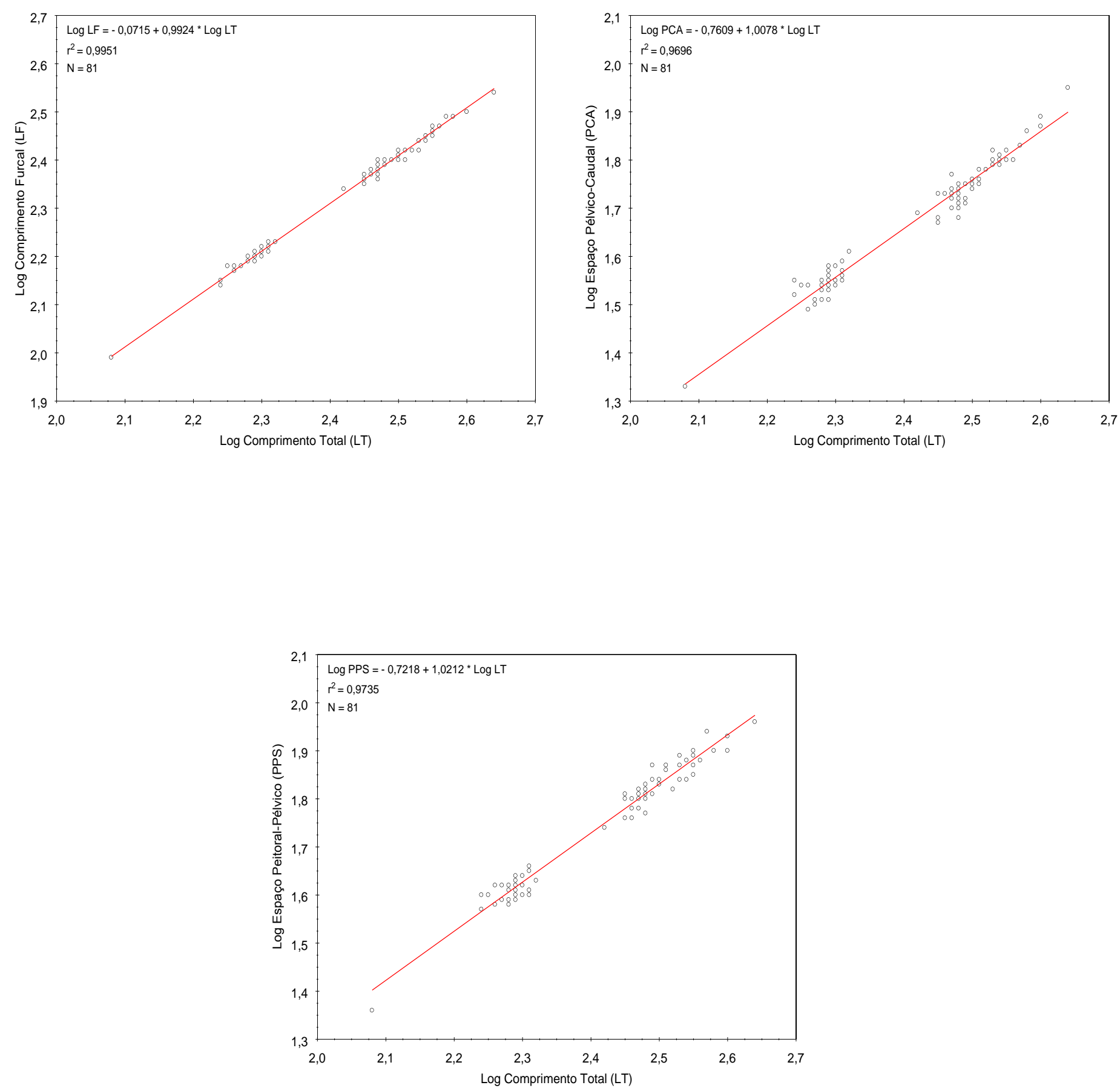

Figura 12: Regressões entre o Comprimento Total (LT) e as variáveis Comprimento Furcal (LF), Espaço Pélvico-Caudal (PCA) e Espaço Peitoral-Pélvico (PPS) - crescimento isométrico. Valores logaritmizados. 

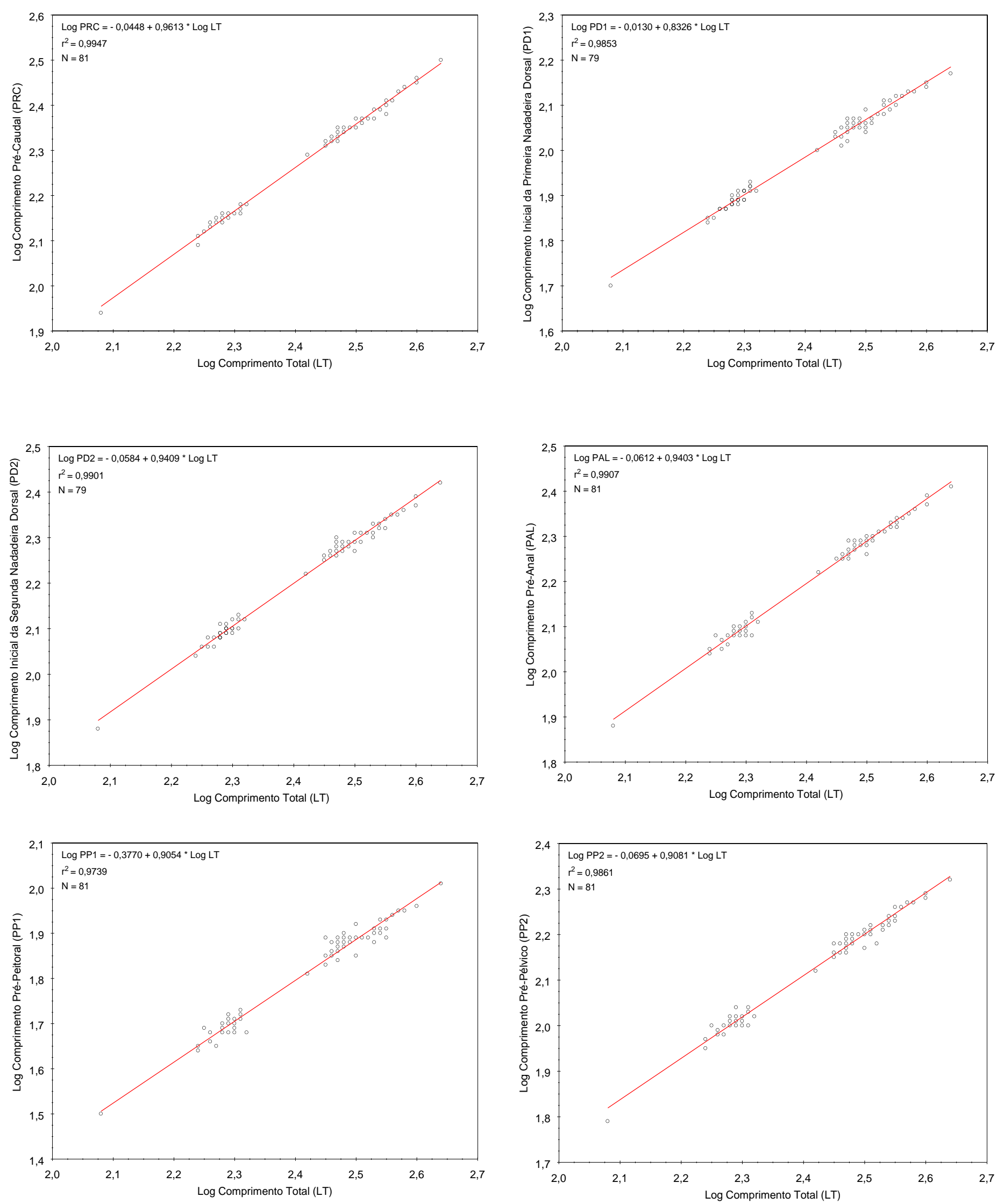

Figura 13: Regressões entre o Comprimento Total (LT) e as variáveis Comprimento Pré-Caudal (PRC), Comprimento Inicial da Primeira Nadadeira Dorsal (PD1), Comprimento Inicial da Segunda Nadadeira Dorsal (PD2), Comprimento Pré-Anal (PAL), Comprimento Pré-Peitoral (PP1) e Comprimento Pré-Pélvico (PP2) - crescimento alométrico negativo. Valores logaritmizados. 

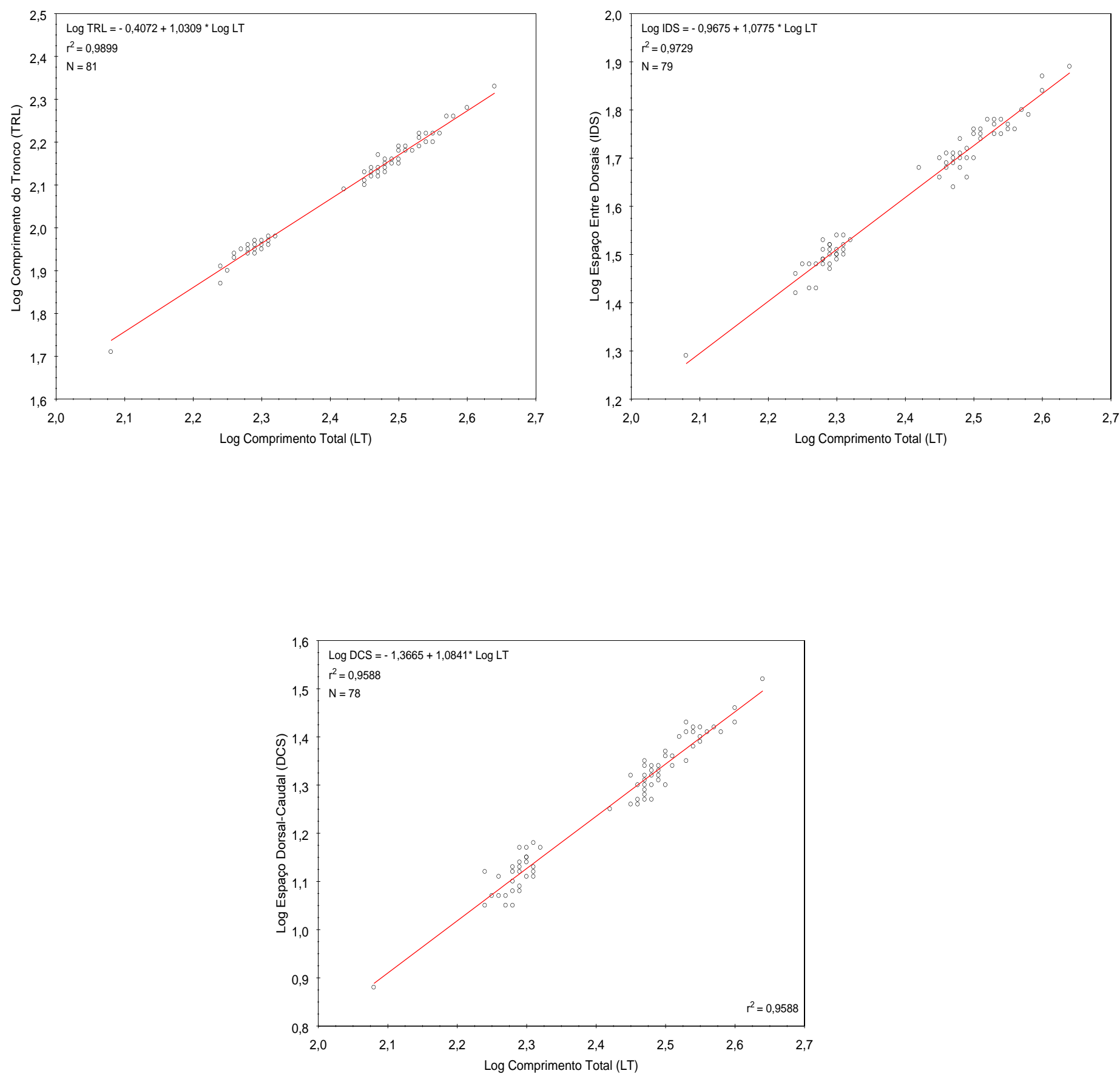

Figura 14: Regressões entre o Comprimento Total (LT) e as variáveis Comprimento do Tronco (TRL), Espaço Entre Dorsais (IDS) e Espaço Dorsal-Caudal (DCS) - crescimento alométrico positivo. Valores logaritmizados. 


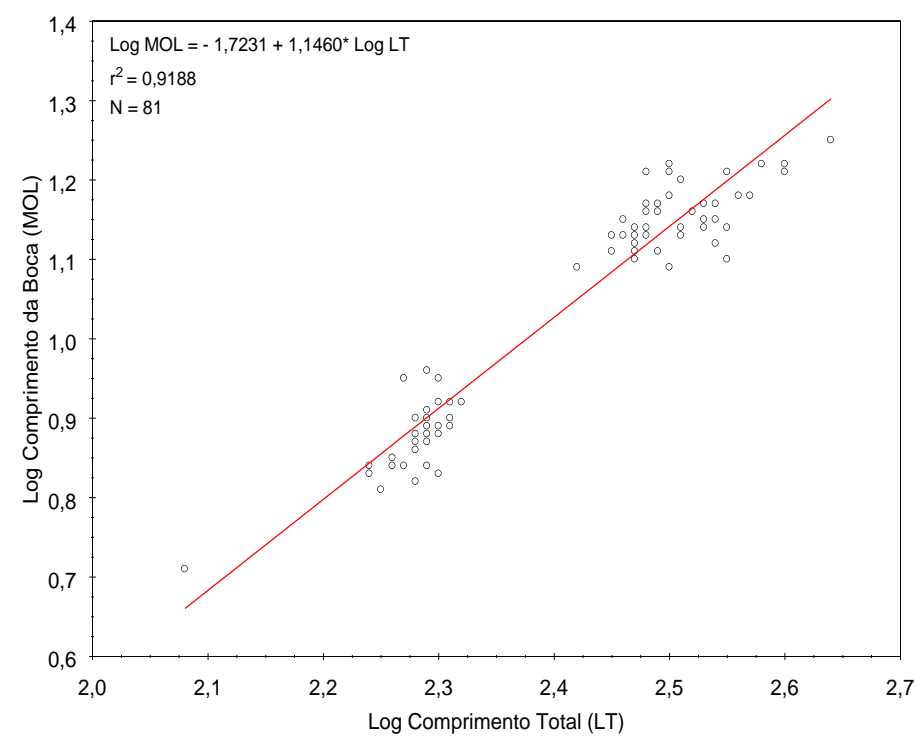

Figura 15: Regressão entre o Comprimento Total (LT) e a variável Comprimento da Boca (MOL) crescimento alométrico positivo. Valores logaritmizados.
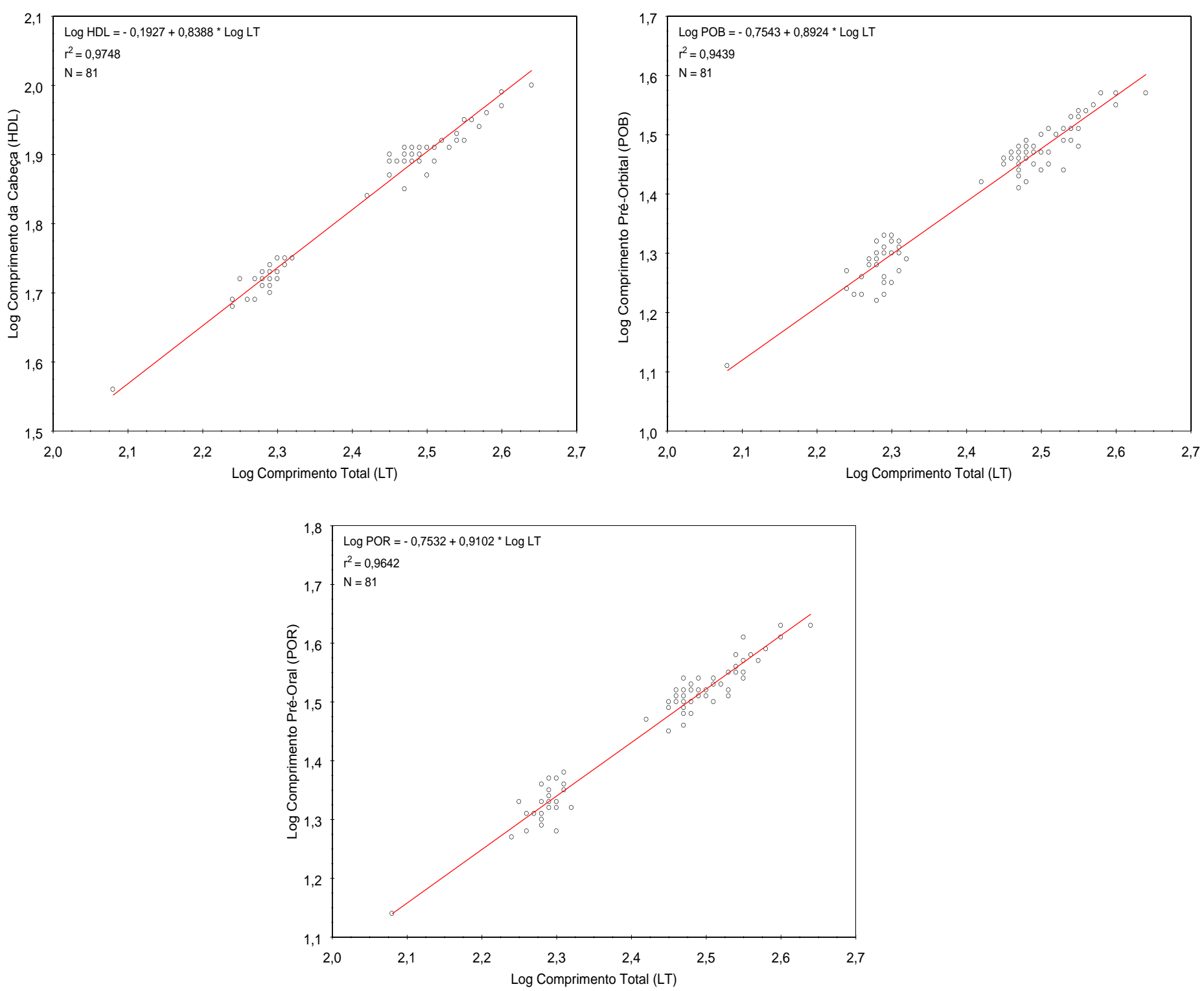

Figura 16: Regressões entre o Comprimento Total (LT) e as variáveis Comprimento da Cabeça $(\mathrm{HDL})$, Comprimento Pré-Orbital (POB) e Comprimento Pré-Oral (POR) - crescimento alométrico negativo. Valores logaritmizados. 

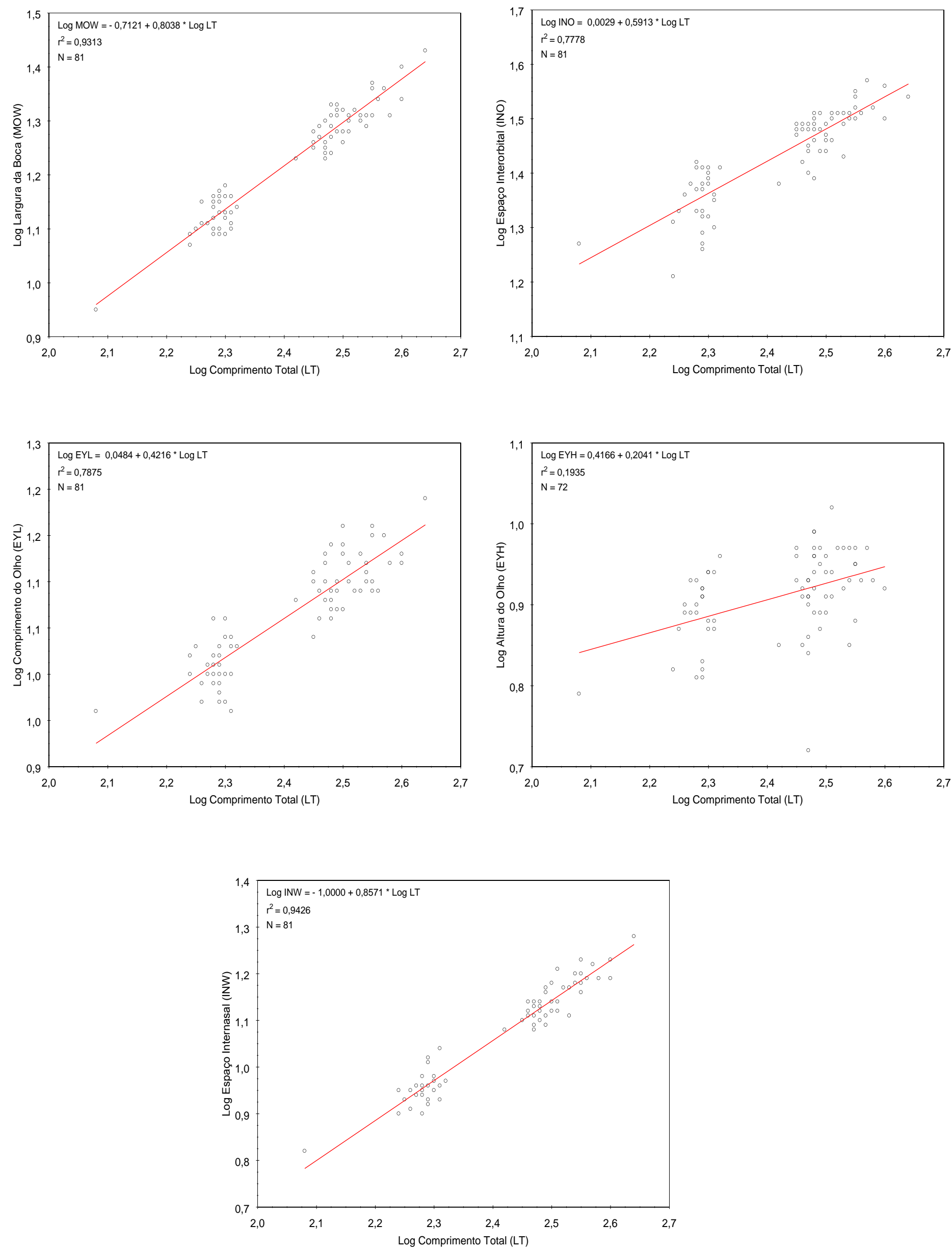

Figura 17: Regressões entre o Comprimento Total (LT) e as variáveis Largura da Boca (MOW), Comprimento do Olho (EYL), Altura do Olho $(E Y H)$ e Espaço Internasal (INW) - crescimento alométrico negativo. Valores logaritmizados. 

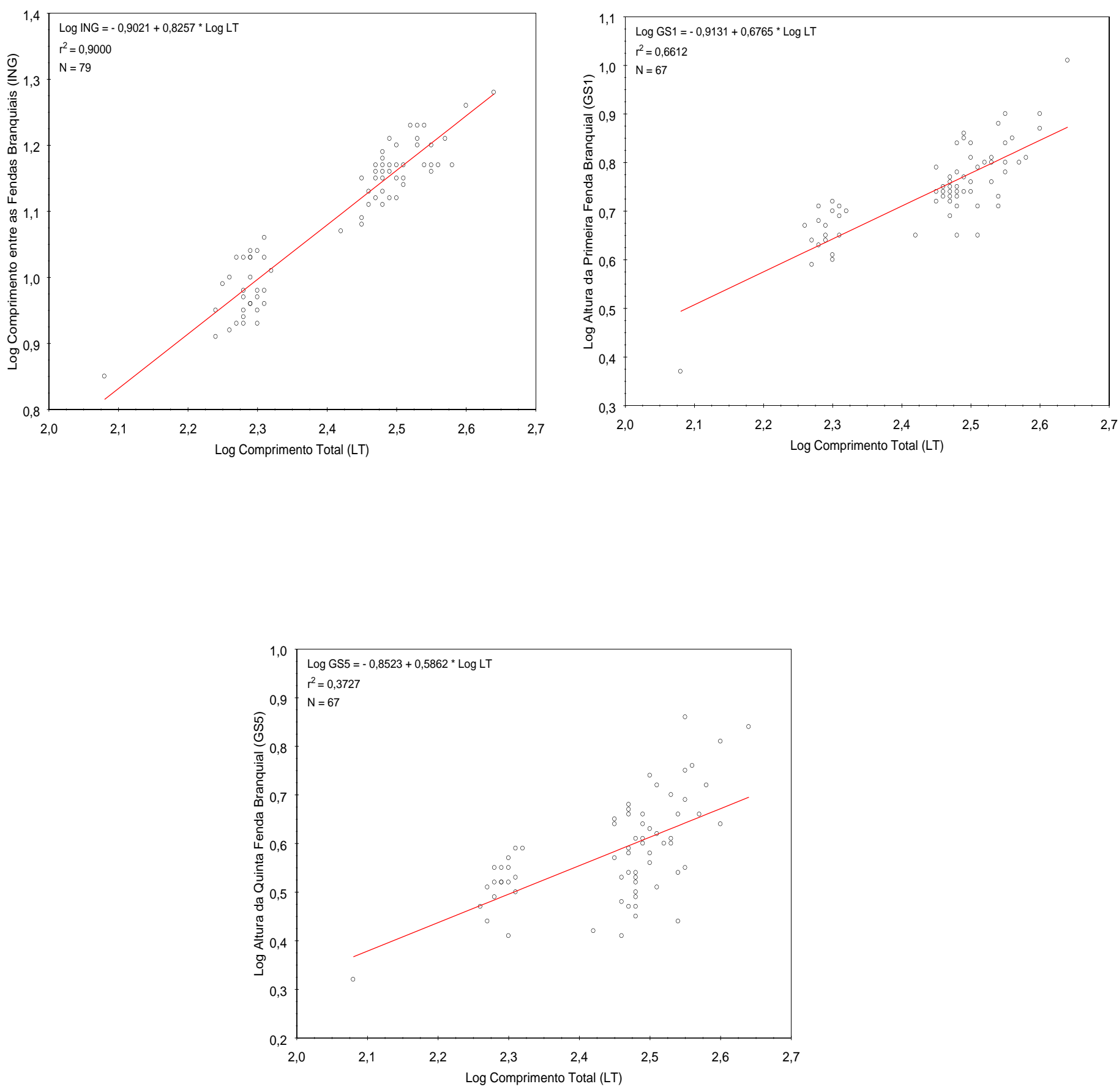

Figura 18: Regressões entre o Comprimento Total (LT) e as variáveis Comprimento entre as Fendas Branquiais (ING), Altura da Primeira Fenda Branquial (GS1) e Altura da Quinta Fenda Branquial (GS5) - crescimento alométrico negativo. Valores logaritmizados. 

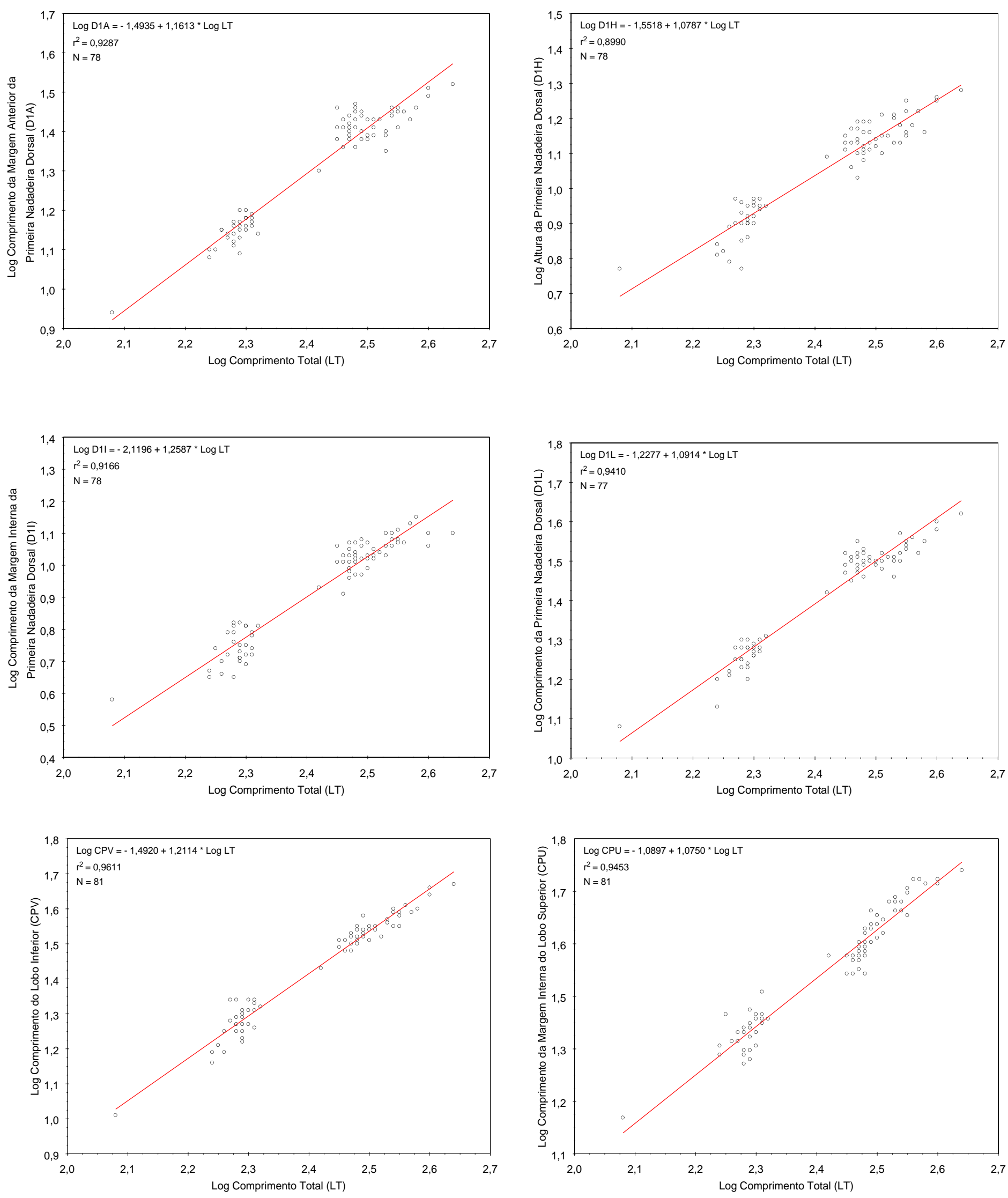

Figura 19: Regressões entre o Comprimento Total (LT) e as variáveis Comprimento da Margem Anterior da Primeira Nadadeira Dorsal (D1A), Altura da Primeira Nadadeira Dorsal (D1H), Comprimento da Margem Interna da Primeira Nadadeira Dorsal (D1I), Comprimento da Primeira Nadadeira Dorsal (D1L), Comprimento do Lobo Inferior (CPV) e Comprimento da Margem Interna do Lobo Superior (CPU) - crescimento alométrico positivo. Valores logaritmizados. 

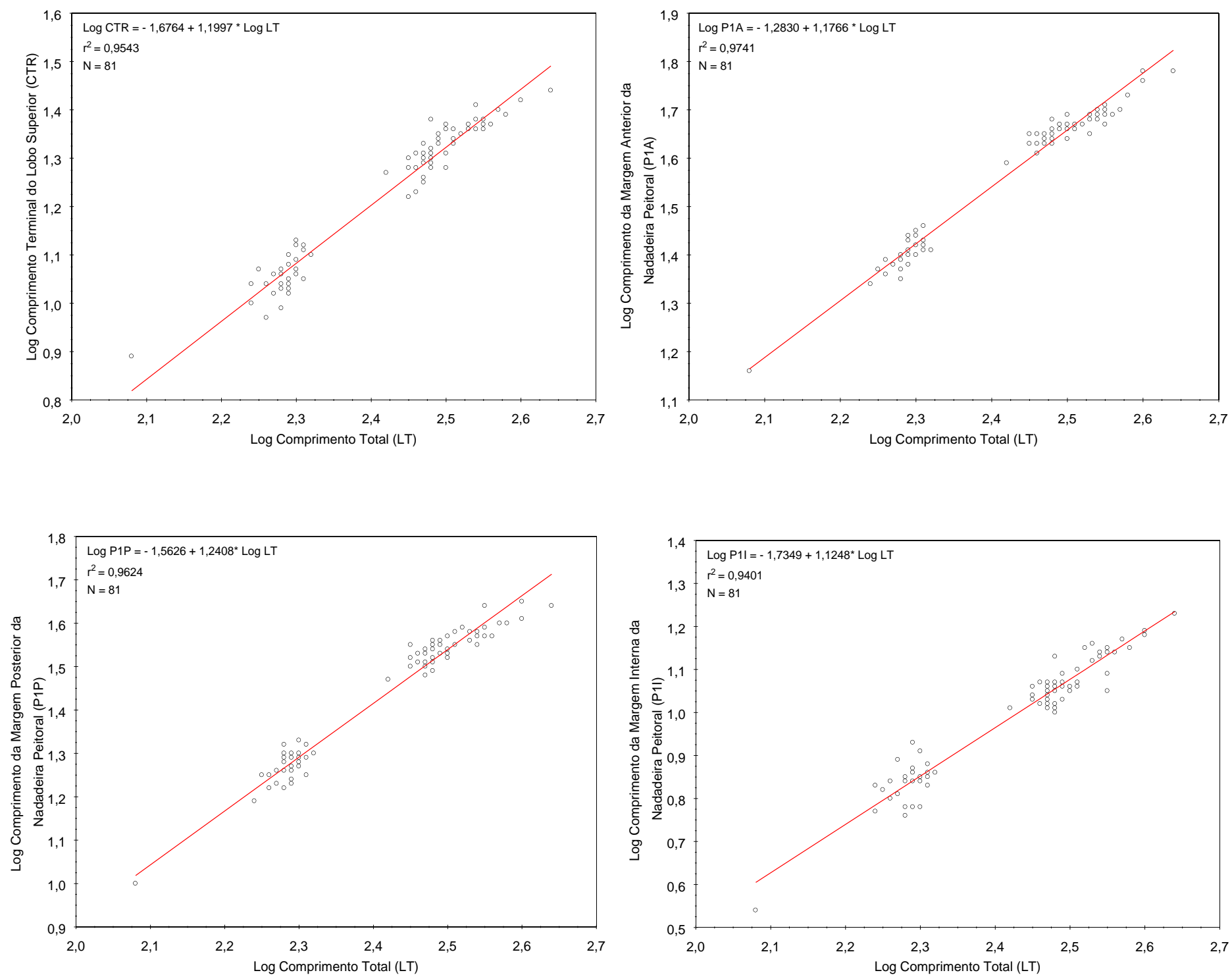

Figura 20: Regressões entre o Comprimento Total (LT) e as variáveis Comprimento Terminal do Lobo Superior (CTR), Comprimento da Margem Anterior da Nadadeira Peitoral (P1A), Comprimento da Margem Posterior da Nadadeira Peitoral (P1P) e Comprimento da Margem Interna da Nadadeira Peitoral (P1I) - crescimento alométrico negativo. Valores logaritmizados. 

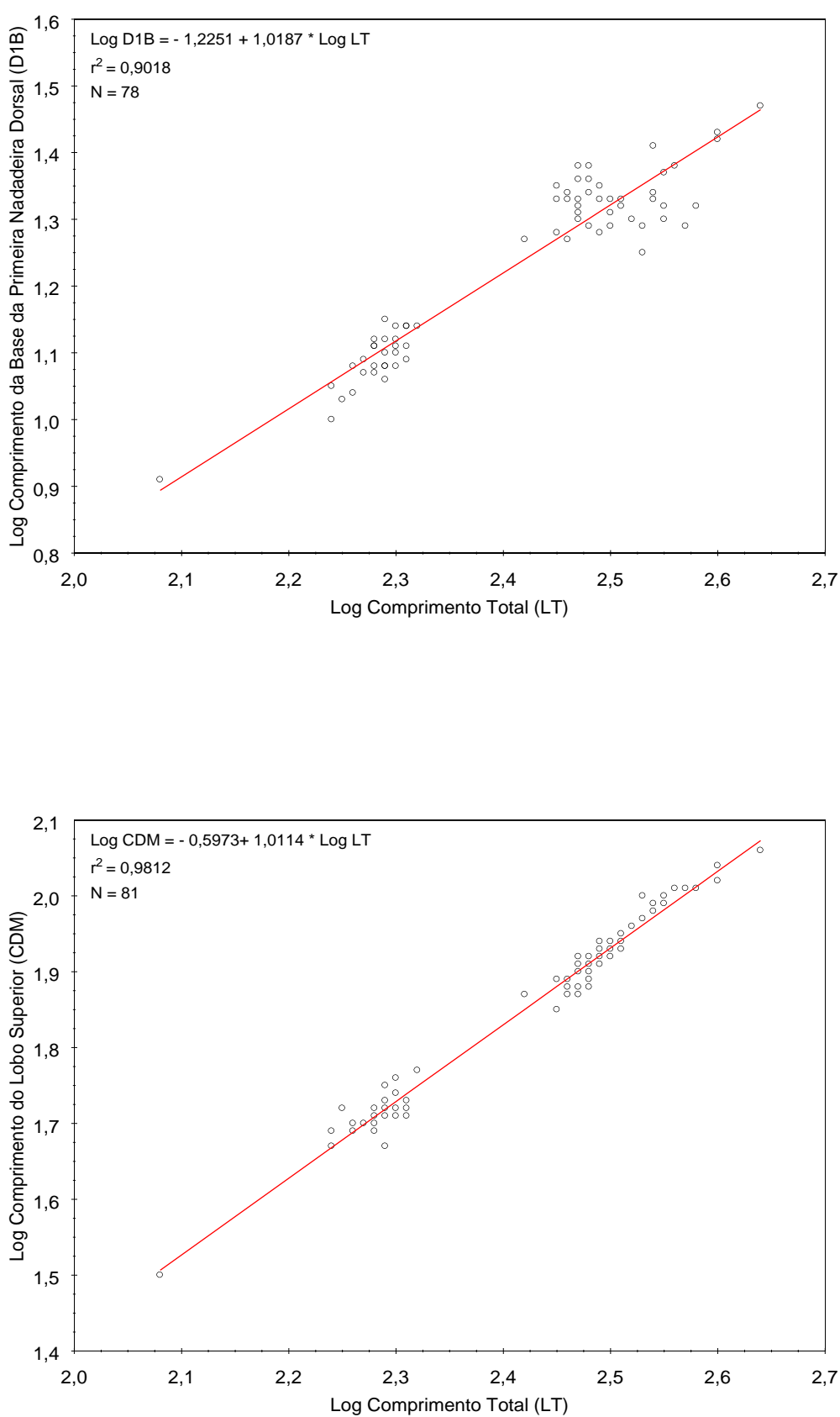

Figura 21: Regressões entre o Comprimento Total (LT) e as variáveis Comprimento da Base da Primeira Nadadeira Dorsal (D1B) e Comprimento do Lobo Superior (CDM) - crescimento isométrico. Valores logaritmizados. 

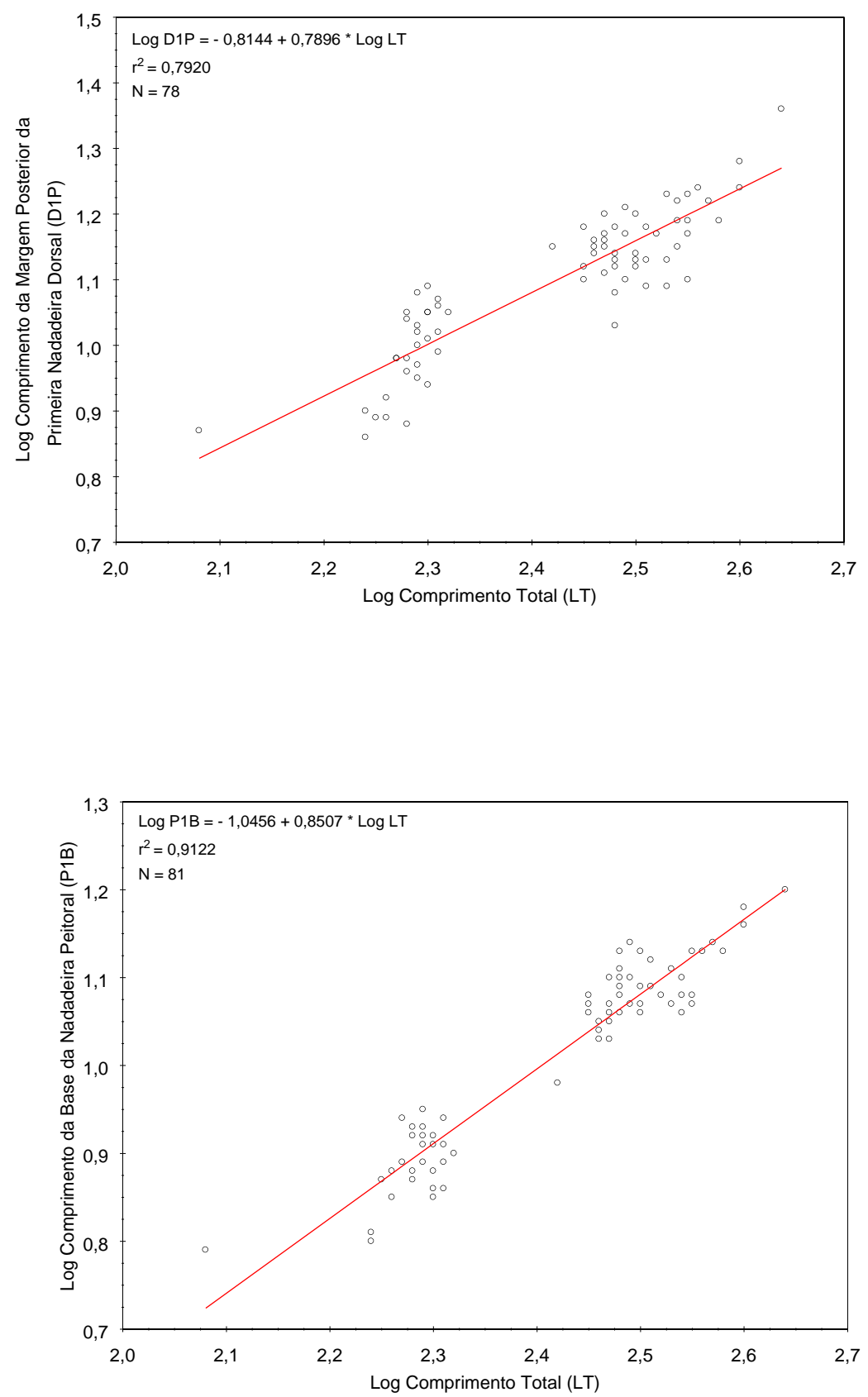

Figura 22: Regressões entre o Comprimento Total (LT) e as variáveis Comprimento da Margem Posterior da Primeira Nadadeira Dorsal (D1P) e Comprimento da Base da Nadadeira Peitoral (P1B) - crescimento alométrico positivo. Valores logaritmizados. 


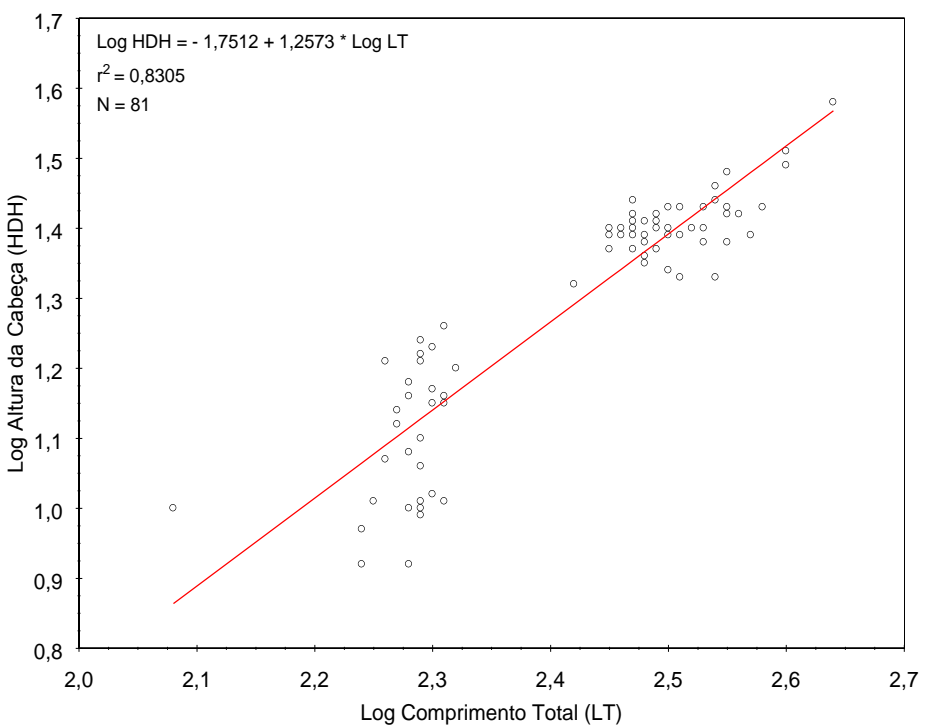

Figura 23: Regressão entre o Comprimento Total (LT) e a variável Altura da Cabeça $(H D H)$ crescimento alométrico positivo. Valores logaritmizados.
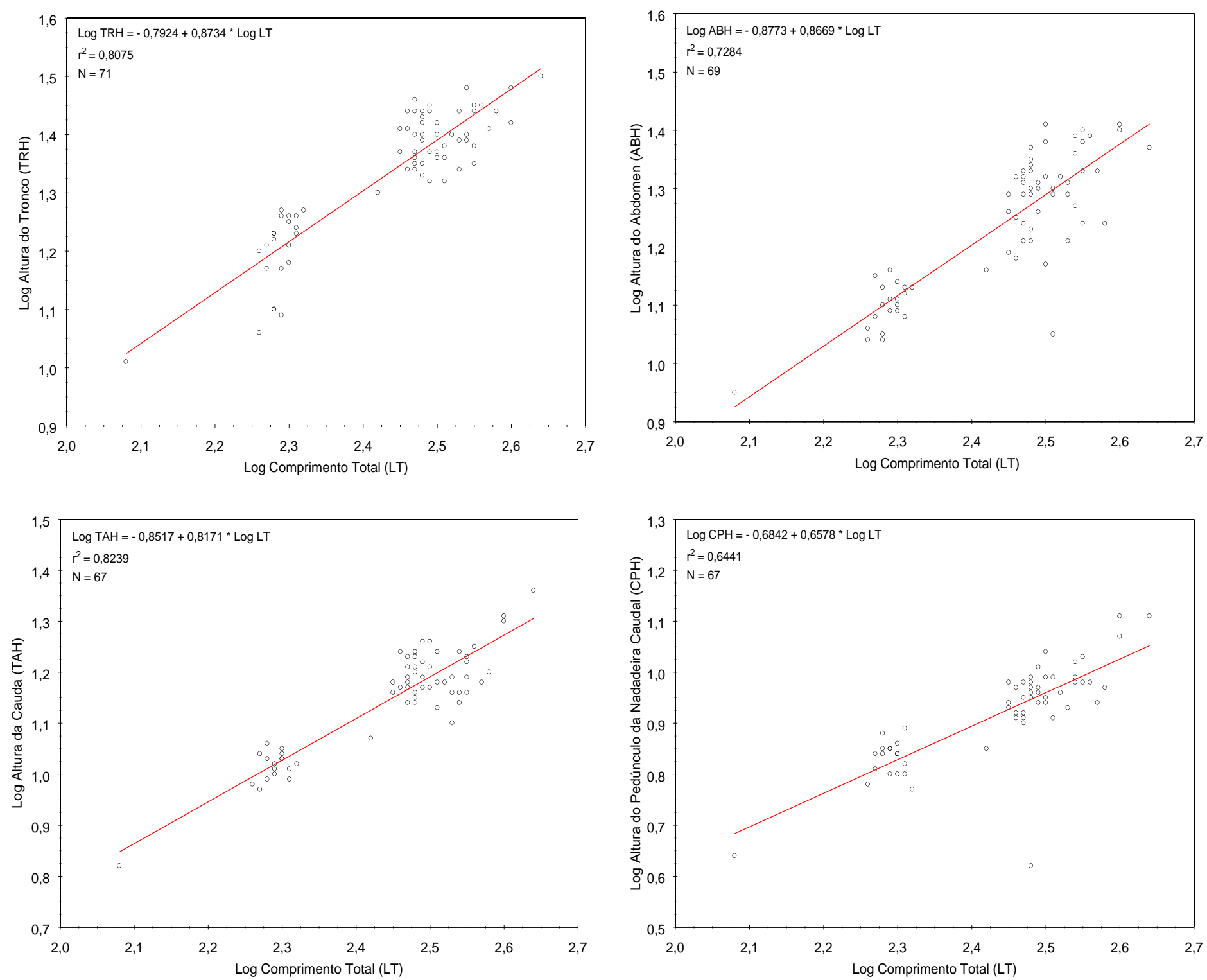

Figura 24: Regressões entre o Comprimento Total (LT) e as variáveis Altura do Tronco (TRH), Altura do Abdomen (ABH), Altura da Cauda (TAH) e Altura do Pedúnculo da Nadadeira Caudal $(\mathrm{CPH})$ - crescimento alométrico negativo. Valores logaritmizados. 


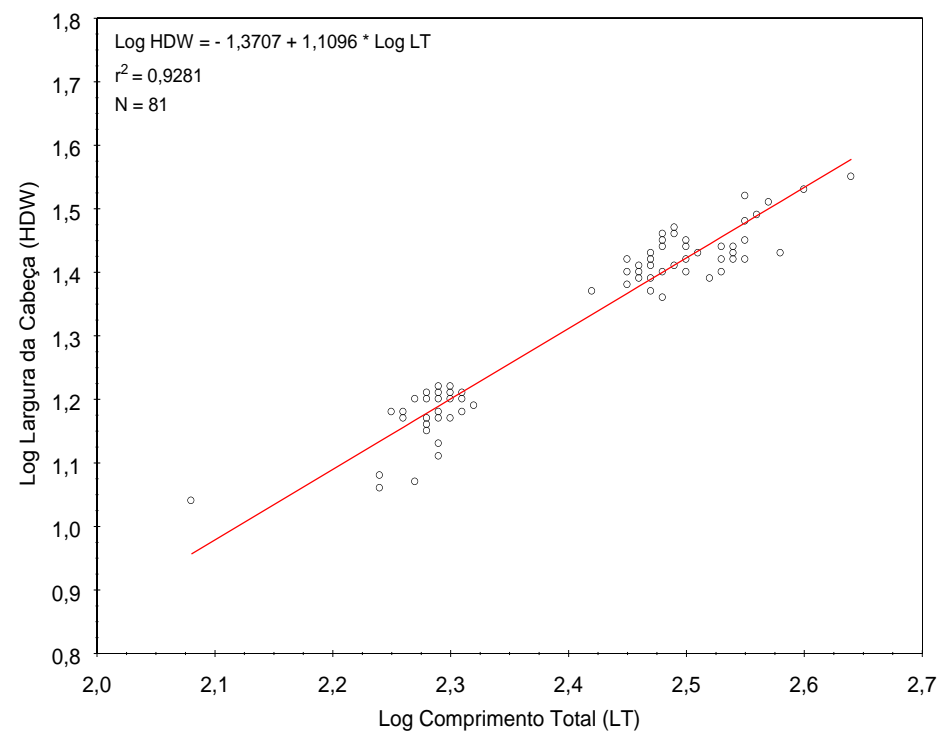

Figura 25: Regressão entre o Comprimento Total (LT) e a variável Largura da Cabeça (HDW) crescimento alométrico positivo. Valores logaritmizados.
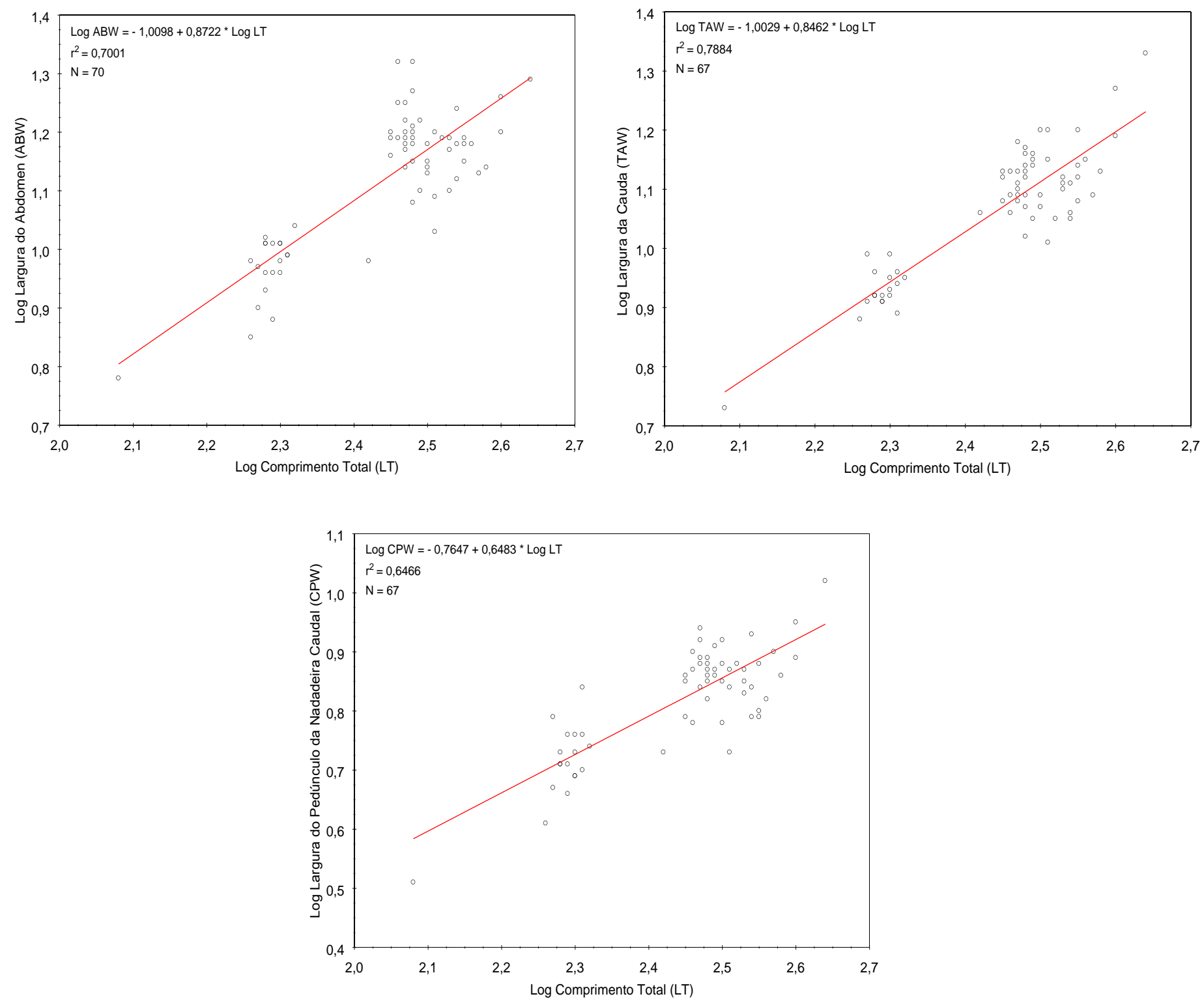

Figura 26: Regressões entre o Comprimento Total (LT) e as variáveis Largura do Abdomen (ABW), Largura da Cauda (TAW) e Largura do Pedúnculo da Nadadeira Caudal (CPW) crescimento alométrico negativo. Valores logaritmizados. 

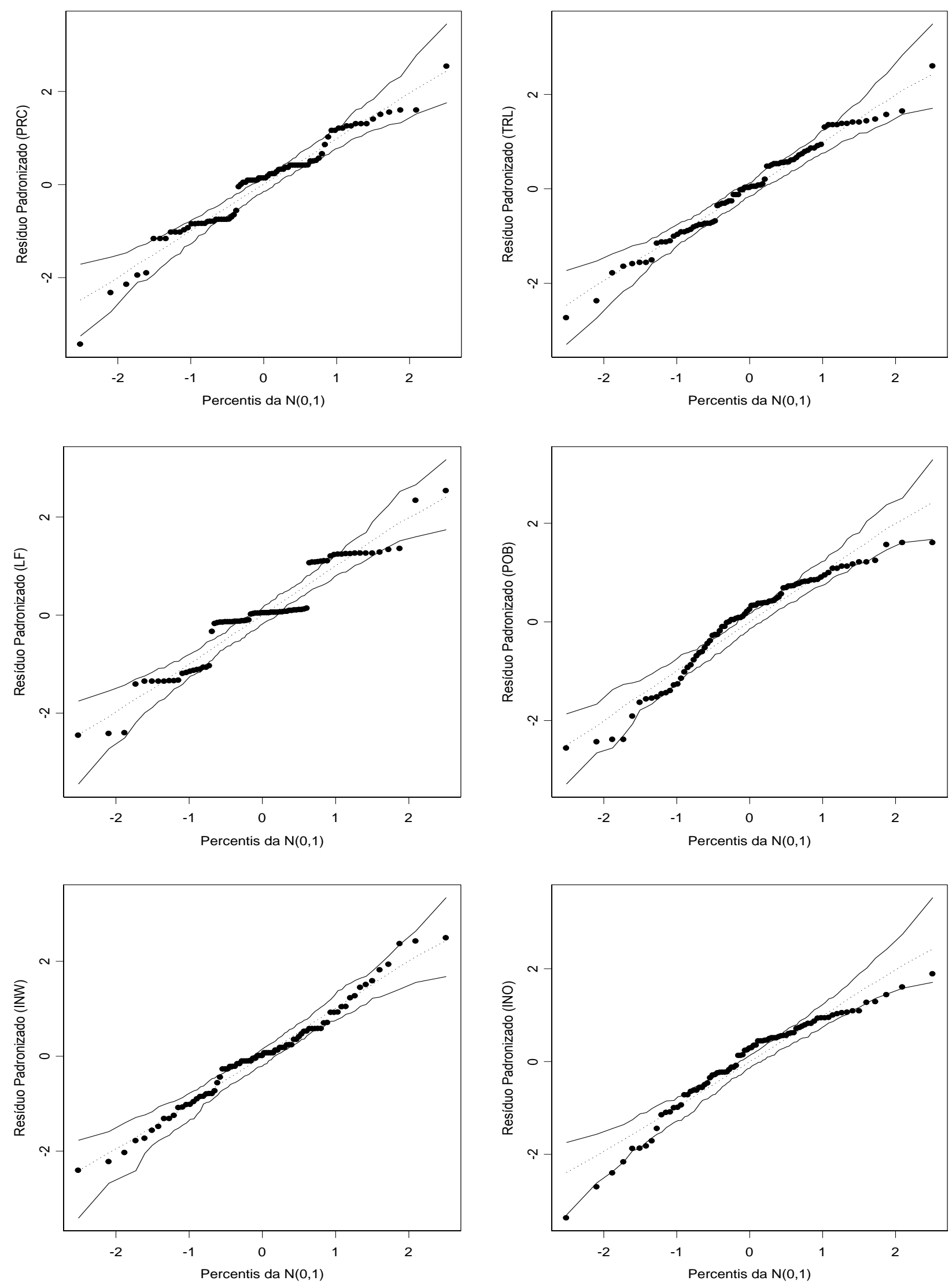

Figura 27: Gráficos de envelope para os resíduos padronizados das variáveis Comprimento PréCaudal (PRC), Comprimento do Tronco (TRL), Comprimento Furcal (LF), Comprimento PréOrbital (POB), Espaço Internasal (INW) e Espaço Interorbital (INO). 

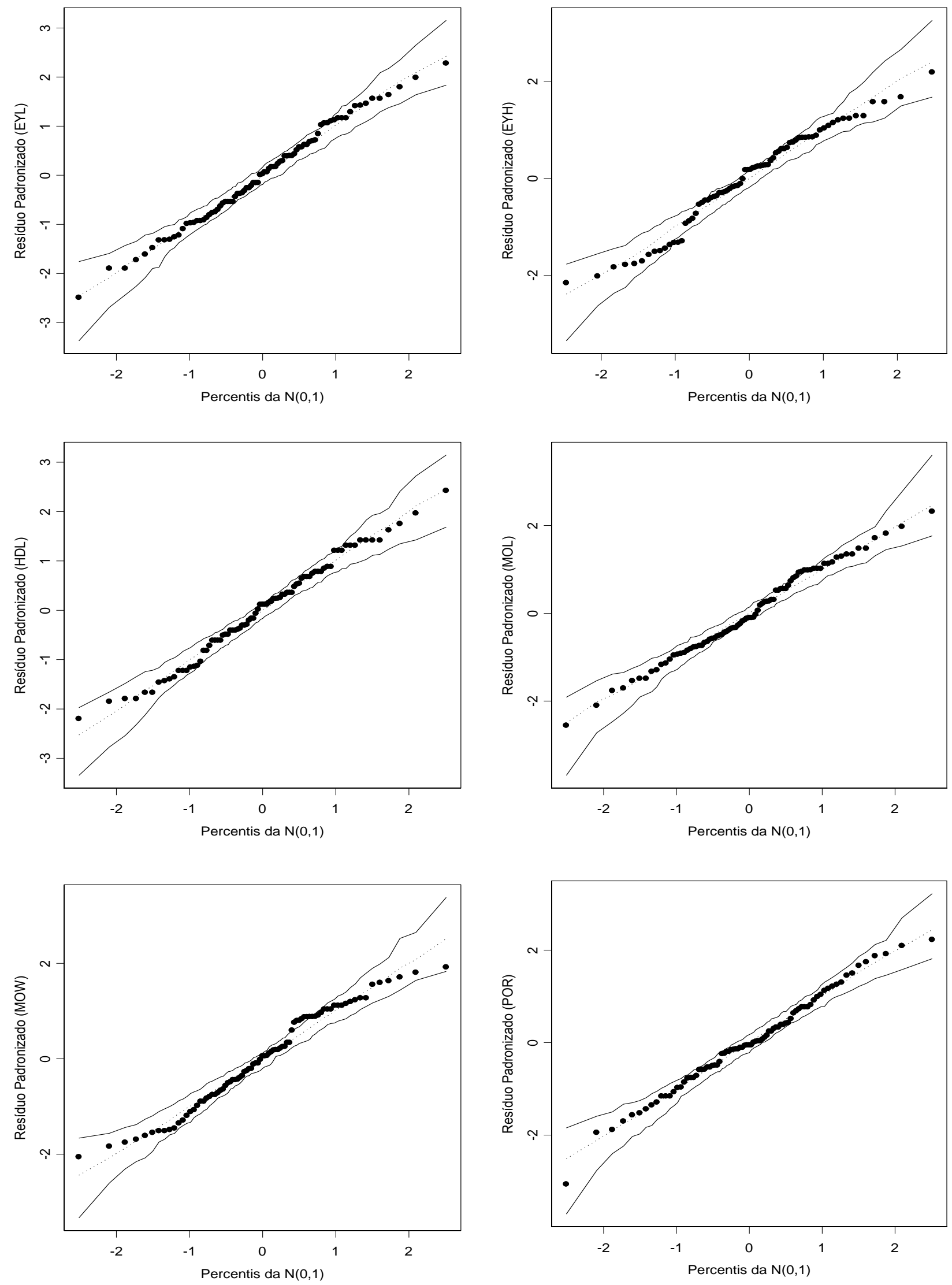

Figura 28: Gráficos de envelope para os resíduos padronizados das variáveis Comprimento do Olho (EYL), Altura do Olho (EYH), Comprimento da Cabeça (HDL), Comprimento da Boca (MOL), Largura da Boca (MOW) e Comprimento Pré-Oral (POR). 

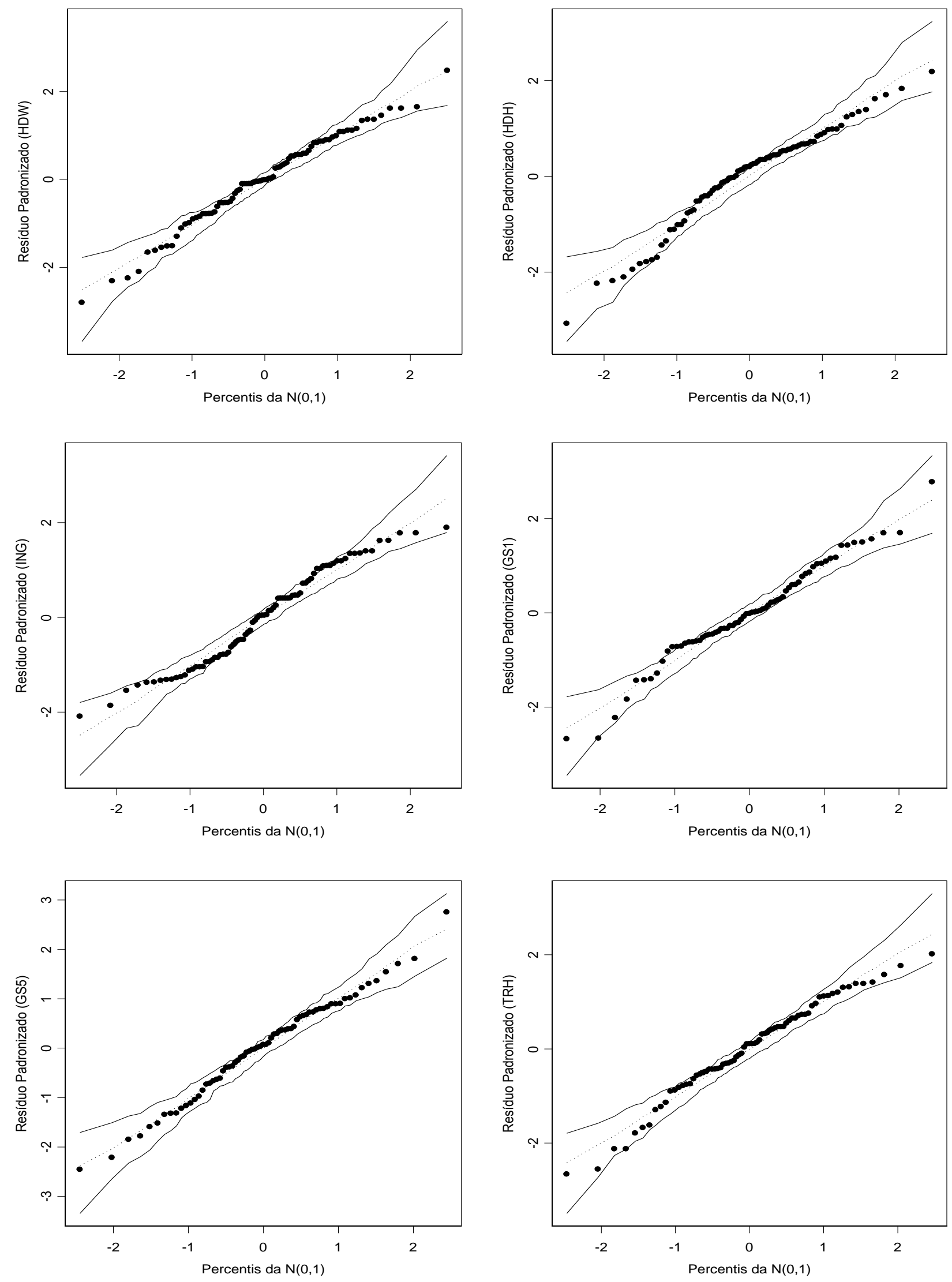

Figura 29: Gráficos de envelope para os resíduos padronizados das variáveis Largura da Cabeça (HDW), Altura da Cabeça (HDH), Comprimento Entre as Fendas Branquiais (ING), Altura da Primeira Fenda Branquial (GS1), Altura da Quinta Fenda Branquial (GS5) e Altura do Tronco $(\mathrm{TRH})$. 

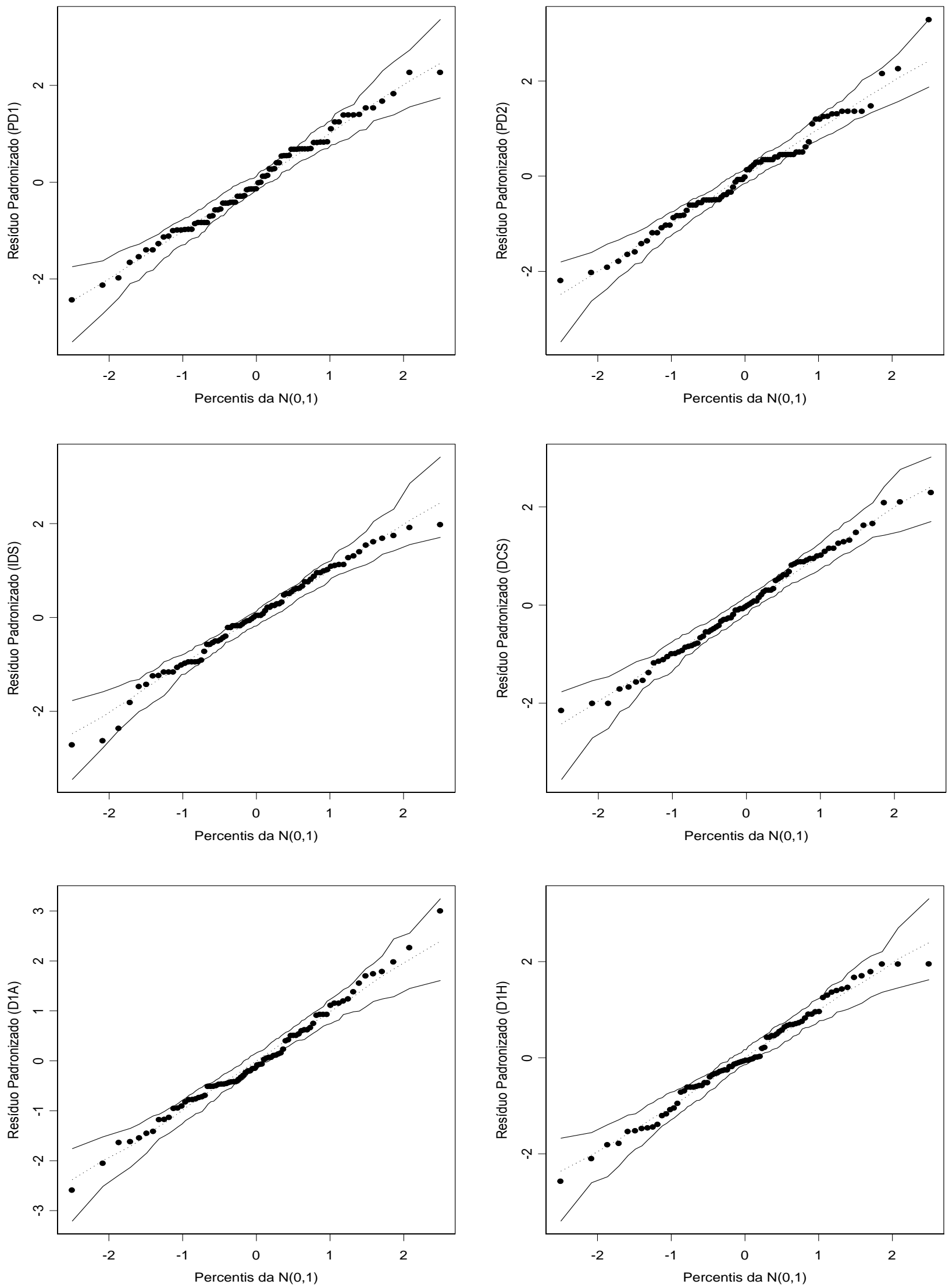

Figura 30: Gráficos de envelope para os resíduos padronizados das variáveis Comprimento Inicial da Primeira Nadadeira Dorsal (PD1), Comprimento Inicial da Segunda Nadadeira Dorsal (PD2), Espaço Entre Dorsais (IDS), Espaço Dorsal-Caudal (DCS), Comprimento da Margem Anterior da Primeira Nadadeira Dorsal (D1A) e Altura da Primeira Nadadeira Dorsal (D1H). 

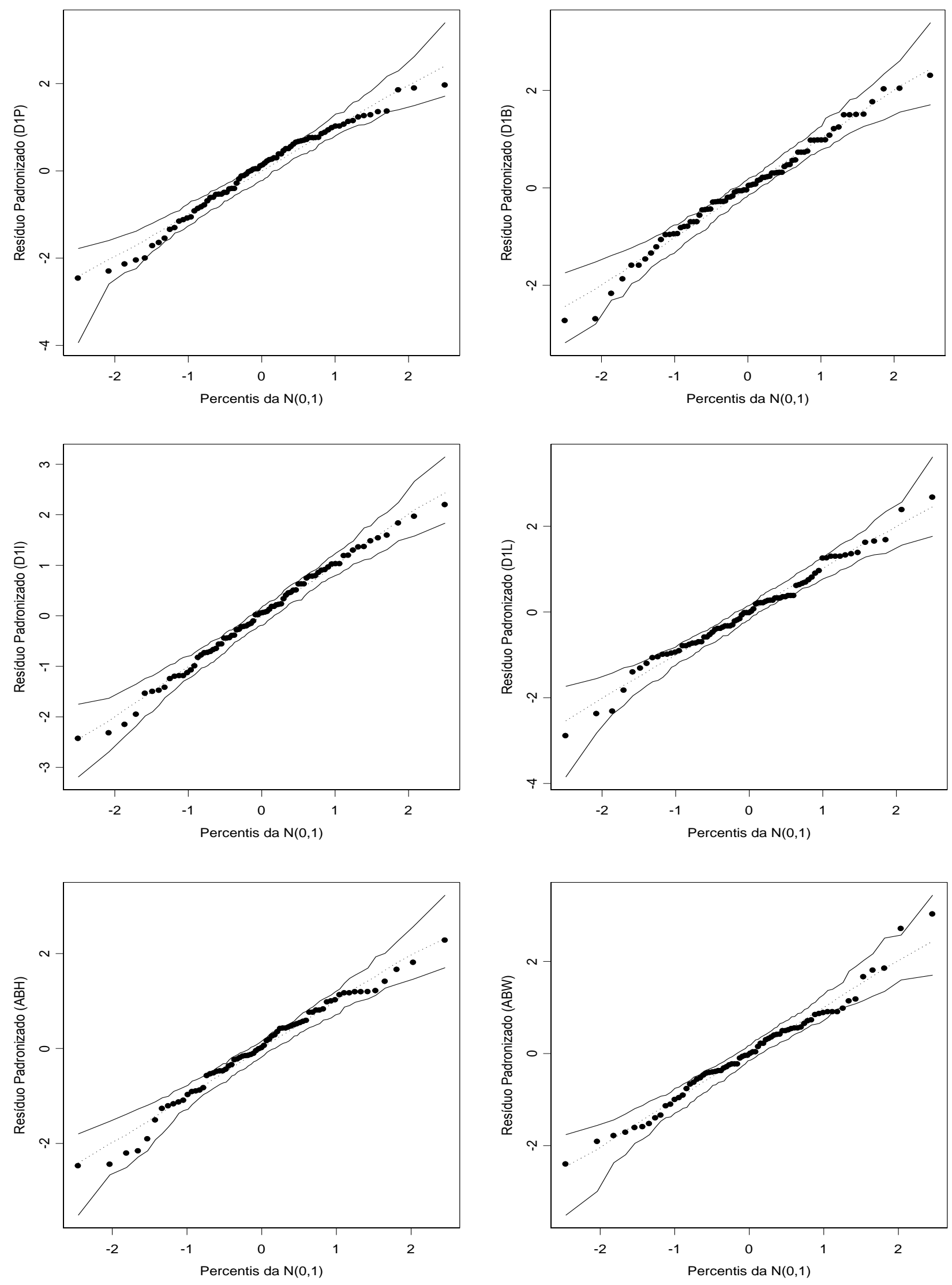

Figura 31: Gráficos de envelope para os resíduos padronizados das variáveis Comprimento da Margem Posterior da Primeira Nadadeira Dorsal (D1P), Comprimento da Base da Primeira Nadadeira Dorsal (D1B), Comprimento da Margem Interna da Primeira Nadadeira Dorsal (D1I), Comprimento da Primeira Nadadeira Dorsal (D1L), Altura do Abdomen (ABH) e Largura do Abdomen (ABW). 

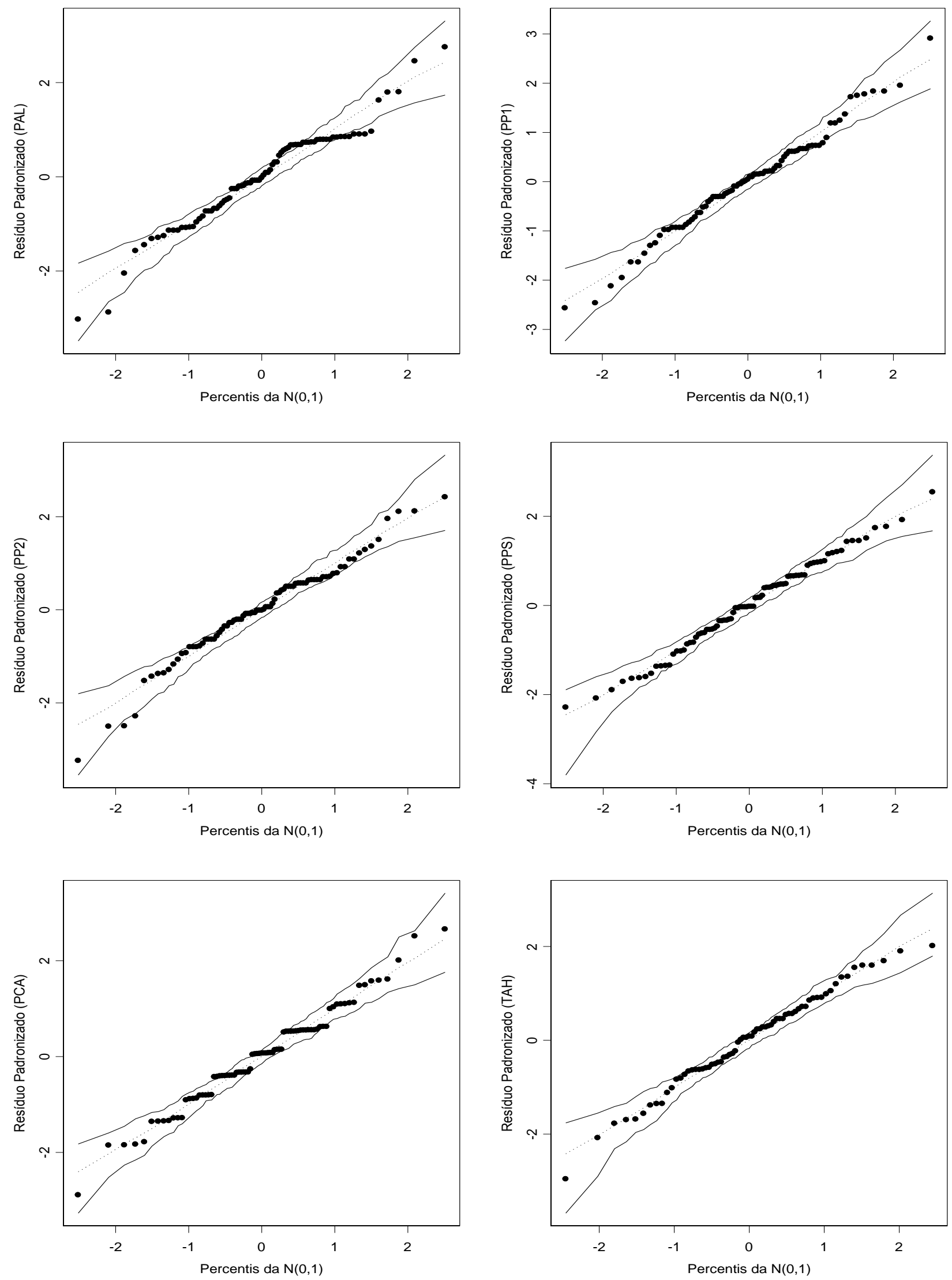

Figura 32: Gráficos de envelope para os resíduos padronizados das variáveis Comprimento PréAnal (PAL), Comprimento Pré-Peitoral (PP1), Comprimento Pré-Pélvico (PP2), Espaço PeitoralPélvico (PPS), Espaço Pélvico-Caudal (PCA) e Altura da Cauda (TAH). 

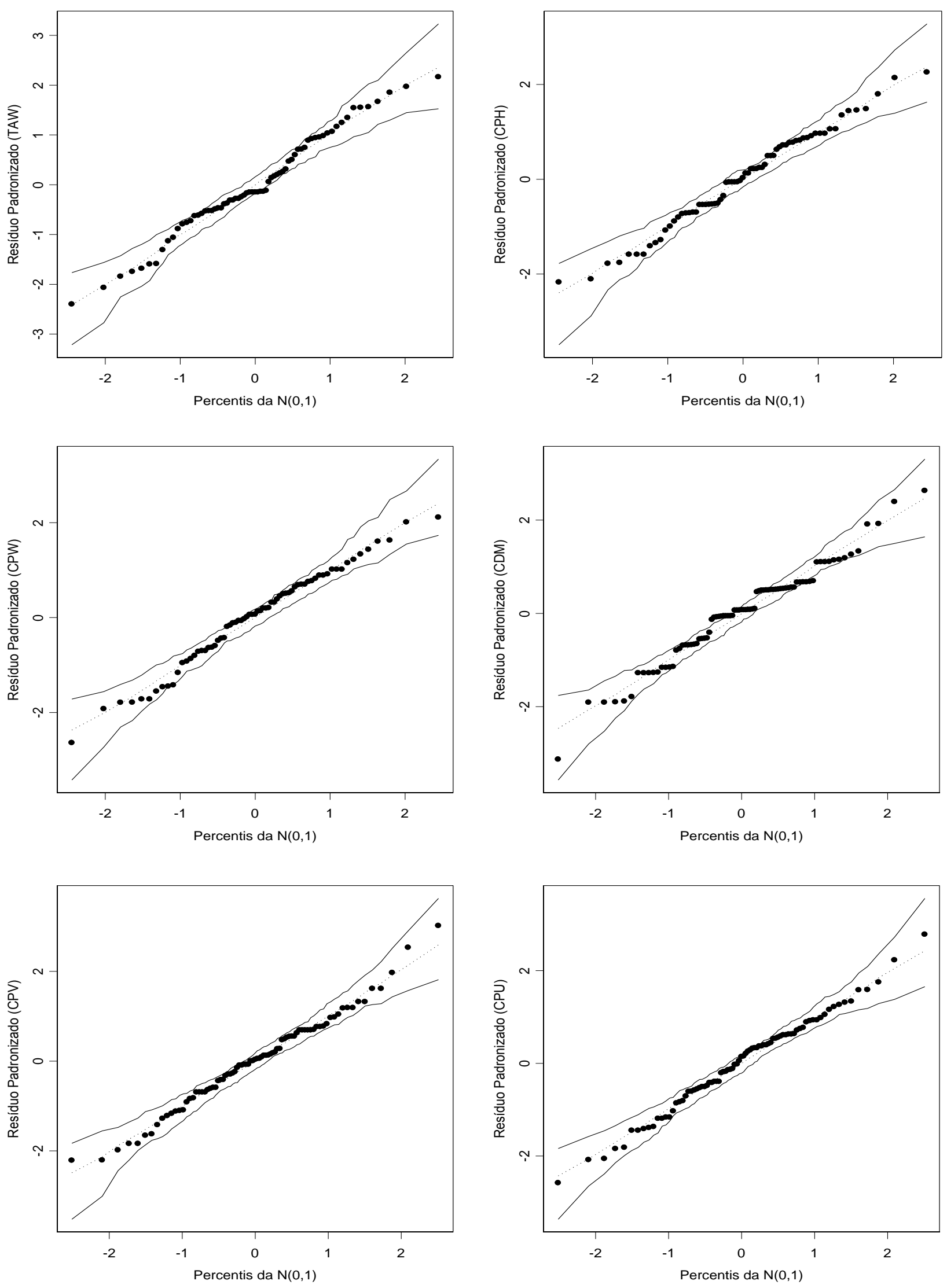

Figura 33: Gráficos de envelope para os resíduos padronizados das variáveis Largura da Cauda (TAW), Altura do Pedúnculo da Nadadeira Caudal (CPH), Largura do Pedúnculo da Nadadeira Caudal (CPW), Comprimento do Lobo Superior (CDM), Comprimento do Lobo Inferior (CPV) e Comprimento da Margem Interna do Lobo Superior (CPU). 

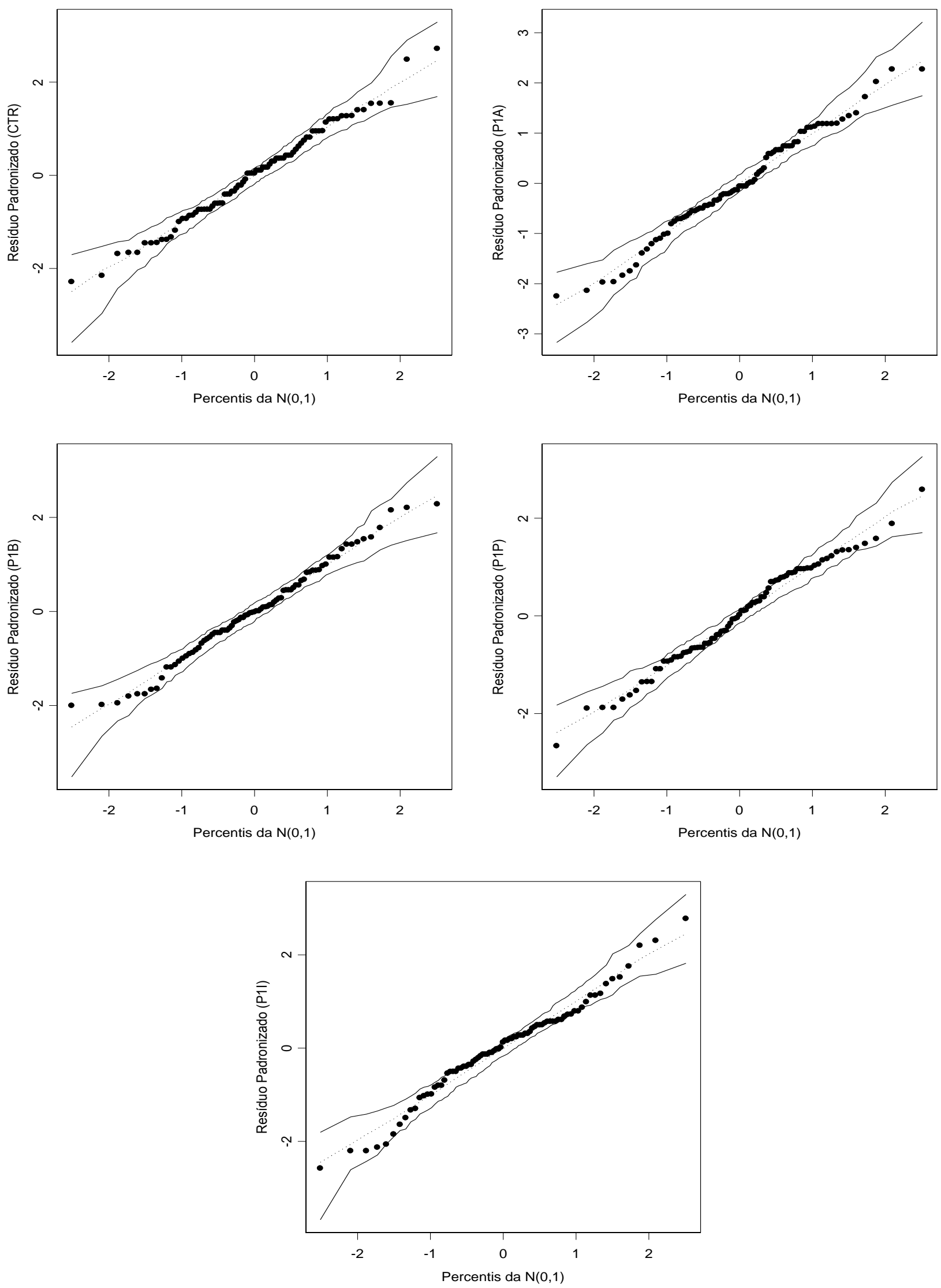

Figura 34: Gráficos de envelope para os resíduos padronizados das variáveis Comprimento do Terminal do Lobo Superior (CTR), Comprimento da Margem Anterior da Nadadeira Peitoral (P1A), Comprimento da Base da Nadadeira Peitoral (P1B), Comprimento da Margem Posterior da Nadadeira Peitoral (P1P) e Comprimento da Margem Interna da Nadadeira Peitoral (P1I). 


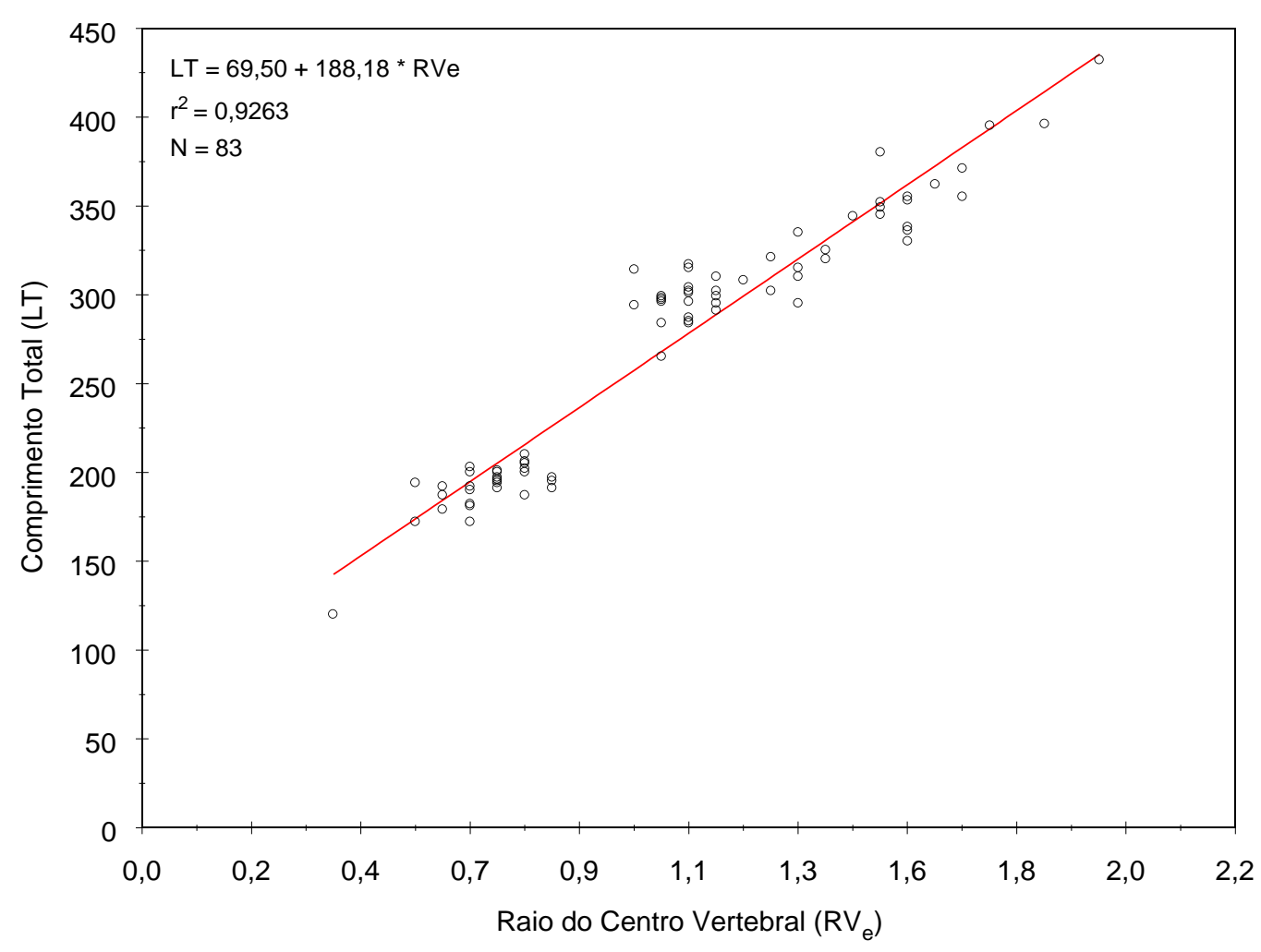

Figura 35: Regressão linear entre a variável Comprimento Total (LT) em relação ao Raio do Centro Vertebral $\left(R V_{e}\right)$. Coeficientes estimados do ajuste, $a=69,50$ e $b=188,18$, utilizados como fatores de correção no modelo modificado da proporção direta de Dahl-Lea.

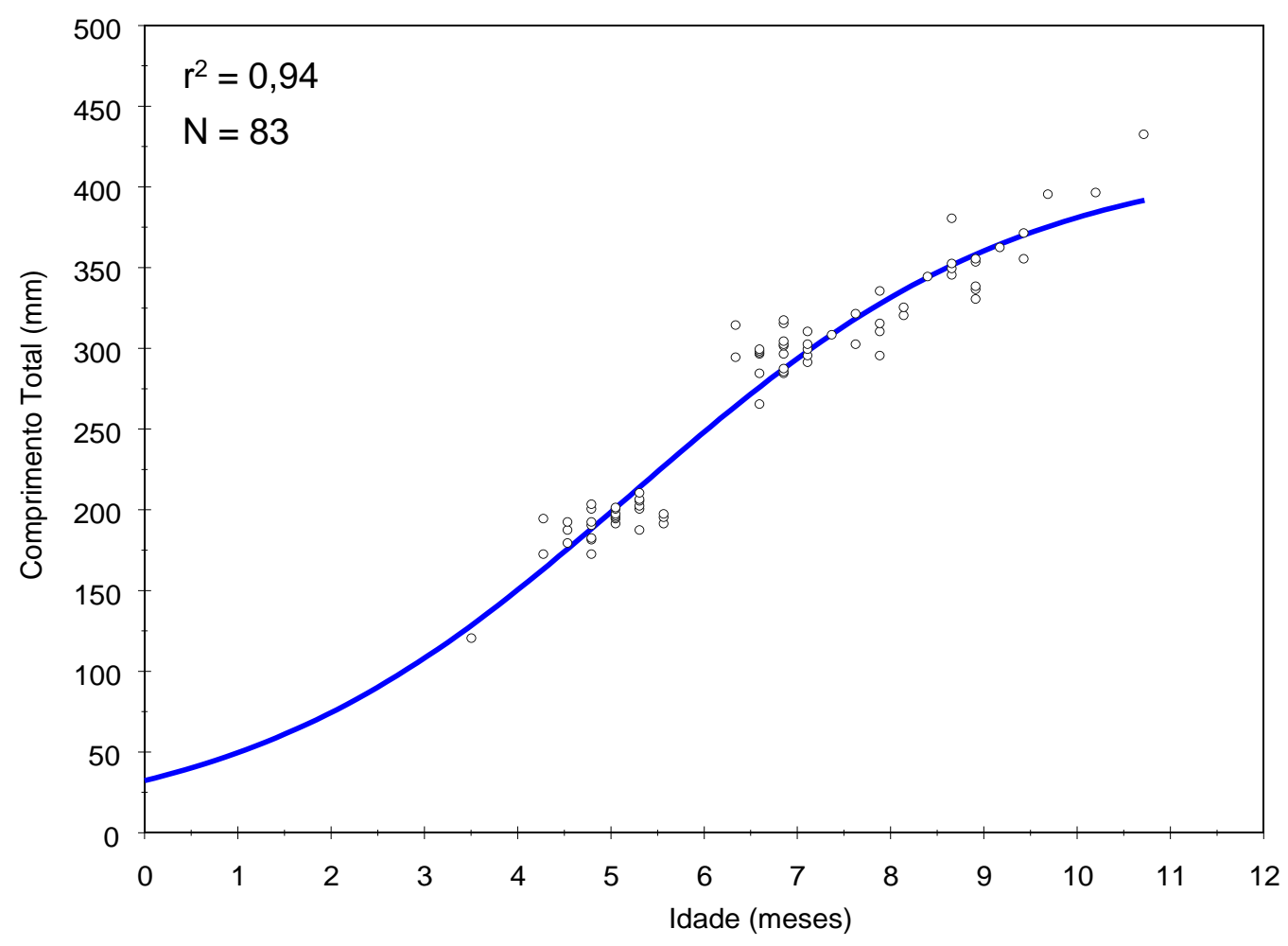

Figura 36: Regressão não linear entre o Comprimento Total (LT) e a Idade, em meses, dos embriões de tubarão-azul, com ajuste do modelo Logístico e seu pseudo-coeficiente de explicação $\left(\mathrm{r}^{2}\right)$. $\mathrm{N}$ = número de indivíduos. 


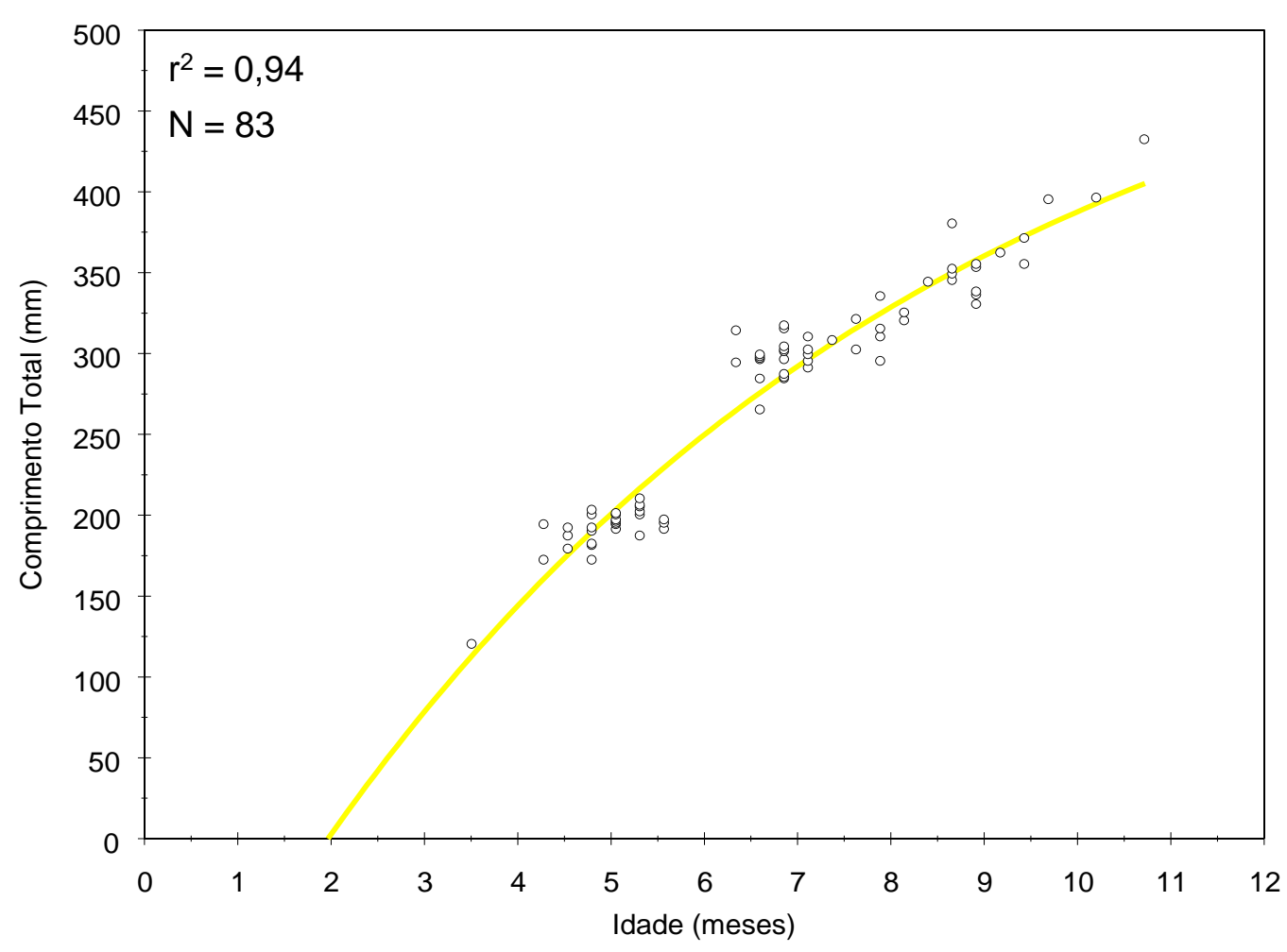

Figura 37: Regressão não linear entre o Comprimento Total (LT) e a Idade, em meses, dos embriões de tubarão-azul, com ajuste do modelo de von Bertalanffy e seu pseudo-coeficiente de explicação $\left(\mathrm{r}^{2}\right) \cdot \mathrm{N}$ = número de indivíduos.

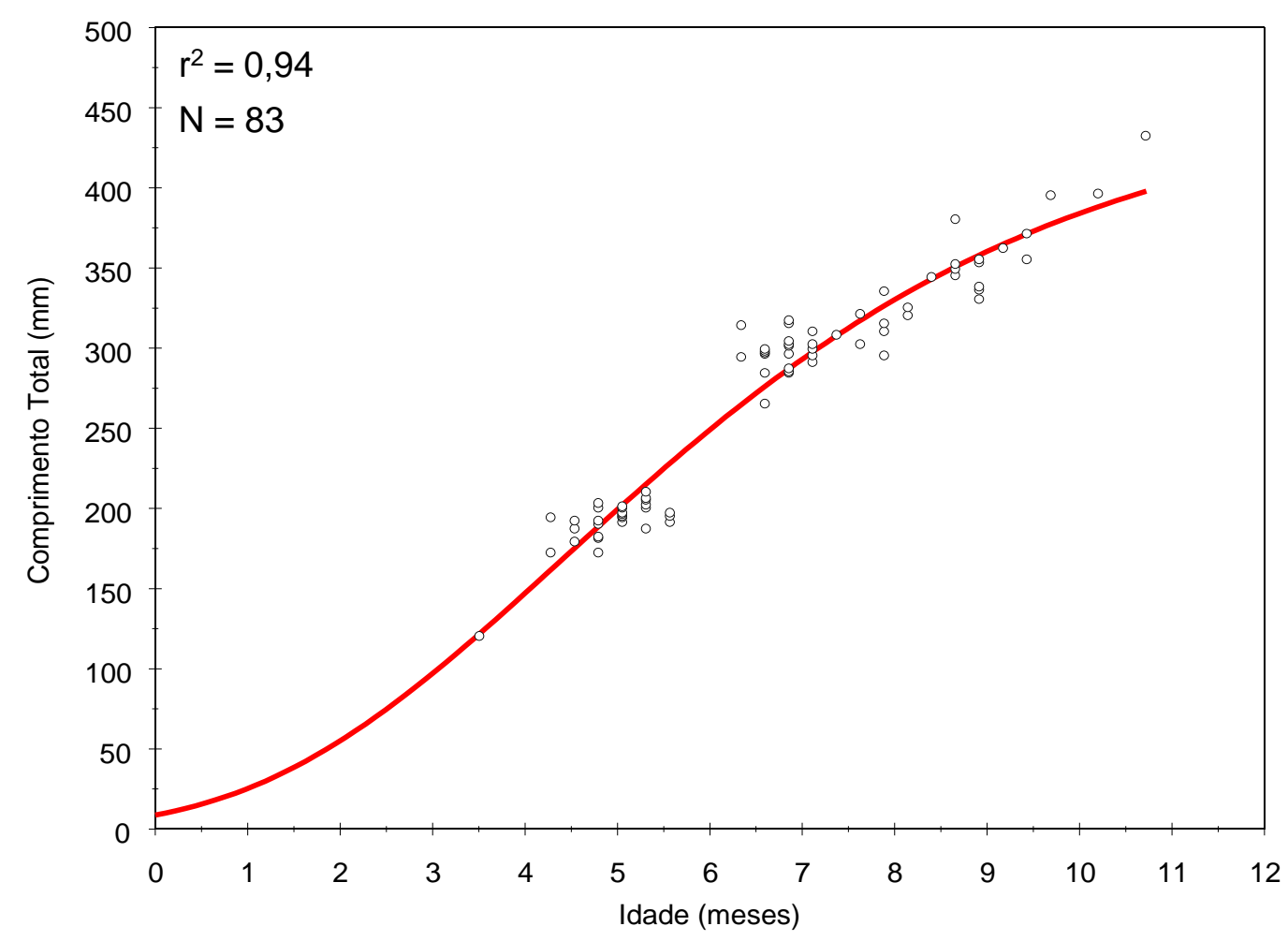

Figura 38: Regressão não linear entre o Comprimento Total (LT) e a Idade, em meses, dos embriões de tubarão-azul, com ajuste do modelo de Gompertz e seu pseudo-coeficiente de explicação $\left(\mathrm{r}^{2}\right) \cdot \mathrm{N}$ = número de indivíduos. 


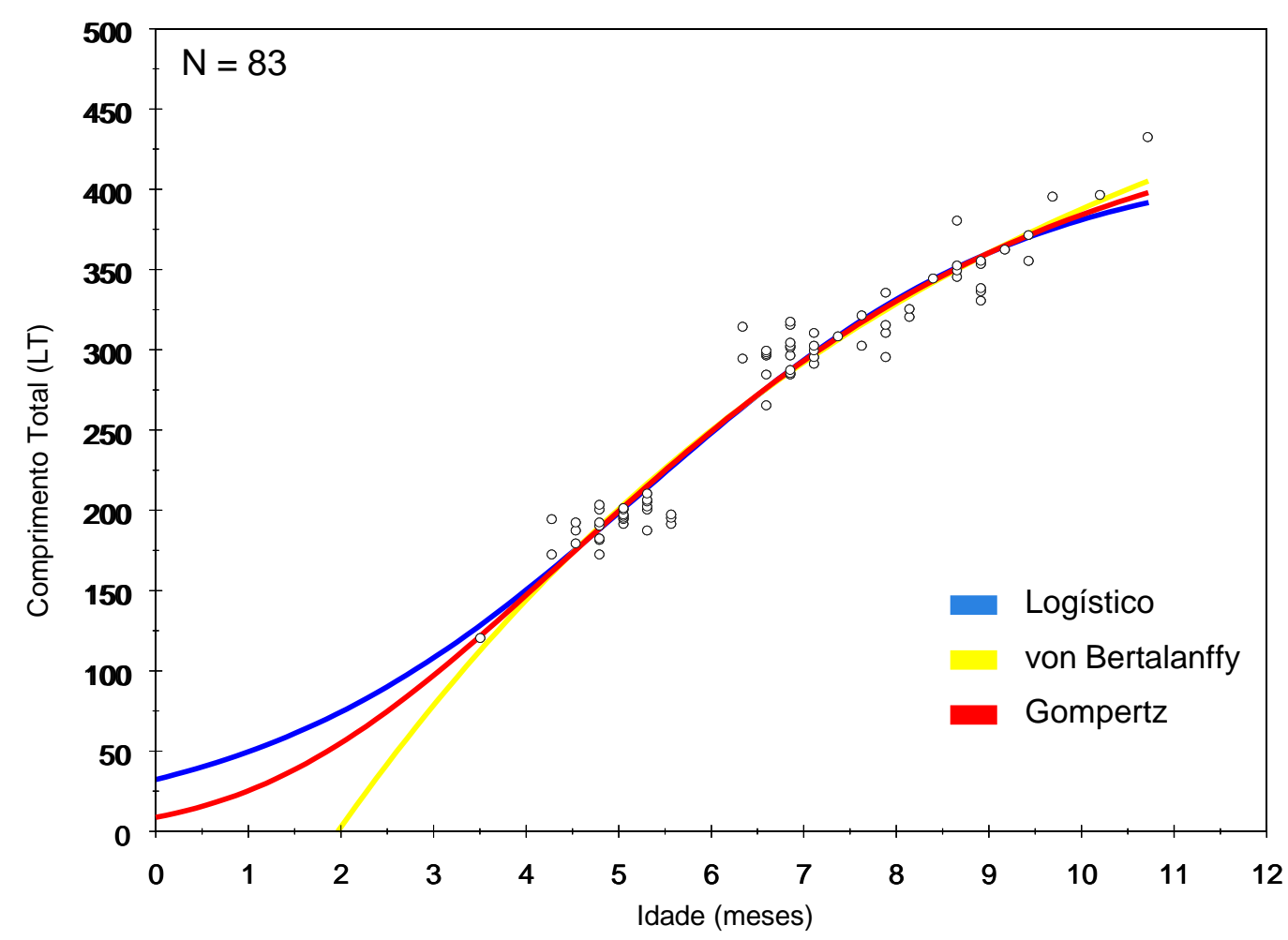

Figura 39: Comparação entre as curvas de crescimento ajustadas por regressões não lineares entre o Comprimento Total (LT) e a Idade, em meses, dos embriões de tubarão-azul, para os três modelos estudados. $\mathrm{N}$ = número de indivíduos. 